\title{
Crypsis and convergence: Integrative taxonomic revision of the Gehyra australis group (Squamata: Gekkonidae) from northern Australia
}

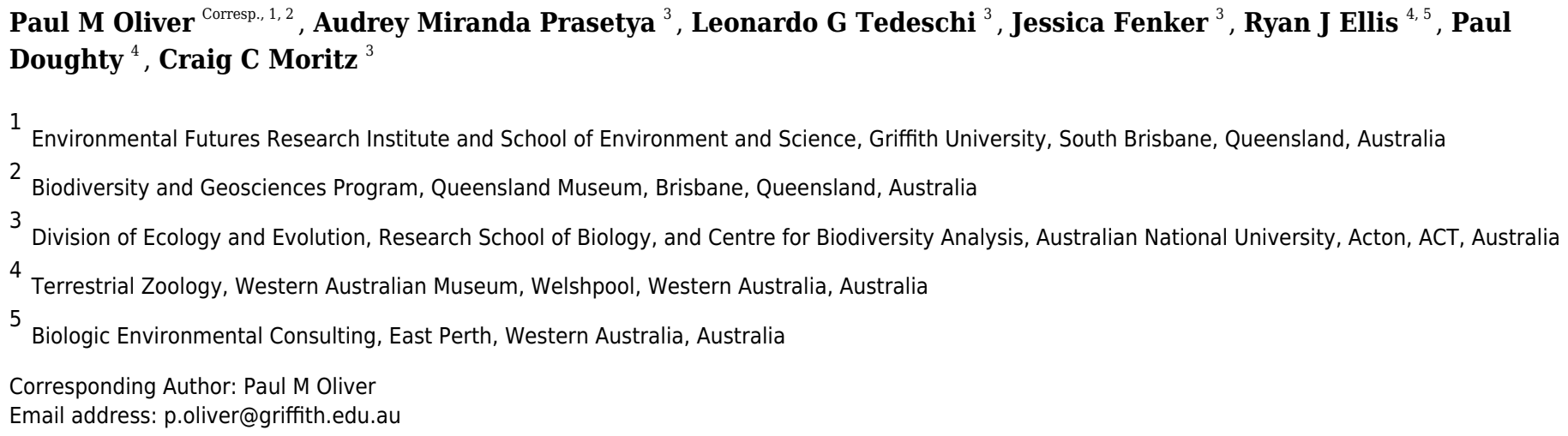

For over two decades, assessments of geographic variation in mtDNA and small numbers of nuclear loci have revealed morphologically similar, but genetically divergent, intraspecific lineages in lizards from around the world. Subsequent morphological analyses often find subtle corresponding diagnostic characters to support the distinctiveness of lineages, but occasionally do not. In recent years it has become increasingly possible to survey geographic variation by sequencing thousands of loci, enabling more rigorous assessment of species boundaries across morphologically similar lineages. Here we take this approach, adding new, geographically extensive SNP data to existing mtDNA and exon capture datasets for the Gehyra australis and G. koira species complexes of gecko from northern Australia. The combination of exon-based phylogenetics with dense spatial sampling of mitochondrial DNA sequencing, SNP-based tests for introgression at lineage boundaries and newly-collected morphological evidence supports the recognition of nine species, six of which are newly described here. Detection of discrete genetic clusters using new SNP data was especially convincing where candidate taxa were continuously sampled across their distributions up to and across geographic boundaries with analyses revealing no admixture. Some species defined herein appear to be truly cryptic, showing little, if any, diagnostic morphological variation. As these SNP-based approaches are progressively applied, and with all due conservatism, we can expect to see a substantial improvement in our ability to delineate and name cryptic species, especially in taxa for which previous approaches have struggled to resolve taxonomic boundaries. 
1 Crypsis and convergence: Integrative taxonomic revision of the Gehyra australis group

2 (Squamata: Gekkonidae) from northern Australia

4 Paul M. Oliver ${ }^{1,2}$, Audrey Miranda Prasetya ${ }^{3}$, Leonardo G. Tedeschi ${ }^{3}$, Jessica Fenker ${ }^{3}$, Ryan J.

5 Ellis, 5 , Paul Doughty ${ }^{4}$ and Craig Moritz ${ }^{3}$

6

$7 \quad{ }^{1}$ Environmental Futures Research Institute and School of Environment and Science, Griffith

8 University, Brisbane, Queensland, Australia

$9 \quad$ 2 Biodiversity and Geosciences Program, Queensland Museum, South Brisbane, Queensland,

10 Australia

$11{ }^{3}$ Division of Ecology and Evolution, Research School of Biology, and Centre for Biodiversity

12 Analysis, The Australian National University, Acton, ACT, Australia

$13{ }^{4}$ Terrestrial Zoology, Western Australian Museum, Welshpool, WA, Australia

$14{ }^{5}$ Biologic Environmental Consulting, East Perth, WA, Australia

15

16

17 Corresponding Author:

18 Paul M. Oliver ${ }^{1}$

19

20 Email address: P.oliver@griffith.edu.au

21 


\section{ABSTRACT}

23 For over two decades, assessments of geographic variation in mtDNA and small numbers of

24 nuclear loci have revealed morphologically similar, but genetically divergent, intraspecific

25 lineages in lizards from around the world. Subsequent morphological analyses often find subtle 26 corresponding diagnostic characters to support the distinctiveness of lineages, but occasionally

27 not. In recent years it has become increasingly possible to survey geographic variation by

28 sequencing thousands of genes, enabling more rigorous assessment of species boundaries across

29 morphologically similar lineages. Here we take this approach, adding new, geographically

30 extensive SNP data to existing mtDNA and exon capture datasets for the Gehyra australis and G.

31 koira species complexes of gecko from northern Australia. The combination of exon-based

32 phylogenetics with dense spatial sampling of mitochondrial DNA sequencing, SNP-based tests

33 for introgression at lineage boundaries and newly-collected morphological evidence supports the

34 recognition of nine species, six of which are newly described here. Detection of discrete genetic

35 clusters using new SNP data was especially convincing where candidate taxa were continuously

36 sampled across their distributions up to and across geographic boundaries with analyses

37 revealing no admixture. Some species defined herein appear to be truly cryptic, showing little, if

38 any, diagnostic morphological variation. As these SNP-based approaches are progressively

39 applied, and with all due conservatism, we can expect to see a substantial improvement in our 40 ability to delineate and name cryptic species, especially in taxa for which previous approaches

41 have struggled to resolve taxonomic boundaries.

42

43 
45

46

47

48

49

50

51

52

53

54

55

56

57

58

59

60

61

62

63

64

65

66

67

9

Subjects: Biodiversity, Taxonomy, Zoology

Keywords: Australian Monsoonal Tropics, Cryptic species, lizard, Hybridisation, Endemism, new species

\section{INTRODUCTION}

Integrative taxonomic analyses utilise multiple independent data sources to illuminate patterns of phenotypic and genetic differentiation (De Queiroz, 2007; Padial et al., 2010). Thus, in addition to the traditional morphological characters upon which taxonomy was founded hundreds of years ago, systematists in recent decades have progressively added a growing battery of genetic approaches to analyse evidence from karyotypes, allozymes, mtDNA sequence data and, increasingly common, loci from the nuclear genome (Oliver, Keogh \& Moritz, 2015). However, genetic species delimitation methods can incorrectly diagnose distinct populations as "species", especially where dispersal rates are low or sampling is sparse (Carstens et al., 2013; Sukumaran \& Knowles, 2017; Leaché et al., 2018; Singhal et al., 2018). In this context there is a need to set a higher bar to avoid over-splitting, one approach being to test for negligible gene flow where geographic boundaries of candidate species abut or overlap (Singhal et al., 2018). Contingent on sufficient geographic sampling, this is now feasible with increasing access to data from thousands of putatively unlinked nuclear loci (Single Nucleotide Polymorphisms, or "SNPs";

Leaché et al., 2014; Leaché \& Oaks, 2017; Melville et al., 2017; Unmack et al., 2017; Georges et al., 2018).

The gekkonid lizards in the genus Gehyra from Australia show conservative body form, variable appearance and have been a test case for implementing new methods to document 
68 species diversity (e.g. King, 1979, 1982; Sistrom, Donnellan \& Hutchinson, 2013; Sistrom et al., 69 2014; Ashman et al., 2018; Kealley et al., 2018; Moritz et al., 2018; summarised in Doughty et 70 al., 2018a). The various genetic techniques have led to increasingly finer resolution of

71 phylogenetic structure, and have recently resulted in major revisions of Gehyra species-groups

72 from the Australian arid zone and the Australian Monsoonal Tropics (AMT) such that the

73 number of recognised species has nearly doubled from 22 to 43 (e.g. Hutchinson et al., 2014;

74 Doughty et al., 2018a,b; Kealley et al., 2018).

75 The Gehyra australis group is a lineage of geckos from the AMT, originally defined as

76 having key morphological (medium size and split lamellae series) and life history (two eggs)

77 features (Mitchell, 1965; King, 1983a). This group is recovered as monophyletic group in genus78 wide molecular phylogenies for Gehyra (Heinicke et al., 2011). They are relatively large-bodied 79 (to $95 \mathrm{~mm}$ snout-vent length) scansorial geckos that occupy arboreal and rocky habitats. Recent 80 analyses of this group based on mtDNA and exon-capture datasets identified numerous divergent 81 lineages or candidate taxa within the eight species currently recognised (Noble et al., 2018;

82 Oliver et al., 2019). The major mtDNA lineages were supported by Oliver et al. (2019) as being 83 evolutionarily independent when applying statistical delimitation methods to the exon capture 84 data. However, most candidate taxa show low levels of morphological differentiation and non85 overlapping distributions with other lineages from the same species complexes (Noble et al., 86 2018; Oliver et al., 2019). Furthermore, while mtDNA sampling was geographically extensive in

87 these previous studies, the level of mtDNA divergence between some recognised and candidate 88 taxa was moderate (Tamura-Nei distances lower than 10\%), and lower than observed between at 89 least some other species of geckos in the same biome that show evidence of gene flow between 90 lineages (Laver, Doughty \& Oliver, 2018; Moritz et al., 2018; Oliver et al., 2019). The sparse 
91 sampling of specimens in the exon capture dataset for each lineage, compared to that for

92 mtDNA, also precluded detailed assessment of introgression at geographic boundaries between

93 candidate taxa.

94 Here, we focus on two species complexes within the greater Gehyra australis group: the

95 G. australis and G. koira species complexes (Mitchell, 1965; Kealley et al., 2018, table 1).

96 Within these two species complexes, there is sufficiently dense spatial sampling to allow for a

97 thorough assessment of morphological and genetic diversity across their distributions in the

98 AMT. In contrast, an assessment of G. robusta and G. borroloola is not possible at this time

99 owing to fewer specimens available, especially at boundaries between lineages (Noble et al.,

100 2018; Oliver et al., 2019). The G. australis complex ranges widely across the AMT (Wilson \&

101 Swan, 2017) and currently comprises one recognised species (Uetz et al., 2019), but four

102 candidate species of arboreal/generalist taxa (Noble et al., 2018). From morphological and

103 ecological perspectives, the G. koira complex consists of mostly large-bodied, saxicoline taxa

104 from the western AMT. The two recognised taxa were originally described as subspecies $-G$.

105 koira koira and G. koira ipsa (Horner, 2005), but have been regarded to be full species in recent

106 field guides (Wilson \& Swan, 2017; Cogger, 2018). Two additional candidate species have also

107 been identified (Oliver et al., 2017, 2019) (Figs. 1, 2). Prior genetic analyses also revealed a

108 single lineage (koira 4 of Oliver et al. [2019]) genetically nested within the G. koira complex that

109 has been consistently assigned to the G. australis complex on the basis of its small size,

110 colouration and arboreal ecology. Given its morphological and ecological distinctiveness from

111 other species in the G. koira complex, we treat this species separately below.

112 In this paper we present additional molecular analyses to Noble et al. (2018) and Oliver et

113 al. (2019) to assess detailed patterns of genetic differentiation. Specifically, we were interested to 
114 test for introgression where lineages come into contact or overlap by applying SNP analyses, as

115 recommended by Singhal et al. (2018). To do this, we applied a new statistical approach to

116 identifying discrete genetic lineages as deviations from a spatial model of isolation by distance

117 within lineages (conStruct; Bradburd, et al. 2018). For low dispersal organisms, this method

118 could be more appropriate than coalescent delimitation methods that assume random mating

119 within lineages (e.g. BPP; Yang \& Rannala, 2010). Specifically, when applied to continuously

120 sampled populations with parapatric or overlapping sympatric distributions, this method has

121 potential as can test for discrete structure vs introgression across lineage boundaries. We also

122 assessed habitat preferences and patterns of morphological variation across candidate taxa within

123 these two species complexes of Gehyra, focussing on size, scalation and pattern. On the basis of

124 these results, we recognise nine species within the G. australis and G. koira complexes, six of

125 which are newly described herein.

126

127 MATERIALS AND METHODS

128 Sampling and specimens

129 Within the G. australis and G. koira complexes nine candidate lineages were identified by

130 previous analyses based on: a) a geographically comprehensive mtDNA sampling including 182

131 individuals in the G. australis complex and 183 individuals of the G. koira complex, and b) more

132 focused nDNA (exon capture) analyses including 17 and 23 individuals from the two complexes,

133 respectively (Fig. 1; Table S1; Noble et al., 2018; Oliver et al., 2019). The mtDNA lineage

134 assignments were used as a basis to: a) select samples for inclusion in a SNP-based investigation

135 into patterns of differentiation across geographic ranges and of recent gene flow at areas of

136 contact between lineages, and b) select genetically typed specimens from which to obtain 
137 morphological data. For the SNP analyses, we selected one individual per locality to ensure

138 independence of samples. A small number of additional non-genotyped samples from localities

139 that were taxonomically unambiguous were added into morphological analyses to increase

140 sample sizes for key morphological traits (especially pore number in males) for poorly-sampled

141 taxa (Table S1).

142 Specimens used in this study were sourced from museum collections across Australia

143 (summarised in abbreviations section below), with many coming from our own field work (CCM

144 field numbers, now housed in appropriate museum collections) with incidental observations on

145 habitat use. The lectotype of G. australis at the Natural History Museum, London, U.K, was also

146 examined. Additional samples for which tail tips only were taken are listed in referred material,

147 and most are currently stored at the ANU. All new material was collected under animal ethics

148 approval from the ANU and collection permits from the relevant authorities in Western

149 Australia, the Northern Territory and Queensland.

150

\section{Molecular genetics}

152 In light of the overall morphological similarity between many of the lineages identified by

153 previous genetic analyses, we undertook additional genetic analysis using SNP data generated by

154 Diversity Array Technology (DArT $\left.{ }^{\mathrm{TM}}\right)$. This method uses restriction-enzyme mediated genome

155 reduction prior to library construction and parallel sequencing (Jaccoud et al., 2001) with Next-

156 Generation-Sequencing platforms to sequence the most informative representations of

157 genomic DNA sampling as an alternative to whole genome sequencing, and has proven

158 valuable for detecting introgression between populations in recent AMT studies (Melville et al.,

159 2017; Unmack et al., 2017; Georges et al., 2018). We sampled across the full geographic range 
160 of each lineage, with a focus on areas of potential contact as identified by analyses of mtDNA

161 datasets, including 106 individuals in total ( 72 from the G. australis complex and 34 from the $G$.

162 koira complex; Table S1). The candidate lineage koira 4 (from Oliver et al., 2019) was not

163 included in these analyses as it was morphologically and ecologically distinctive from other

164 species of the G. koira complex.

165 Sequences generated were processed using proprietary DArT analytical pipelines,

166 including independent SNP calling across sample replicates to estimate repeatability of genotype

167 calls. This pipeline treats the fatq file by filtering poor quality data using stringent selection

168 criteria, generating multiple sequence as reference for marker calls that are aggregated into

169 clusters using the DART fast clustering algorithm with a Hamming distance. Identical sequences

170 are collapsed and low-quality bases in a singleton tag were eliminated or corrected based on

171 multiple sequences as reference. These corrected sequences are analysed on a secondary

172 proprietary pipeline (DArTsoft14), where SNP markers are identified within each cluster to

173 measure the consistency of allele calls examining primarily average and variance of sequence

174 depth, call rate and average counts for each SNP allele, calculating an index of reproducibility

175 for each locus. This pipeline also includes a BLAST, contrasting the sequences with viral and

176 bacterial sequences at GenBank looking for potential contaminants. The final output consists of

177 two files; the SNP calling, including the presence of nucleotide polymorphisms in restriction

178 fragments, and the SiliciDArT file, representing the presence and absence of restriction

179 fragments in each SNP. More details on SNP genotyping can be seen in Wells and Dale (2018)

180 and Georges et al. (2018).

181 To ensure the quality of the data, all monomorphic sites were excluded and we filtered by

182 repeatability across technical replicates $(>99 \%)$ and call rate $(<10 \%$ missing data), we removed 
183 duplicate SNPs in the same fragment using the R package "dartR” (Gruber et al., 2017). To

184 visualize the divergence between samples we also generated a distance-based principal

185 coordinates analysis (PCoA) based on the genetic distance matrix and using "dartR" (Gruber et

186 al., 2017). To address the difficulty of determining discrete population structure with isolation by

187 distance, for each species complex we generated conStruct models with a K between 1-7

188 (Bradburd et al., 2018), but with a focus on the number of candidate lineages. This analysis is a

189 model-based clustering, similar to ADMIXTURE (Alexander et al., 2009), but considers the

190 spatial covariance of genetic data when discriminating discrete populations.

191

192 Morphological analyses

193 Measurements and scale counts were recorded from 140 adult specimens (Table S2) using

194 Mitutoyo electronic digital callipers (to the nearest $0.1 \mathrm{~mm}$ ) and dissecting microscope. We

195 measured 11 characters: snout-vent length (SVL), trunk length (TrunkL: body length between

196 forelimbs and hindlimbs), trunk width (TrunkW: width between ventral skin folds of forelimbs),

197 forelimb length (ForelimbL: elbow to base of wrist), hindlimb length (HindlimbL: knee to heel),

198 head length (HeadL: anterior edge of ear to tip of snout), head depth (HeadD: at deepest point

199 posterior to the eyes), head width (HeadW: widest part), snout length (SnoutL: anterior edge of

200 eye to tip of snout, measured at oblique angle), snout depth (SnoutD: deepest part of snout

201 anterior to eyes) and toe length (ToeL: base of toe to tip of toe pad on fourth right toe). We also

202 counted number of lamellae on the fourth right toe pad (excluding the apical lamellae),

203 supralabials (to midpoint of eye) and infralabials (to midpoint of eye). Pre-cloacal pores were

204 scored in all male specimens. In this group, as pore number increases, the diameter of distal

205 pores decreases dramatically. Internasals were counted following Cogger (2018), counting all 
206 scales between the nares and bordering the top of the rostral. Chin scalation terminology and

207 scoring followed Hutchinson et al. (2014: figure 4). Relative lengths of first and second chin

208 shields were measured using an ocular micrometer.

209 Data analyses were done using R (R Core Team, 2016) and R Studio (RStudio Team,

210 2015). All morphometric measurements were log-transformed to improve normality and sexual

211 dimorphism was checked using t-tests. No consistent significant indications of sexual

212 dimorphism were found therefore sexes were pooled. Subsequently, transformed values of the

213 traits were then regressed against SVL to obtain residual scores standardized for body size -

214 these were the values used for further analyses.

215 Linear Discriminant Analysis (LDA) was then used to iteratively search for distinct

216 combinations of traits that diagnose major lineages. Initial analyses included all species pooled

217 together, with subsequent comparisons focusing on the major complexes (i.e. within the $G$.

218 australis and G. koira complexes). The LDAs were done using the MASS package (Venables \&

219 Ripley, 2002) along with the Caret package (Kuhn et al., 2012) for accuracy testing using K-fold

220 cross-validation (0.3 training, 100 repetitions).

221 Colouration and pattern descriptions were made based on both preserved specimens and

222 photographs of live or recently euthanised specimens where available. Live specimens undergo

223 significant temporal shifts in the intensity of colouration, ranging through pinkish with no colour

224 pattern to darker with obvious patterning over periods of $12 \mathrm{~h}$ or less. This colour transition has

225 been reported for many species of Gehyra and may be linked to factors such as background

226 substrate and time of day (Skipwith \& Oliver, 2014; Oliver et al., 2016b; Kealley et al., 2018).

227 Diagnostic differences in pattern among species were generally apparent when individuals were

228 darkly pigmented. We term this darker pigmented state the "base colouration". Unless otherwise 
229 reported, descriptions of key aspects of dorsal colouration and patterning tend to focus on

230 animals at the base colouration.

231

232 Rationale for species recognition

233 We recognise species based on evidence from multiple independent data sources for a history of

234 evolutionary independence (i.e. the generalised lineage concept sensu De Queiroz, 2007). We

235 define species as lineages that satisfy two or more of the following criteria: (i) statistically-

236 supported reciprocal monophyly in nDNA phylograms and corresponding support from

237 coalescent delimitation tests (in Oliver et al. [2019]), and see below); (ii) evidence from SNPs

238 for discrete population structure especially around parapatric boundaries; or (iii) diagnostic

239 morphological characters based on post-hoc analyses of groups that satisfy (i) or (ii). We note

240 that lack of gene flow, supported by multiple lines of evidence and sufficient sampling of

241 geographic space and genes, is sufficient to delimit species. As the genetic evidence is more

242 compelling than the morphological evidence for several of the Gehyra species described here, we

243 provide a table of diagnostic genetic markers to provide character-based definitions of species

244 that are code-compliant (Table 1).

245 The electronic version of this article in portable document format will represent a

246 published work in accordance with the International Commission on Zoological Nomenclature

247 (ICZN), and hence the new names contained in the electronic version are effectively published

248 under that Code from the electronic edition alone. This published work and the nomenclatural

249 acts it contains have been registered in ZooBank, the online registration system for the ICZN.

250 The ZooBank LSIDs (Life Science Identifiers) can be resolved and the associated information

251 viewed through any standard web browser by appending the LSID to the prefix 
252 http://zoobank.org/. The LSID for this publication is: urn:1sid:zoobank.org:pub:9EA86EF0-

253 DB81-40ED-9DB9-58DBEF9B59D6. The online version of this work is archived and available

254 from the following digital repositories: PeerJ, PubMed Central and CLOCKSS.

255 To avoid as much repetition as possible in the descriptions and diagnoses of the taxa in

256 this morphologically conserved group, we provide brief diagnoses that apply to all or most

257 member of the two species complexes. In the diagnoses, we provide detailed comparisons of the

258 focal taxon to other similar geographically approximate taxa to facilitate discrimination of

259 species for users. The descriptions are brief, and refer to the diagnoses of the species complex,

260 the species diagnoses and to the tables of genetic and morphological characters. Colouration and

261 pattern are presented in detail for each species, as variation can be subtle and requires more

262 detail to convey differences.

263 In the following results we use species names as per taxonomic treatments below; these

264 cross reference with the lineage names used by Oliver et al. (2019) as follows:

265 australis $1=$ Gehyra gemina sp. nov.

266 australis 2 = Gehyra australis Gray, 1845

267 australis $3=$ Gehyra arnhemica sp. nov.

268 australis $4=$ Gehyra lauta sp. nov.

269 koira $1=$ Gehyra koira Horner, 2005

270 ipsa = Gehyra ipsa Horner, 2005

$271 \quad$ koira $2 \quad=$ Gehyra lapistola sp. nov.

272 koira $3=$ Gehyra calcitectus sp. nov.

273 koira $4=$ Gehyra chimera sp. nov. 


\section{RESULTS}

\section{Genetic species delimitation}

277 The results of mitochondrial- and exon-based phylogenetic analyses are presented elsewhere

278 (Noble et al., 2018; Oliver et al., 2019). In brief, the major mtDNA lineages within each species

279 were found to be monophyletic in concatenated nuclear gene phylogenies (with 2-11 individuals

280 per lineage and 1634 loci) and were supported as separate taxa using coalescent methods (50

281 loci). There was complete concordance of lineage membership across mtDNA and aggregate

282 nDNA datasets. Accordingly, mtDNA barcodes provide accurate diagnostics for the candidate

283 species. Diagnostic amino acids for each candidate species were identified in the ND2 gene and

284 are presented in Table 1.

285

After filtering the DArT SNP data, we obtained a total of 11,113 SNPs for 72 individuals

286 of the G. australis complex and 9,516 SNPs for 34 individuals of the G. koira complex. In an

287 initial PCoA including all samples across both species complexes, there was strong

288 differentiation among the four lineages in the G. australis complex in all PCoA axes, but less

289 differentiation among members of the G. koira complex. There was little evidence of recent gene

290 flow between all the eight candidate taxa that were included in the analysis (i.e. no obviously

291 intermediate samples between major clusters), including many samples from areas of parapatry

292 and overlap.

293 Subsequent analyses focused on differences within each species complex. For the $G$.

294 australis complex, the first principal coordinate of the PCoA accounted for $35.7 \%$ and the

295 second for $28.0 \%$ of the variance (63.7\% in total) (Fig. 3A). Crucially, in samples in overlap or

296 parapatric zones, there was no sign of admixture, supporting the evolutionary independence of

297 all four candidate species. We observed little evidence of differentiation (i.e. subclusters) within 
298 any of the four candidate species in the G. australis complex; one exception was slight 299 separation of individuals of G. gemina sp. nov. sampled from the Gulf and Barkly Tableland 300 region vs those from the Victoria River District and westwards. The strongest outlier was a 301 specimen from the northern edge of the arid zone in the NT (NTM R38156 (field \# CCM1948)), 302 and far from the known range of the other lineages, that appeared intermediate between $G$. 303 gemina sp. nov. and G. australis and had mtDNA from the former (arrow in Fig. 3A). The 304 ConStruct result at $\mathrm{K}=4$, the number of candidate species, presented the same outcome with four 305 distinct lineages. Even in areas where G. genima sp. nov. overlap with the other candidate 306 species, there is no admixture, as highlighted in the pie charts, except for the same sample as 307 above (Fig. 3A). In the G. koira complex the first two principal coordinates of PCoA accounted for $39.9 \%$ and $18.1 \%$ of the variance, representing $58 \%$ of the variance in the total (Fig. 3B). Each of the

310 four candidate species included forms a highly discrete cluster in this complex with no evidence 311 of any intermediates or outliers. As in the G. australis complex, geographically proximal 312 samples from different taxa cluster closely with other samples of the same lineage. Visual 313 inspection, however, suggests genetic heterogeneity within candidate species in the G. koira 314 complex, notably across the range of the widespread G. koira and between two geographic 315 isolates of the limestone-associated G. calcitectus sp. nov. The ConStruct result at $\mathrm{K}=4$ (again, 316 the number of candidate lineages) yielded less consistent results. This analysis largely 317 distinguished G. koira from a combination of geographically disjunct populations of the distantly 318 related G. calcitectus sp. nov. and G. lapistola sp. nov. (Fig. 1), however G. ipsa appeared as a 319 mix of the other taxa (Fig. 3B). As ConStruct relies on sufficient geographic sampling to 320 estimate effects of isolation by distance, we speculate that this result may reflect an interaction 
321 between the small samples sizes for some taxa (especially G. ipsa) and the geographic

322 disjunction within other taxa (especially G. calcitectus sp. nov). These two factors may effect the 323 estimation of ancestral admixture within ConStruct (Bradburd et al., 2018).

\section{Morphological analyses}

326

327

328

329

330

331

333

334

335

336

338

340

341

342

343

Multivariate analyses (LDAs) of general body morphology indicated that there was substantial overlap in patterns of morphological variation, except for the large bodied G. ipsa (Fig. 4A). One notable feature of the combined analysis is that the tree-dwelling G. chimera sp. nov. was distinctive from closely related lineages in the otherwise saxicolous $G$. koira complex, but overlapped more extensively with lineages in the mostly arboreal G. australis complex (see also Oliver et al., 2019). Overall, there is less separation in body size and shape in the G. australis complex than in the G. koira complex (Fig. 4B-C). In the latter, there is clear separation between individuals of G. ipsa, G. chimera sp. nov., G. calcitectus sp. nov. and G. lapistola sp. nov., but G. koira overlaps the last two extensively.

Despite this overall lack of differentiation in multivariate analyses, univariate comparisons suggested trait differences among lineages (Fig. 5). In comparisons including taxa in both of the two species complexes, members of the G. australis complex (except for the largebodied G. lauta sp. nov.) were generally smaller than the lineages in the G. koira complex, and also tended to have shorter hind limbs (Fig. 5). Within the G. australis complex males of G. arnhemica sp. nov. and G. lauta sp. nov. both had relatively high numbers of pre-cloacal pores in highly tapered series (outer pores much smaller than inner pores) (Fig. 6; Table 2). Within the G. koira complex, compared to the nominate taxon G. koira, G. ipsa was considerably larger (Fig. 4C) and had a lower number of pre-cloacal pores, G. lapistola sp. nov. had a lower number of 
344 pores, and G. calcitectus sp. nov. had both relatively wider head dimensions and lower number 345 of pores (Table 2; Fig 5).

346 Examination of scalation also suggested some differences in head and chin scale variation

347 (Fig. 7). Specifically, in the G. koira complex, G. ipsa often, but not always, had a characteristic

348 enlarged scale between the inner postmentals (see more discussion of this character in the

349 systematics of the G. koira complex below).

350 In colour and pattern there were again some differences, generally more apparent in the

351 base colouration in life than in preservative (Figs. 8-10). In the G. australis complex, G. gemina

352 sp. nov. and G. arnhemica sp. nov. frequently had a dorsal pattern of blotches, barring or

353 vermiculations, while adult G. lauta sp. nov. were plain and unpatterned (Fig. 8). Within the G.

354 koira complex, G. ipsa and G. koira often had a bolder pattern on the head and dorsum including

355 a moderately distinctive dark postorbital stripe, and light and dark dorsal banding or blotching

356 (Fig. 9). Gehyra calcitectus sp. nov. was highly variable, but tended to have light ocelli (as

357 opposed to bands), whereas G. lapistola sp. nov. tended to have little or no dorsal pattern (Fig 9;

358 Table 2). Gehyra chimera sp. nov. tended have a light greyish dorsum with scattered darker

359 brownish flecks and bands, very similar to most species in the G. australis complex (Fig. 10).

360

361 Systematics of the Gehyra australis complex

\section{Summary assessment of species diversity and boundaries}

363 The primary evidence for the presence of multiple species within G. australis sensu lato comes

364 from the genetic analyses, with only subtle differences revealed in post hoc analyses of

365 morphology. Moreover, there was little reason to suspect high species diversity in the $G$.

366 australis complex based on observations of variation in morphology, pattern and behaviour by 
367 themselves, prior to the molecular genetic analyses (pers. obs.). The four candidate taxa within

368 this complex were originally delineated using phylogenetic and coalescent-based analyses of an

369 extensive set of exonic sequences, albeit with small sample sizes per taxon. Having greatly

370 expanded geographic sampling for nDNA SNPs to represent the full geographic ranges,

371 including parapatric and overlap zones, we find strong genetic cohesion within lineages, clear

372 genetic distinctiveness at geographic boundaries and, hence, strong evidence for lack of

373 introgression between these taxa. There are slight (Fig. 4B; Table 2) but consistent

374 morphological differentiation in some traits, especially pore number, and aspects of scalation and

375 size. Strong concordance of mtDNA with nDNA means that the former can be used to

376 genetically diagnose taxa where morphology is ambiguous (e.g. juveniles and females in many

377 cases). One individual that may potentially be a hybrid was identified. This specimen was from

378 the wall of a roadhouse outside the natural range of one putative parental (G. australis) and close

379 to the limits if the distribution of the other (G. gemina sp. nov.) suggesting this is an

380 anthropogenically-mediated, aberrant occurrence. On the basis of this evidence for genetic

381 cohesion and evolutionary differentiation we recognise four evolutionarily distinct and cohesive

382 lineages (species) within the G. australis complex.

\section{Nomenclatural history and application of names}

385 The original description of Gehyra australis was based on two specimens in the NHMUK (Gray, 386 1845). Subsequently Cogger et al. (1983) designated NHMUK xxii.55b (Port Essington, NT) as 387 a lectotype and NHMUK xxii.55a as a paralectotype of G. australis (locality: Swan River, WA). 388 Genotyped specimens from the type locality of G. australis (Port Essington, NT) are all 389 positioned within the 'australis 2' clade, indicating 'australis 2' corresponds with true $G$. 
390

391

392

393

394

395

396

397

398

399

400

401

402

403

404

405

406

407

408

409

410

411

412

australis Gray, 1845. The lectotype of G. australis may also be further morphologically

distinguished from G. lauta sp. nov. and G. arnhemica sp. nov. by its relatively shorter pore series (Fig. 10) (14 vs 21-26, 22-32, respectively).

There are no other available names for the three additional clades in the G. australis complex identified from our analyses. Phyria punctulata Gray, 1842 has previously been treated as a synonym of G. australis and/or a nomen oblitum; however, Ellis et al. (2018) indicated the description of this form may not correspond with $G$. australis owing to an allusion to divided lamellae along with the meaning of the name which means "small spots". Instead, the description may be of a species within the G. nana group (i.e. mostly likely G. nana Storr or G. paranana Bourke, Doughty, Tedeschi, Oliver \& Moritz) or a composite type series comprised of more than one Gehyra species. In the absence of a type specimen, it is not possible to confidently allocate Phyria punctulata to any known species with certainty, and the name is considered a nomen oblitum since it has not been in use since it was proposed in 1842 (Ellis et al., 2018).

Accordingly, the name Phyria punctulata is not considered to be a name of relevance to any of the G. australis or G. koira complex taxa resulting from this study. Gekko (Gehyra) grayi has sometimes been considered a synonym of G. australis; however, Cogger, Cameron \& Cogger (1983) placed this name in the synonymy of eastern populations of $G$. variegata (i.e. now $G$. versicolor Hutchinson, Sistrom, Donnellan \& Hutchinson), and it is not considered relevant to any lineages in the G. australis group. Following Kaiser et al. (2013) and an official statement from the Australian Society of Herpetologists (2016: accessed 28 April 2019) we do not consider nomenclatural acts pertaining to the Australasian herpetofauna that have appeared outside the peer-reviewed literature. 


\section{Gehyra australis complex diagnosis and description}

414 A group of medium to moderately-large sized Gehyra (max SVL 68.1-83.1 mm), torso slightly

415 dorsoventrally compressed with fine homogenous rounded scales on dorsum and flattened scales

416 on ventrum, snout moderately long with rounded tip and covered with enlarged rounded scales,

417 eyes large and protruding, ear opening small, rostral wide and in contact with nostrils, large

418 internasals bordering nares separated by $0-3$ smaller internasals of greatly varying size, nostril in

419 contact with rostral scale, limbs short with claws on digits II-V, claws protruding from dorsal

420 surface of expanded toe pad, hindlimbs without a posterior skinfold, subdigital lamellae under

421 fourth toe undivided or at most with shallow indistinct groove, tail cylindrical tapering to a fine

422 point, base colouration of dorsum in life usually grey and either plain without pattern, or with

423 fine vermiculations and scattered spots, in males 9-32 pre-cloacal pores in shallow chevron, and

424 in females two eggs per clutch.

425

426 Gehyra australis Gray, 1845

427 Western Top End Gecko

428 aus2 of Noble et al. (2018)

429 aus2 of Oliver et al. (2019)

430 Figs. 6-7, 8A, 11-12

431

432 Lectotype. NHMUK xxii.55b, adult male, from Port Essington, NT fide Gray (1845) (-11.36 ${ }^{\circ} \mathrm{S}$,

433132.15 [approximate co-ordinates inferred from Google Earth]) (Fig. 11). 
434 Paralectotype. NHMUK xxii.55a, Swan River, WA (= Gehyra variegata fide Cogger, Cameron 435 \& Cogger, 1983).

436 Referred material. See Tables S1-2.

437 Diagnosis. A large Gehyra species (up to $68.1 \mathrm{~mm} \mathrm{SVL),} \mathrm{differing} \mathrm{from} \mathrm{all} \mathrm{other} \mathrm{Gehyra} \mathrm{species}$ 438 outside of the G. australis complex as per the diagnosis above. Differs from other members of 439 the G. australis complex in the combination of: moderate size within complex (adult SVL up to $44068.1 \mathrm{~mm}$, mean $62.7 \mathrm{~mm})$; pre-cloacal pores in males not numerous (11-14), mostly equal in 441 size, not extending onto limbs and not distinctly tapering in size distally; suture between first and 442 second chin shields usually straight; second chin shields approximately two thirds length of first 443 chin shields (mean ratio 0.63 , range $0.58-0.70$ ); and base colouration of adults smoky grey to

444 brown, often with faint but extensive pattern of indistinct darker grey or brown vermiculations 445 across the head, body and tail. Further diagnosed from other species within the G. australis 446 complex genetically by three unique amino acids in the ND2 locus (Table 1).

447 Gehyra australis may occur in close geographic proximity to two other members of the

448 G. australis group; G. lapistola sp. nov. and G. pamela. Gehyra australis differs from G.

449 lapistola sp. nov. by its smaller size (mean and maximum adult SVL, respectively: $62.7 \mathrm{~mm}$ and $450 \quad 68.1 \mathrm{~mm}$ vs $74.2 \mathrm{~mm}$ and $79.5 \mathrm{~mm}$ ) and also tending to have more extensive dorsal patterning of 451 vermiculations and flecking (vs plain grey or brown with no or very little pattern); and from $G$. 452 pamela in lacking prominent pale spots and ocelli (vs present), having a rounded snout tip in 453 dorsal aspect (vs squarish), and in having smaller chin shields (extending to approximately level 454 with posterior edge of second infralabial vs approximately level with posterior edge of third 455 infralabial) (see King [1982] for images), and in having a lower number of pre-cloacal pores in 456 adult males (11-14 vs 18-24). 
Within the G. australis complex, G. australis occurs in contact or in potential sympatry

458

459

460

461

462

463

464

465

466

467

468

469

470

471

472

473

474

475

476

477

478

479

with $G$ arnhemica sp. nov. and G. gemina sp. nov. Gehyra australis differs from G. arnhemica sp. nov. in having a lower number of pre-cloacal pores in males (10-14 vs 21-26), and also in tending to have less distinct and extensive dorsal patterning in life (faint barring vs a clear network of vermiculations). Gehyra australis differs from G. gemina sp. nov. in having posterior edge of first infralabial generally $\sim 50 \%$ or greater of second supralabial (vs $\sim 60 \%$ or less) and outer edge of first pair of chin shields in contact with second pair usually strait (vs usually convex). It differs from G. lauta sp. nov. in its smaller size (mean and maximum adult SVL, respectively: $62.7 \mathrm{~mm}$ and $68.1 \mathrm{~mm}$ vs $71.4 \mathrm{~mm}$ and $83.1 \mathrm{~mm}$ ), second chin shields usually less than three-quarters length of first chin shields (mean and range ratios 0.63 [0.58-0.70] vs 0.77 [0.70-0.88]), and fewer pre-cloacal pores (10-14 vs 22-32), generally not extending onto limbs. Based on the morphological characters we have examined, G. australis is most similar morphologically to G. arnhemica sp. nov. (particularly weakly patterned females), G. gemina sp. nov. (both sexes) and G. chimera sp. nov. (both sexes) of the G. koira complex. The relatively disjunct distributions (particularly G. chimera sp. nov.) permit identification in most cases when accurate locality data is available. Along the southern edge and central portions of the Top End region where some of these species may occur in sympatry, genetic data may be required to confidently identify specimens to species (see Table 1 for diagnostic amino acids).

Description. As for G. australis complex description treated herein above, with the differences and variation outlined in the diagnoses above and Table 2.

Colour and pattern. In life, colouration smoky grey to brown, often with scattered indistinct darker brown or darker grey flecks, spots, vermiculations or transverse bars extending across the dorsal and lateral surfaces of head, body, limbs and tail. Specimens found under lights and/or on 
480 light substrates (such as the wall of houses) tend be pink and to show very faint or no patterning

481 (Fig. 8A), but often become darker when placed in a darker environment (P.M. Oliver, pers.

482 obs.). In preservative, base colouration light to medium grey, sometimes with a brownish tinge,

483 pattern generally absent or minimal and always indistinct, at most consisting of weak medium

484 grey transverse bands, but more usually of very indistinct grey mottling and/or very tiny light

485 ocelli.

486

Distribution, habitat and ecology. Known only from the NT, concentrated in the western portion

487 of the Top End region, extending from Port Essington west through Darwin and surrounds, then

488 along the western seaboard, as far south as Gregory NP, and east to at Eva Valley on the

489 southern edge of the Arnhem Plateau (Fig. 2). There are very few records of G. australis (s.1.)

490 from the Arnhem Plateau itself and no specimens from there have tissues for genotyping.

491 Gehyra australis occurs on trees in both rocky areas and on open plains and woodlands.

492 On trees it is most commonly observed on the lower trunks or large branches between $0-4 \mathrm{~m}$

493 from the ground. It occurs rarely on rocky microhabitats, and then in areas where G. lapistola sp.

494 nov. or G. pamela are absent, such as sandstone country around Hayes Creek and on both

495 limestones and sandstones around Katherine (P.M. Oliver, pers. obs.). It has also been observed

496 on human structures such as buildings (under lights) and concrete bridges and causeways.

497 Anecdotal reports suggest that it may have been displaced from some anthropogenic habitats by

498 Hemidactylus frenatus Dumeril \& Bibron (Greer, 1989).

499

500 Gehyra arnhemica sp. nov.

501 urn:lsid:zoobank.org:act:33DB9200-D783-4738-9B5A-50A6AF4155C1

502 East Arnhem Land Gecko

Peer) reviewing PDF | (2019:04:36958:1:2:NEW 27 Sep 2019) 
503 aus3 of Noble et al. (2018)

504 aus3 of Oliver et al. (2019)

505

506 Figs. 6-7, 8B-C, 13

507

508 Holotype. NTM R22626, adult male, collected from Long Billabong, Savannah Way, 2 km N

509 Cox River, Roper Gulf, NT (-15.3067 S, 135.3408 E), collected by P. Horner, 19 May 1996.

510 Paratypes $(N=12)$. Northern Territory: NTM R38171 (field \# CCM2271), NTM R38172 (field

511 \# CCM2272), Lake Katherine, NT (-14.3079, $\left.135.0610^{\circ} \mathrm{E}\right)$; NTM R38173 (field \# CCM2408),

512 Ngukurr, NT (-14.6550 S, $\left.134.7812^{\circ} \mathrm{E}\right)$; NTM R38174 (field \# CCM2573), NTM R38175 (field

513 \# CCM2575), NTM R38176 (field \# CCM2576), Cox River area, Limmen NP, NT (-15.3167º

514 135.3409²); NTM R38178 (field \# CCM6511), NTM R38179 (field \# CCM6516), Emu

515 Springs, NT (-13.1562 S, $\left.134.8506^{\circ} \mathrm{E}\right)$; NTM R38180 (field \# CCM6554), NTM R38181 (field

516 \# CCM6555), NTM R38182 (field \# CCM6595), 3.0 km SW Gikal, NT (-12.0813ㅇ,

517 136.2942 $\left.{ }^{\circ} \mathrm{E}\right)$; NTM R38183 (field \# CCM6647), 1.5 km NE Gikal, NT (-12.0522 ${ }^{\circ}$ S,

$\left.518 \quad 136.3210^{\circ} \mathrm{E}\right)$.

519 Referred material. See Tables S1-S2.

520 Diagnosis. A large Gehyra species (up to $68.2 \mathrm{~mm}$ SVL) differing from all other Gehyra species

521 outside of the G. australis complex as per the complex diagnosis above. Differs from other

522 members of the G. australis complex in the combination of: moderate size within complex (adult

523 SVL up to $68.2 \mathrm{~mm}$, mean $63.0 \mathrm{~mm}$ ); pre-cloacal pores in males numerous (21-26), often

524 extending onto limbs and reduced in size distally; suture between first and second chin shields 
525 usually straight; second chin shields approximately two thirds length of first chin shields (mean

526 ratio 0.67 , range $0.57-0.77$ ); and base colouration of adults smoky grey to brown, often with

527 distinct and extensive pattern of darker-brown vermiculations, stripes, scalloping and/or blotches

528 across the head, body and tail.

529 Further diagnosed from other species within the G. australis complex genetically by three

530 unique amino acids in the ND2 locus (Table 1). Some specimens, especially juveniles and

531 females, may only be diagnosable from other members of the G. australis complex and $G$.

532 chimera sp. nov. on the basis of locality and/or genetic data.

533 Gehyra arnhemica sp. nov. overlaps or contacts the distribution of G. australis and G.

534 gemina sp. nov. and is very similar morphologically to both species; however, males of $G$.

535 arnhemica sp. nov. differ from both in having a higher number of pre-cloacal pores (21-26 vs

536 11-14 in G. australis and 10-16 in G. gemina sp. nov.). It further differs from G. gemina sp.

537 nov. in outer edge of first pair of chin shields in contact with second pair usually strait (vs

538 usually convex). Gehyra arnhemica sp. nov. further tends to differ from G. australis in having a

539 more extensive and bolder pattern of dark brown blotches, lines and/or scalloping on the head,

540 torso and tail. From G. lauta sp. nov., it differs in its smaller size (mean and maximum adult

541 SVL, respectively: $68.2 \mathrm{~mm}$ and $63.0 \mathrm{~mm}$ vs $71.4 \mathrm{~mm}$ and $83.1 \mathrm{~mm}$ ).

542 Gehyra arnhemica sp. nov. also overlap or abuts with the distribution of the rock-

543 dwelling taxa G. borroloola and G. pamela; however, it can be readily differentiated from both

544 by the absence of prominent pale spots and ocelli (vs present), and by having smaller chin

545 shields (extending to approximately level with posterior edge of second infralabial vs

546 approximately level with posterior edge of third infralabial) (see King 1982). 
547 Description. As for G. australis complex description above, with the differences and variation

548 outlined in the diagnoses above and in Table 2.

549 Colour and pattern. Recently deceased (Gikal, North-east Arnhem Land) and live specimens

550 (Wongalara Station) have pale brown-grey dorsal surface with unaligned dark brown streaks,

551 paired blotches or extensive vermiculations, sometimes bordered by paler margins across the

552 dorsum (Fig. 8B-C). Head and limbs likewise greyish, again with some to extensive dark brown

553 spots and/or striping, including a moderately prominent and clearly defined postorbital stripe.

554 Head also with occasional pale spots. Original tails with some to extensive dark brown

555 patterning. In preservative, dorsal colouration light to medium grey, often with transverse darker

556 grey bands or series of blotches along the dorsum and tail, grey bands sometimes with faint off-

557 white margins, especially on tail, further dark grey flecks, splotches of maculations present

558 across the dorsal surfaces, some specimens also show very indistinct off-white dorsal

559 maculations. Ventral colouration off-white with or without pale grey maculations, especially

560 around the lateral extremities and on the throat.

561 Summary description of holotype (NTM R22626). All measurement in mm: SVL 63.2; TrunkL

562 23.3; TrunkW 10.7; ForelimbL 6.9; HindlimbL 7.9; HeadL 14.2; HeadD 7.2; HeadW 11.5;

563 SnoutL 5.8; SnoutD 5.2; ToeL 6.4. Rostral flat and rectangular, with slightly rounded dorsal

564 corners and medial crease on dorsal half. Nostrils separated by two large internasals; supralabials

565 to mid-point of eye 8 on both sides. Infralabials 9 on both sides; mental scale triangular, chin

566 shields elongate, rounded and in two pairs; parainfralabials rounded, enlarged and varying from

567 round to oblong. Limbs relatively short, with 9 divided subapical subdigital lamellae undivided

568 under fourth right toe. Tail original. Pre-cloacal pores 25, arranged in a broad chevron formation. 
569 Distribution, habitat and ecology. Distribution centred on the eastern portion of the Top End

570 region of the NT, including offshore islands to the north (Inglis Island) and east (Groote

571 Eylandt), south as far as Limmen NP, and west to the upper Jalboi River (Fig. 2). There is also

572 an isolated record from Gudjekbin in north central Arnhem Land, suggesting that this species

573 occurs more widely in this relatively poorly sampled region.

$574 \quad$ Occurs on both arboreal and rocky microhabitats. At Wongalara station in southern

575 Arnhem Land they have been recorded from smooth-barked Eucalypt trees (Corymbia

576 polycarpa) in seasonally inundated woodlands, and were also not found on Melaleuca sp. trees in

577 the same habitat (J. Smith, pers. comm.). At Emu creek outstation (central Arnhem Land) they

578 were on smooth-bark Eucalypt trees and human structures, while in north-east Arnhem Land

579 (e.g. around Mata Mata) they were abundant on large rock boulders and none were seen on trees,

580 although no smooth barked trees were observed at these sites (C. Moritz, pers. obs.).

581 Etymology. The species epithet refers to the Arnhem Land region of the north-east Top End of

582 the NT, in reference to the species occurrence and apparent endemism to the region.

583

584 Gehyra gemina sp. nov.

585 urn:lsid:zoobank.org:act:BC6CA755-1F3D-4E03-9A09-8E2F1174CC09

586 Plain Tree Gecko

587 aus1 of Noble et al. (2018)

588 aus1 of Oliver et al. (2019)

589 Figs. $6-7,8 \mathrm{D}, 10 \mathrm{C}, 14$ 
591 Holotype. WAM R179349 (field \# CCM3042), adult male, collected from Saw Tooth Gorge, 592 WA $\left(-18.4252^{\circ} \mathrm{S}, 127.8197^{\circ} \mathrm{E}\right)$, collected by A.C. Alfonso Silva, M. Pepper and S. Potter, 11 593 July 2014.

594 Paratypes $(N=20)$. Western Australia: WAM R177723 (field \# CCM3221), Muluk rest area, 39 $595 \mathrm{~km} \mathrm{SSW}$ Warmun, WA (-17.3389², $\left.128.0525^{\circ} \mathrm{E}\right)$; WAM R177725 (field \# CCM3224), WAM 596 R177726 (field \# CCM3225), Purnululu NP access road, WA (-17.4203으, $\left.128.0922^{\circ} \mathrm{E}\right)$; WAM 597 R177728 (field \# CCM3298), Gogo Station, WA (-18.4731 S, 125.8171); WAM R177732 (Field 598 \# CCM3374), Gibb River Road, Wilinggin Conservation Park, WA (-17.15351º , 599 125.42159²E); WAM R177734 (field \# CCM7280), WAM R17735 (field \# CCM7281), 600 Lissadell Station, WA (-16.6635 $\left.{ }^{\circ} \mathrm{S}, 128.5265^{\circ} \mathrm{E}\right)$; WAM R177737 (field \# CCM7303), Mt. 601 Nyulasy, WA (-16.7655 $\left.{ }^{\circ} \mathrm{S}, 128.2730^{\circ} \mathrm{E}\right)$. Northern Territory: NTM R38152 (field \# CCM0367), 602 Calvert Hills Station, NT (-17.1979º S, 137.4343E); NTM R38153 (field \# CCM0404), 603 McArthur River Station, NT (-16.6383ํㄱ, $\left.135.8462^{\circ} \mathrm{E}\right)$; NTM R38154 (field \# CCM0406), 604 McArthur River Station, NT (-16.6505으, $\left.135.8493^{\circ} \mathrm{E}\right)$; NTM R38155 (field \# CCM0554), 605 Gregory NP, NT (-15.6109 S, $\left.131.1160^{\circ} \mathrm{E}\right)$; NTM R38157 (field \# CCM2218), NTM R38158 606 (field \# CCM2219), NTM R38159 (field \# CCM2220), Munbililla (Tomato Island) Limmen NP, 607 NT (-14.7794오 $\left.{ }^{\circ}, 134.6667^{\circ} \mathrm{E}\right)$; NTM R38160 (field \# CCM2479), Butterfly Springs, Limmen 608 NP, NT (-15.62723요 $135.4623^{\circ}$ E);NTM R38161 (field \# CCM2612), Southern Lost City, 609 Limmen NP, NT (-15.6272 S; $\left.135.4623^{\circ} \mathrm{E}\right)$; NTM R38162 (field \# CCM2618), Fossil Fern, 610 Lorella Springs Station, NT (-15.6795, $\left.135.6247^{\circ} \mathrm{E}\right)$; NTM R38163 (field \# CCM3044), 611 Limbunya Station, NT (-17.5189 S, $\left.129.8759^{\circ} \mathrm{E}\right)$; NTM R38164 (field \# CCM6376),

612 Mallapunya Station, NT (-16.9732 $\left.{ }^{\circ} \mathrm{S}, 135.8030^{\circ} \mathrm{E}\right)$.

613 Referred material. See Tables S1-S2. 
615 species outside of the G. australis complex as per the diagnosis above. Differs from other

616 members of the G. australis complex in the combination of: moderate size within complex (adult

617 SVL up to $68.9 \mathrm{~mm}$, mean $62.9 \mathrm{~mm})$; pre-cloacal pores in males not numerous (10-16),

618 generally equal in size, not extending onto limbs and not distinctly tapering in size distally from

619 largest median pore, distal most pores equal to no smaller than one-half the size of median

620 pore; outer edge of first chin shield concave where it contacts the second chin shield, rarely

621 straight; second chin shields approximately two-thirds length of first chin shields (mean ratio

6220.64 , range $0.56-0.75)$; and base colouration of adults smoky grey to brown, often with faint but

623 extensive pattern of indistinct darker grey or brown vermiculations across the head, body and

624 tail. If transverse lines present on dorsum, lines are irregular and without strait edges. unique amino acids in the ND2 locus (Table 1).

627

The geographic range of G. gemina sp. nov. overlaps or contacts the distribution of all

628 three other species in the G. australis complex; it differs from G. lauta sp. nov. in its smaller size 629 (mean and maximum adult SVL respectively: $62.1 \mathrm{~mm}$ and $68.9 \mathrm{~mm}$ vs $71.4 \mathrm{~mm}$ and $83.1 \mathrm{~mm}$ ), 630 second chin shields usually less than three-quarters length of first chin shields (mean and range 631 ratios 0.69 [0.56-0.75] vs 0.77 [0.70-0.88]), and fewer pre-cloacal pores (10-16 vs 22-32), not 632 extending onto limbs and of relatively similar size; from G. arnhemica sp. nov. by fewer pre633 cloacal pores in males (10-16 vs 21-26) not extending onto limbs and outer edge of first pair of 634 chin shields in contact with second pair usually convex, rarely strait (vs usually strait); and from 635 G. australis by posterior edge of first infralabial generally $\sim 60 \%$ or less of second supralabial (vs 
636 generally $50 \%$ or greater) and outer edge of first pair of chin shields in contact with second pair

637 usually convex, rarely strait (vs usually strait)

638

Gehyra gemina sp. nov. is morphologically most similar to G. arnhemica sp. nov.

639 (particularly juveniles and females), G. australis (both sexes) and G. chimera sp. nov. (both

640 sexes) of the G. koira complex, and genetic data may be necessary to identify individuals with

641 certainty, particularly in areas of sympatry or parapatry.

642 Description. As for G. australis complex description above, with the differences and variation

643 outlined in the diagnoses above and in Table 2.

644 Colour and pattern. Specimens photographed in life from the Kimberly (King Leopold Ranges,

645 Gogo Station, Halls Creek) show a pale off-white to grey dorsal surface, with variable amounts

646 of darker brown or grey streaks, flecks or vermiculations, and occasionally very indistinct

647 whitish dorsal bands (Fig. 8D). When transverse bands present, lines are irregular and without

648 strait edges. Head and limbs likewise greyish, again with some to extensive brown or darker grey

649 spots and or striping, including a moderately to weakly defined postorbital stripe. Original tails

650 also with some to extensive darker brown patterning. In preservative, dorsal background

651 colouration varies from light to dark grey, sometimes plain and unpatterned, but sometimes with

652 dark grey vermiculations and blotching on the head and/or across the dorsum and tail. Ventral

653 surfaces of body pale cream with no extensive grey maculations. Subcaudal surfaces usually pale

654 cream.

655 Summary description of holotype (WAM R179349). All measurements in mm: SVL 62.1; TrunkL

656 27.8; TrunkW 10.5; ForelimbL 7.7; HindlimbL 8.3; HeadL 14.2; HeadD 6.4; HeadW 11.5;

657 SnoutL 6.1; SnoutD 4.7; ToeL 5.1. 
658 Rostral broadly rectangular, with flat dorsal edge and rounded corners; medial crease on upper

659 half; internasals 4; supralabials (to mid-point of eye) 8; Infralabials 8 (left) 9 (right); mental scale

660 triangular, chin shields elongate, rounded and in two pairs. Body slightly compressed. Limbs

661 relatively short, subdigital lamellae undivided, 10 on fourth right toe. Tail regrown. Pre-cloacal

662 pores 10, equal in size, arranged in a broad chevron formation, not extending onto limbs.

663 Distribution, habitat and ecology. Occurs widely through the northern deserts of WA and the

664 NT. Occurs from Broome in the west, east throughout the Kimberley region of WA, north to

665 Victoria River and the southern edge of the Arnhemland region, and throughout the Gulf

666 Country in the NT (Fig. 2). The apparent hiatus of G. gemina in the central portion of the

667 northern desert region may be artefact of poor sampling across the region; however, a shallow

668 genetic disjunction across this relatively arid and sparsely vegetated area (e.g. the 2 clusters in

669 the PCoA; Fig. 3A) indicates that the absence of records may represent true disjunction between

670 populations.

671 Generally found on trunks or large branches of trees with few, if any, records from rocky

672 microhabitats. Also found on buildings. Some isolated populations, usually as commensals may

673 be introduced especially to the southern extremities of the range (see results).

674 Etymology. The species epithet is from the Latin word gemina (twin, same), in reference to the

675 species' morphological similarities shared with other members of the G. australis complex, $G$.

676 australis in particular.

677 Remarks. The wide distribution of this form across the southern portions of the AMT broadly

678 overlaps with the northern deserts region (sensu Cracraft, 1991; but see González-Orozco et al.,

679 2014). This distribution also mirrors that of several other species and lineages that have likewise 
680 only been identified recently, supporting the hypothesis that the southern AMT has a distinct

681 associated endemic biota (Smith et al., 2011; Catullo et al., 2014; Laver et al., 2017).

682

683 Gehyra lauta sp. nov.

684 urn:Isid:zoobank.org:act:02B9D2DC-9499-41E3-BD1E-D0F0C8880F83

685 Gulf Tree Gecko

686 aus4 of Noble et al. (2018)

687 aus4 of Oliver et al. (2019)

688

689 Figs. 6-7, 8E-F, 15

690

691 Holotype. QM J90707, adult male, collected from Sybella Creek, Dajarra Road, 17.2 km S

692 Mount Isa, Qld (-20.876 ${ }^{\circ}, 139.458^{\circ}$ E), collected by M.N. Hutchinson, P.M. Oliver, M.A.

693 Cowan and D.L. Rabosky, 20 April 2010.

694 Paratypes $(N=14)$. Northern Territory: NTM R38184 (field \# CCM0438), MacArthur Station,

695 NT (-16.7101 ${ }^{\circ} \mathrm{S}, 136.2042^{\circ}$ E). Queensland: QM J96621 (field \# CCM0244), Gunpowder Ridge,

696 Qld (-19.7503으, $\left.139.3808^{\circ} \mathrm{E}\right)$; QM J96622 (field \# CCM0247), West Leichardt Station, Qld (-

$\left.69720.6027^{\circ} \mathrm{S}, 139.6839^{\circ} \mathrm{E}\right)$; QM J96623 (field \# CCM0322), Bowthorn Station tip, Qld (-18.0938,

698 138.3017E); QM J96624 (field \# CCM0345), Kingfisher Station Qld (-17.8854 ${ }^{\circ}$ S, $\left.138.2810^{\circ} \mathrm{E}\right)$;

699 NTM R21309-12,Musselbrook Reservoir, Qld (-18.592º S, 138.124E); QM J47904 Elizabeth

700 Gorge, Bowthorn Station, Qld (18.216 $\left.\mathrm{S}, 138.333^{\circ} \mathrm{E}\right)$; QM J75291 Lawn Hill NP, Qld (- 
$\left.70118.692^{\circ} \mathrm{S}, 138.491^{\circ} \mathrm{E}\right) ;$ QM J78786, $\left.10 \mathrm{~km} \mathrm{WNW} \mathrm{Kajabbi,} \mathrm{Qld} \mathrm{(-19.776}{ }^{\circ} \mathrm{S}, 139.896^{\circ} \mathrm{E}\right)$; QM

702 J88487, Mount Isa area, Qld (-20.514º S, 139.461 $\left.{ }^{\circ} \mathrm{E}\right)$; QM J90711, Sybella Creek, Dajarra Road,

$70317.2 \mathrm{~km} \mathrm{~S}$ Mount Isa, Q1d (-20.876 $\left.\mathrm{S}, 139.458^{\circ} \mathrm{E}\right)$.

704 Referred material. See Tables S1-S2.

705 Diagnosis. A large Gehyra species (up to $83.1 \mathrm{~mm}$ SVL), differing from all other Gehyra species 706 outside of the G. australis complex as per the diagnosis above. Differs from other members of 707 the G. australis complex in the combination of: large size within complex (adult SVL up to 83.1 $708 \mathrm{~mm}$, mean $72.2 \mathrm{~mm}$ ); pre-cloacal pores in males numerous (22-32), often extending onto limbs 709 and reduced in size distally; suture between first and second chin shields usually straight; second 710 chin shields more than two thirds length of first chin shields (mean ratio 0.77 , range $0.70-0.88$ );

711 and adults with a plain grey to purplish brown dorsal colouration across the head and body with 712 no or at most a faint pattern.

713 Further diagnosed from other species within the G. australis complex genetically by 10 714 unique amino acids in the ND2 locus (Table 1).

715 Gehyra lauta sp. nov. overlaps geographically with three other species in the G. australis 716 group: G. dubia, G. gemina sp. nov. and G. robusta. It differs from G. dubia by its larger size 717 (mean and maximum adult SVL, respectively: $72.2 \mathrm{~mm}$ and $83.1 \mathrm{~mm}$ vs $56.5 \mathrm{~mm}$ and $64.7 \mathrm{~mm}$ ), 718 higher number of pre-cloacal pores (22-32 vs 12-20), and its relatively plain grey dorsal 719 colouration in life (vs at least some darker spotting or mottling, and often also a distinct 720 postorbital stripe); from G. robusta in having little or no dorsal pattern (vs distinct brown and

721 light grey spots and stripes) and higher number of pores in males (22-32 vs 12-17); and from $G$. 722 gemina sp. nov. by its larger size (mean and maximum adult SVL, respectively: $72.2 \mathrm{~mm}$ and $72383.1 \mathrm{~mm}$ vs $62.1 \mathrm{~mm}$ and $68.9 \mathrm{~mm})$, higher number of pores (22-32 vs 10-16), often extending 
724 onto limbs and reduced in size distally, posterior edge of first infralabial generally $\sim 50 \%$ or

725 greater of second supralabial (vs $\sim 60 \%$ or less) and outer edge of first pair of chin shields in

726 contact with second pair usually strait, rarely slightly concave (vs usually convex) and second

727 pair of chin shields usually more than two-thirds length of first chin shields (mean and range

728 ratios $0.77[0.70-0.88]$ vs $0.64[0.56-0.75])$.

729

Of the remaining species in the G. australis complex, G. australis and G. arnhemica sp.

730 nov., the relatively disjunct and allopatric distribution permits identification in most areas where

731 accurate locality data is available. Morphologically, G. lauta sp. nov. differs from G. australis in

732 its larger size (mean and maximum adult SVL, respectively: $71.4 \mathrm{~mm}$ and $83.1 \mathrm{~mm}$ vs $62.7 \mathrm{~mm}$

733 and $68.1 \mathrm{~mm}$ ), second chin shields usually more than three-quarters length of first chin shields

734 (mean and range ratios $0.77[0.70-0.88]$ vs $0.63[0.58-0.70]$ ), and more numerous pre-cloacal

735 pores (22-32 vs 10-16), usually extending onto limbs, with distal pores no greater than one-half

736 the size of median pore (vs not extending onto limbs, with distal most pores no smaller than one-

737 half size of median pore). From G. arnhemica, it differs by its larger size (mean and maximum

738 adult SVL, respectively: $71.4 \mathrm{~mm}$ and $83.1 \mathrm{~mm}$ vs $63.0 \mathrm{~mm}$ and $68.2 \mathrm{~mm}$ ).

739 Description. As for G. australis complex description treated herein above, with the differences

740 and variation outlined in the diagnoses above and in Table 2.

741 Colour and pattern. Photographs of the holotype (QM J90707), paratypes (QM J96621-4) and

742 uncollected adults (Calvert River, NT) in life show adults to have a pale silvery-grey to purplish-

743 brown dorsal surface with generally no discernible pattern, or at most indistinct lighter off-white

744 regions on the body and tail (Fig. 8E-F). Juveniles (QM J96621 and CCM318 with SVL 42-43

$745 \mathrm{~mm}$ ) are more silvery brown with stronger, but still indistinct dark brown transverse bands or

746 blotches. These differences in colouration suggest that this species undergoes an ontogenetic 
747 colour change, but colouration information from more samples is required to confirm this. In

748 preservative, dorsal surfaces of head, body, limbs and tail varies from medium grey to light

749 brownish grey to with no discernible pattern. Ventral surfaces buff, sometimes with fine greyish

750 maculations along the lateral edges and/or forming indistinct mottling across subcaudal surfaces.

751 Summary description of holotype (QM J90707). All measurement in mm: SVL 72.7; TrunkL

752 36.8; TrunkW 13.1; ForelimbL 9.4; HindlimbL 11.2; HeadL 17.2; HeadD 8.4; HeadW 13.9;

753 SnoutL 7.4; SnoutD 6.0; ToeL 6.9. Rostral flat and rectangular, with medial crease on upper

754 third; internasals 2; supralabials to mid-point of eye 9 on right and 8 on left. Infralabials 10 on

755 both sides; mental scale pentagonal with rounded anterior edges; chin shields elongate, rounded

756 and in three pairs, second pair more than two thirds length of first pair; parainfralabials rounded,

757 heterogenous in size from small to moderately large. Body slightly compressed. Limbs relatively

758 short, subapical subdigital lamellae undivided, 9 on fourth right toe. Tail regrown. Pores 26,

759 largest median pores up to approximately 5 times diameter of smallest distal most pores.

760 Distribution, habitat and ecology. Restricted to the rocky ranges of north-western Qld and north-

761 eastern NT, genetically verified records extend from China Wall in the west to Mount Gordon in

762 the Selwyn Ranges to the east (Fig. 2). All records of G. australis from further east in Qld are

763 likely G. dubia or different currently unrecognised Gehyra taxa (P. Couper, C. Hoskin, pers.

764 comm.). While this species is generally known from areas with rocky ranges, within this habitat

765 it is almost always collected from tree trunks, especially smooth barked Corymbia sp. or Grevilla

766 sp. (P.M. Oliver, C. Moritz, pers. obs.), with G. robusta occurring on nearby rocky

767 microhabitats.

768 Etymology. The species epithet is from the Latin word lautus (washed, neat, elegant), in

769 reference to the plain or washed out dorsal pattern of the species. 


\section{Systematics of the Gehyra koira complex}

\section{Summary assessment of species diversity}

774 Previous analyses of exonic sequences identified arboreal individuals resembling G. australis

775 from the western Kimberley as being a distinct lineage within the otherwise saxicolous G. koira 776 complex. Gehyra chimera sp. nov. is phylogenetically deeply nested within the G. koira

777 complex, with different datasets variably grouping it with the western and/or southern Kimberley

778 taxa G. ipsa and G. calcitectus sp. nov. (Oliver et al., 2019; Fig. 1). However, this taxon is

779 ecologically more similar to the G. australis complex, being primarily arboreal and often found

780 far from rocky microhabitats. Phenotypically it resembles members of the G. australis complex,

781 especially G. gemina sp. nov. in overall morphology (Fig. 4A, 10), size and grey dorsal

782 colourations with dark-brownish vermiculations. On the basis of morphological and genetic

783 divergence from other members of the G. koira complex, we first present a description of this

784 lineage as a new species.

785 Within the remaining largely saxicolous populations of the G. koira complex, prior 786 phylogenetic and coalescent analyses of exon sequences (Oliver et al., 2019; Fig. 1) identified

787 four saxicolous candidate species - the large-bodied G. ipsa and three parapatric lineages within 788 G. koira (s.1.). For these, geographically comprehensive sampling for nDNA SNPs revealed 789 cohesive and, in PCoA, clearly separated genetic clusters, including individuals from parapatric 790 boundaries. As for the G. australis complex, there was strong concordance of mtDNA clades 791 with nDNA genetic identity. The statistical (conStruct) analysis yielded results less clear than

792 was the case for the G. australis group, which we tentatively attribute to inability to model 
793 isolation by distance in taxa with restricted (G. ipsa) or naturally disjunct (G. calitectus sp. nov.)

794 distributions. In this group, there is clearer morphological separation of taxa (Fig. 4C), with

795 consistent morphological differentiation in one or more of the following traits (with the outliers

796 noted), overall size (G. ipsa), colour pattern (G. lapistola sp. nov., G. calitectus sp. nov.), pore

797 number (G. calitectus sp. nov.) and aspects of scalation (G. ipsa). There was also some evidence

798 of ecological differentiation or displacement with G. calitectus sp. nov., which is known only

799 from widely disjunct patches of limestone karst (with G. koira on adjacent sandstones),

800 suggesting a close association with this particular habitat. Combining evidence for genetic

801 cohesion (PCoA), prior analyses of exonic sequence data and morphological differences, we

802 recognise each of these four lineages as separate species.

803 On the basis of geography and morphology two of these lineages unequivocally correspond

804 to named taxa; G. ipsa is a large bodied form with a restricted distribution on the Purnululu

805 Massif in the eastern Kimberley, while the smaller and much more widespread koira 1

806 corresponds with true G. koira (type locality Keep River NP, NT) (Horner, 2005). When

807 originally described the distribution of these two taxa was widely disjunct; however, subsequent

808 sampling has filled the gap, and genetic data show that both occur in the Purnululu Massif,

809 posing challenges for identification of smaller and non-genotyped specimens from this area (see

810 below under the redescription of G. ipsa).

811 No scientific names have previously been proposed for either the arboreal taxon in the

812 western Kimberley, or the three other saxicolous lineages in the G. koira complex, so we

813 formally name each of these herein.

814 
815 Gehyra chimera sp. nov.

816 urn:lsid:zoobank.org:act:E2BF5779-651D-4CB4-BF67-B7E286750DB2

817 Western Kimberley Tree Gecko

818 koira4 of Oliver et al. (2019)

819 Figs. 6-7, 10A-B, 16

820

821 Holotype. WAM R177687 (field \# CCM3372), adult male, collected from Bell Creek Crossing,

822 Gibb River Road, WA (-17.1686 ${ }^{\circ}$ S, $125.3611^{\circ}$ E), collected by P.M. Oliver, P. Skipwith and G.

823 Armstrong, 9 November 2014.

824 Paratypes $(N=14)$. Western Australia: WAM R177673 (field \# CCM0694), WAM

825 R177674 (field \# CCM0714), Doongan Station homestead, WA (-15.37866 $\left.\mathrm{S}, 126.31163^{\circ} \mathrm{E}\right)$;

826 WAM R177675 (field \# CCM0873), Gibb River-Kalumburu Road, 25km W Theda homestead,

827 WA (-14.834 $\left.{ }^{\circ} \mathrm{S}, 126.3001^{\circ} \mathrm{E}\right)$; WAM R177682 (field \# CCM1239), WAM R177683 (field \#

828 CCM1240), Silent Grove Ranger Station, WA (-17.0666 $\left.{ }^{\circ} \mathrm{S}, 125.2501^{\circ} \mathrm{E}\right)$; WAM R177684 (field

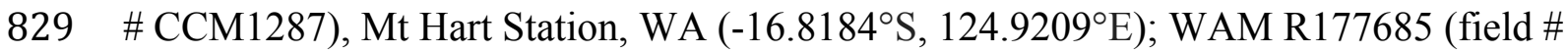

830 CCM3370), WAM R177686 (field \# CCM3371), Bell Creek Crossing, Gibb River Road, WA (-

$831 \quad 17.1686^{\circ} \mathrm{S}, 125.3611^{\circ} \mathrm{E}$ ); WAM R177688 (field \# CCM3375), WAM R177689 (field \#

832 CCM3376), Silent Grove campground, Wilinggin Conservation Park, WA (-17.0669 ,

$\left.833125.2476^{\circ} \mathrm{E}\right)$; NMV D76976, Silent Grove campground, Wilinggin Conservation Park, WA (-

$\left.83417.0677^{\circ} \mathrm{S}, 125.2477^{\circ} \mathrm{E}\right)$; NMV D77000, King Leopold Ranges, on Gibb River Road, WA (-

$\left.83517.1298^{\circ} \mathrm{S}, 125.2428^{\circ} \mathrm{E}\right)$; NMV D77043-44, Mt Hart Station, WA (-16.8180 $\left.{ }^{\circ} \mathrm{S}, 124.9207^{\circ} \mathrm{E}\right)$.

836 Referred material. See Tables S1-S2.

Peer) reviewing PDF | (2019:04:36958:1:2:NEW 27 Sep 2019) 
837 Diagnosis. A large Gehyra species (up to $73.7 \mathrm{~mm} \mathrm{SVL}$ ) most similar morphologically to 838 members of the G. australis complex (despite occurring within the G. koira complex), differing

839 from all other Gehyra species outside the G. australis complex (including other members of the 840 G. koira complex) as per the group diagnosis above. Differs from members of the G. australis 841 and G. koira complexes in the combination of: large size compared to G. australis complex 842 members and moderate size within the G. koira complex (adult SVL up to $73.7 \mathrm{~mm}$, mean 62.5 $843 \mathrm{~mm}$ ); in males 9-11 pre-cloacal pores in shallow chevron; suture between first and second chin 844 shields usually straight; second chin shields usually just over two thirds length of first chin 845 shields (mean ratio 0.75 , range $0.68-0.80$ ); usually $3-4$ internasal scales, rarely 2 ; base 846 colouration of dorsum in life usually greyish and either plain and without pattern, or at most with 847 greyish brown vermiculations and scattered spots.

$848 \quad$ Further diagnosed from other members of the G. australis and G. koira complexes 849 genetically by two unique amino acids in the ND2 locus (Table 1). Some specimens, particularly 850 juveniles and females, may only be diagnosable from of parapatric and potentially sympatric $G$. 851 gemina sp. nov. and G. koira specimens on the basis of locality and/or genetic data.

852 Gehyra chimera sp. nov. is most similar to G. gemina sp. nov.; however, in addition to 853 diagnostic genetic data in the ND2 gene, G. chimera sp. nov. also tends to differ in having:

854 longer second chin shields, usually just over two thirds length of first chin shields (mean ratio 8550.75 , range $0.68-0.80$ ) vs usually two thirds or less length (mean ratio 0.67 , range $0.56-0.75$ ); 856 higher number of internasals (3-4[80.6\%], rarely 2[19.4\%] vs usually 2[61.9], rarely 3

857 [38.1\%]); and a deeper snout (SnoutD/SVL mean ratio 0.84 , range $0.81-0.87$ vs mean ratio 0.79 , 858 range $0.71-0.85)$. 
860 large Gehyra in the western Kimberley (G. koira, G. occidentalis King and G. xenopus Storr),

861 from which it differs as follows: from G. koira by its smaller size (mean and maximum adult

862 SVL, respectively: $62.5 \mathrm{~mm}$ and $73.7 \mathrm{~mm}$ vs $72.5 \mathrm{~mm}$ and $80.4 \mathrm{~mm}$ ), lower number of pre-

863 cloacal pores in males (9-11 vs 13-23), and its relatively plain grey dorsal colouration in life (vs

864 brownish with at least some transverse barring or banding); from G. occidentalis in having

865 undivided subdigital lamellae (vs divided); and from G. xenopus in lacking wedge shaped patch

866 that divides the proximate subdigital lamellae and in its greyish dorsal pattern (vs mid-brown

867 with numerous light and dark ocelli).

868 Description. As for G. australis complex description treated herein above, with the differences

869 and variation outlined in the diagnoses above and in Table 2.

870 Colour and pattern. Based on photographs of the holotype and paratypes (WAM R177683-9)

871 from the King Leopold Ranges, base colouration of all dorsal and lateral surfaces purplish-grey

872 to very light pinkish grey, overlain by light to dark grey blotches, vermiculations, flecking and/or

873 distinct bands, sometimes with additional very indistinct and thin light grey bands, and usually

874 also with grey post- and pre-orbital stripes (Fig. 10). Venter mostly off-white with relatively little

875 pattern. In preservative dorsal background colouration light brownish grey, with either no further

876 pattern, or dark-brown vermiculations and blotching on the head and/or across the dorsum and

877 tail. Ventral surfaces of body pale cream, with or without extensive fine grey maculations

878 especially towards lateral edges and on throat. Subcaudal surfaces usually pale cream with

879 extensive grey maculations laterally, and occasionally also forming thin and indistinct subcaudal

880 bands. 
881 Summary description of holotype (WAM R177687). All measurement in mm: SVL 56.1; TrunkL

882 23.4; TrunkW 9.2; ForelimbL 6.0; HindlimbL 7.1; HeadL 12.9; HeadD 6.1; HeadW 10.3;

883 SnoutL 5.3; SnoutD 4.6; ToeL 5.5. Rostral notched dorsally, with medial crease in dorsal third.

884 Nostrils separated by 3 internasal scales, with medial scale much smaller; supralabials to mid-

885 point of eye 7 on both sides. Infralabials 8 on both sides; mental scale pentagonal; chin shields in

886 two pairs, first pair elongate and second pair rounded; parainfralabials rounded, heterogenous in

887 size. Limbs relatively short, with 8 undivided lamellae on right fourth toe. Tail original. Pre-

888 cloacal pores 9, arranged in a broad chevron formation.

889 Distribution, habitat and ecology. Found in the west of the Kimberley region of WA, as far south

890 as Bell Gorge in the King Leopold Ranges, west to Koolan and Kingfisher Islands on the

891 northern edge of the Yampi Peninsula, and north as far as Theda Station (Fig. 2). Almost

892 exclusively known from trees in savannah woodlands, and also regularly found on human

893 structures such as amenities blocks in the same habitat. It occurs in close proximity to, but not

894 sympatric with, G. gemina sp. nov. in the King Leopold Ranges, Prince Regent River NP and at 895 Theda Station.

896 Etymology. The species named after Chimera, a monstrous hybrid creature of Greek mythology 897 composed of parts of multiple animals, pertaining to the close morphological similarity to the $G$. 898 australis complex juxtaposed against clear genetic membership in the G. koira complex.

899

900 Gehyra koira complex (excluding G. chimera): diagnosis and descriptions

901 A group of medium sized to large Gehyra (max SVL 77.1-94.9 mm), body shape slightly

902 dorsoventrally compressed with fine homogenous rounded scales on dorsum and flattened scales 
903 on ventrum, snout moderately long with rounded tip, eyes large and protruding, ear opening

904 small, large internasals bordering nares separated by $0-6$ smaller internasals of greatly varying

905 size, nostril in contact with rostral scale, limbs short with claws on digits II-V, claws protruding

906 from dorsal surface of expanded toe pad, no skinfold behind the hindlimbs, subdigital lamellae

907 under fourth toe undivided or at most with a weak medial groove, tail cylindrical tapering to a

908 fine point, dorsum in life usually greyish to brown, and either plain and without pattern or more

909 usually with some dark and light banding, vermiculations and scattered spots, in males 9-25 pre-

910 cloacal pores arranged in a shallow chevron formation, and in females two eggs per clutch.

911

912 Gehyra koira Horner, 2005

913 King's Rock Gecko

914 koiral of Oliver et al. (2019)

915 Figs. 6-7, 9A-B, 17

916

917 Holotype. NTM R22406, adult female, collected from Nganlang Art Site, Keep River NP, NT (-

$\left.91816.0409^{\circ} \mathrm{S}, 128.9113^{\circ} \mathrm{E}\right)$, collected by P. Horner, 27 April 1996.

919 Paratypes $(N=45)$. Western Australia: NTM R7043, Kununurra, WA; NTM R7113-14,

920 Kununurra, WA. Northern Territory: NTM R3875, Wickham River, Gregory NP, NT; NTM

921 R9125-27, R9130, R9132, Keep River NP, NT; NTM R9471, Victoria River Bridge area,

922 Victoria Highway, NT; NTM R10079, R10518-19, R10521-22, R10524-26, Keep River NP,

923 NT; NTM R12770, Jasper Gorge, Buchanan Highway, NT; NTM R13265, Victoria River Bridge

924 area, Victoria Highway, NT; NTM R18626-28, Bradshaw Station, NT; NTM R20774-75, 
925 Timber Creek, NT; NTM R22404, Jarrnarm Escarpment, Keep River NP, NT; NTM R22910,

926 Spirit Hills, NT; NTM R23365, Jellabra Rockhole, Tanami Desert, NT; NTM R23754-55,

927 Lonely Springs Creek Crossing, Buntine Highway, NT; NTM R23800, R23804, Wickham River,

928 Gregory NP, NT; NTM R24103, North Kollendong Valley, Bradshaw Station, NT; NTM

929 R24251-52, R24254-55, Fitzmaurice River, Bradshaw Station, NT; NTM R24623, Augustus

930 Hole, Spirit Hills Station, NT; NTM R24850, R24853, Lobby Creek, Bradshaw Station, NT;

931 NTM R25499, Jasper Gorge, Buchanan Highway, NT; NTM R27279, Pigeon Hole, Gregory NP,

932 NT; WAM R108446 (formerly NTM R10520), Keep River, NP, NT; WAM R108447 (formerly

933 NTM R22462), Limestone Gorge, Gregory NP, NT; WAM R108448 (formerly NTM R24253),

934 Fitzmaurice River, Bradshaw Station, NT.

935 Referred material. See Tables S1-S2.

936 Diagnosis. A large Gehyra species (up to $78.3 \mathrm{~mm}$ SVL), differing from all other Gehyra species

937 outside of the G. koira complex as per the diagnosis above. Differs from other members of $G$.

938 koira complex in the combination of: large size (adult SVL up to $78.3 \mathrm{~mm}$, mean $70.3 \mathrm{~mm}$ ); pre-

939 cloacal pores in males numerous (12-23); second chin shields almost always more than two

940 thirds length of first chin shields (mean ratio 0.72, range 0.64-0.79); first chin shield pair not

941 bordered posteriorly by a single enlarged medial gular scale, or if present, median scale is not the

942 largest in first row of gulars; adults in base colouration with tan to brown dorsum and tails,

943 usually with some distinct transverse light and/or dark barring and a distinct to indistinct brown

944 postorbital stripe.

945 Further diagnosed from other species within the G. koira complex genetically by 1

946 unique amino acid in the ND2 locus (Table 1). 
948 moderate to large-sized Gehyra. Two of these are distantly related and can be easily

949 distinguished: G. koira differs from G. occidentalis in having undivided lamellae (vs divided);

950 and from G. xenopus in lacking a wedge-shaped patch of granules that divide the proximal

951 subdigital lamellae and dorsal pattern of barring or banding (vs numerous light and dark ocelli).

952 Gehyra koira can be distinguished from the four remaining sympatric taxa (all members of the

953 australis group) as follows: from G. ipsa by its smaller size (mean and maximum adult SVL,

954 respectively: $70.3 \mathrm{~mm}$ and $78.3 \mathrm{~mm}$ vs $84.9 \mathrm{~mm}$ and $94.9 \mathrm{~mm}$ ) and absence of an enlarged

955 medial gular scale behind the first pair of chin shields, or when present, median scale not the

956 largest in first row of gular scales (vs present and always the largest in first gular row); from $G$.

957 calcitectus sp. nov. (see below) in having a dorsal pattern generally lacking light-coloured ocelli

958 (vs usually present); from G. gemina sp. nov. in its larger size (mean and maximum adult SVL,

959 respectively: $70.3 \mathrm{~mm}$ and $78.3 \mathrm{~mm}$ vs $84.9 \mathrm{~mm}$ and $94.9 \mathrm{~mm})$ and higher number of pores (13-

96023 vs 10-16); and from G. lapistola sp. nov. (see below) by its brown dorsum with light

961 transverse bars and or spots (vs generally plainer and almost unpatterned) and generally higher

962 number of pores (13-23 vs 9-13).

963 Description. As for G. koira complex description treated herein above, with the differences and

964 variation outlined in the diagnoses above and in Table 2.

965 Colouration and pattern. In life, base colouration of dorsal and upper lateral surfaces brownish-

966 grey to medium-brown (Fig. (9A-B). Torso pattern variable, sometimes unpatterned, but usually

967 with 5-8 very pale grey irregular transverse dorsal bands or series of blotches which themselves

968 are sometimes bordered by patches of darker brown pigmentation, additional light yellowish-

969 grey dorsal spots or blotches also often present. Head usually with faint to strong brown 
970 postorbital and canthal stripes, and often light yellowish spotting and flecking. Original tails

971 usually with same base colouration as dorsum, and often also with light grey and dark brown

972 banding. Regrown tails unpatterned. In preservative, dorsal ground colour grey to light brown,

973 usually, but not always, with faint to distinct thin lighter grey and/or dark brown transverse

974 banding or barring. Head same colour as torso, unpatterned, or with indistinct paler and/or darker

975 brown spotting and blotching, dark postorbital stripe also apparent in approximately half of the

976 recently preserved specimens examined. Ventral surfaces of torso, head, limbs and buff, largely

977 unpatterned, but often with scattered greyish-brown maculations, especially on throat, limbs and

978 latero-ventral surfaces of torso.

979 Distribution, habitat and ecology. Widespread across approximately the eastern half of the

980 Kimberley region of WA, occurring as far west as Theda Station, north to the coast, including 981 some offshore islands such as Adolphus and Sir Graham Moore Islands, and as far south as the

982 limestone ranges on Mt Piere Station (Fig. 2). It also occurs widely in the escarpments of the

983 Victoria River region of the western portion of the NT, extending at least to the eastern block of

984 Gregory/Judbarra NP.

985 Occurs in most rocky range habitats within its distribution including granite, sandstone 986 and limestone ranges. It is often observed on open rocky faces several metres from cover or 987 retreats, and also forages on the trunk and branches of trees and shrubs within rocky areas. It 988 overlaps with the ecologically similar G. occidentalis at some sites in the southern Kimberley, 989 with known sympatry at one site at Mornington (C. Moritz, pers. obs.).

990

991 Gehyra ipsa (Horner, 2005)

992 Bungle Bungle Ranges Gecko 
993 ipsa of Oliver et al. 2019

994 Figs. 6-7, 9C-D, 18

995

996 Holotype. WAM R101238, adult male, collected from Piccaninny Massif, Purnululu (Bungle

997 Bungle) NP, WA (-17.45 $\left.{ }^{\circ}, 128.40^{\circ} \mathrm{E}\right)$, collected by N. Gambold, 25 August 1989.

998 Paratypes $(N=11)$. Western Australia: NTM R28098 (formerly WAM R104285), Echidna

999 Chasm, Purnululu (Bungle Bungle) NP, WA; NTM R28099 (formerly WAM R101239),

1000 Picaninny Massif, Purnululu (Bungle Bungle) NP, WA; WAM R101237*, Picaninny Massif,

1001 Purnululu (Bungle Bungle) NP, WA; WAM R104283*, Osmand Valley Station, WA; WAM

1002 R104284, Frog Hole Gorge, Purnululu (Bungle Bungle) NP, WA; WAM R104285, R104290-91,

1003 Echidna Chasm, Purnululu (Bungle Bungle) NP, WA; WAM R104286, R104288, R104295,

1004 Picaninny Gorge, Purnululu (Bungle Bungle) NP, WA; WAM R104289*, Wulwuldji Spring,

1005 Purnululu (Bungle Bungle) NP, WA.

1006 Three paratypes marked with an asterisk are treated herein as G. koira and not true G. ipsa based

1007 on combination of medial scale of first gular row not being enlarged, or if enlarged, not the

1008 largest, small size ( $<75 \mathrm{~mm} \mathrm{SVL}$ ), and co-occurrence with specimens genotyped as G. koira. In

1009 the absence of dorsal pattern lacking distinct light tan ocelli or blotches, specimens were not

1010 considered to be assignable to G. calcitectus sp. nov. Due to the morphological overlap and

1011 potential occurrence of sympatry of both species, in addition to G. calcitectus sp. nov., there

1012 remains some uncertainty as to the species in which these specimens apply.

1013 Referred material. See Tables S1-S2. 
1014 Diagnosis. A large Gehyra species (up to $94.9 \mathrm{~mm} \mathrm{SVL),} \mathrm{differing} \mathrm{from} \mathrm{all} \mathrm{other} \mathrm{Gehyra} \mathrm{species}$

1015 outside of the G. koira complex as per the diagnosis above. Differs from other members of the $G$.

1016 koira complex in the combination of: large size within complex (adult SVL up to $94.9 \mathrm{~mm}$, mean

$101784.9 \mathrm{~mm}$, largest of the G. koira complex); pores in males moderately numerous (15-18); first

1018 chin shield pair bordered posteriorly by a single enlarged medial scale, $\sim 1.5-4$ times the size of

1019 adjacent scales and always the largest in first row of gular scales posterior to chin shields; second

1020 chin shields approximately two thirds length of first chin shields (mean ratio 0.78 , range $0.75-$

1021 0.81); adults in base colouration with tan to brownish dorsum with light transverse barring, a

1022 distinct to indistinct brown postorbital stripe, tails usually with at least some distinct transverse

1023 light and/or dark barring.

1024 Further diagnosed from other species within the G. koira complex genetically by 4 1025 unique amino acids in the ND2 locus (Table1).

1026 Gehyra ipsa is likely to occur in parapatry or even sympatry with G. koira (which it is

1027 morphologically most similar to), G. gemina sp. nov. and possibly G. calcitectus sp. nov. It can

1028 often be differentiated from all three by the combination of larger size (mean and maximum

1029 adult SVL, respectively: $84.9 \mathrm{~mm}$ and $94.9 \mathrm{~mm}$ vs $70.3 \mathrm{~mm}$ and $78.3 \mathrm{~mm}$ ), presence of an

1030 enlarged medial scale behind the first pair of chin shields, which is always the largest in the first

1031 row of gular scales posterior to chin shields (vs absence or, if present, not the largest scales in

1032 first gular row) and dorsal pattern comprising transverse light bands (vs often comprising light

1033 pale tan ocelli or blotches in G. calcitectus sp. nov.).

1034 Description. As for G. koira complex description treated herein above, with the differences and 1035 variation outlined in the diagnoses above and in Table 2. 
1036 Colour and pattern. In life base colouration of dorsum, head, limbs and tail light to medium-

1037 brown base colouration (Fig. 9C-D). Patterned with light grey barring on the torso, flecking on

1038 the posterior portion of head, and barring on the tail, and further dark brown postorbital stripes

1039 and jagged tail bands. Original tails usually same base colouration as dorsum, sometimes with

1040 light-grey and/or dark brown banding. Regrown tails unpatterned. In preservative, dorsal ground

1041 colour light greyish-brown, often with faint to distinct lighter grey and/or dark-brown transverse

1042 banding or barring. Head occasionally with further light grey spotting, and/or an indistinct

1043 medium brown postorbital stripe. Ventral surfaces of torso, head, limbs and buff, largely

1044 unpatterned, but often with scattered greyish-brown maculations, especially on throat, limbs and

1045 latero-ventral surfaces of torso.

1046 Distribution, habitat and ecology. Gehyra ipsa is known only from the south-western edge of the

1047 Bungle Bungle Range in Purnululu NP, located in the southwest of the Kimberley region of WA

1048 (Fig. 2). Known to occur in a restricted area spanning Piccaninny Gorge, out along Piccaninny

1049 Creek and Whipsnake Gorge. Previous records previously assigned to this species from along the

1050 northern edge of the massif and nearby sites are considered to be G. koira. Gehyra ipsa is usually

1051 observed on open rock faces (especially within gorges) and often occurs in close association with

1052 small Ficus trees growing from the rock faces.

1053 Remarks. Further detailed geographic and genetic sampling within the Bungle Bungle Range,

1054 particularly along the northern edge, is required to better understand patterns of geographic,

1055 ecological and genetic interaction between G. ipsa and G. koira.

1056 Examination of the type series of G. ipsa, including the 11 putative G. ipsa paratypes,

1057 revealed three of the 11 paratypes lacked the diagnostics corresponding with the species

1058 treatment herein. The three specimens lacked an enlarged median gular scale posterior to first 
1059 pair of chin shields that was the largest in the first row of gular scales (Fig. 7) and were also

1060 substantially smaller than the maximum size reached by the type specimen (WAM R101238) and

1061 genotyped G. ipsa. Where an enlarged median gular scale was present in genotyped G. koira, the

1062 scale was generally not the largest present in the first row of gular scales posterior to the chin

1063 shields. On this basis we propose the hypotheses that: i) an enlarged medial scale behind the first

1064 pair of chin shields is diagnostic for G. ipsa, ii) G. ipsa is restricted to the southern edge of the

1065 Purnululu Massif and iii) G. ipsa and G. koira occur in sympatry on the southern edge of the

1066 Purnululu Massif. Therefore, based on present data available, we redefine the distribution of both

1067 species, and treat some paratypes of G. ipsa as G. koira (see paratypes above).

1068 The formal elevation and redefinition of its range of $G$. koira brings the number of

1069 recognised short-range endemic lizards from the Bungle Bungle Ranges to two (the other species

1070 being Lerista bunglebungle Storr), with additional undescribed taxa known to occur within the

1071 ranges (B. Maryan, pers. comm.). This suggests that the distinctive geology and deep gorges of

1072 the Bungle Bungle Range has mediated localised persistence and divergence, similar to nearby

1073 limestone ranges (Oliver et al., 2017).

1074

1075 Gehyra lapistola sp. nov.

1076 urn:lsid:zoobank.org:act:37EA721F-35D0-4F22-A5FF-24B63EB2F91C

1077 Litchfield Tree Gecko

1078 koira2 of Oliver et al. (2019)

1079

1080 Figs. 6-7, 9E-F, 19 
1081

1082 Holotype. NTM R37093, adult male, collected from Dorat Road, approximately $6 \mathrm{~km}$ from 1083 Stuart Highway, NT (-13.2851 $\left.{ }^{\circ} \mathrm{S}, 131.1174^{\circ} \mathrm{E}\right)$, collect by P.M. Oliver, M. Hammer and P. 1084 Skipwith, 28 September 2013.

1085 Paratypes $(N=11)$. Northern Territory: NTM R21786, Litchfield NP, NT $\left(-13.22^{\circ} \mathrm{S}, 130.73^{\circ} \mathrm{E}\right)$; 1086 NTM R36708, Fish River Gorge, Fish River Station, NT (-14.2660 S, $\left.130.8936^{\circ} \mathrm{E}\right)$; NTM 1087 R37055, Dorat Road, Robin Falls area, NT (-13.35 S, 131.14E); NTM R37051, Daly River 1088 Road, Daly River region, NT (exact latitude and longitude unknown); NTM R37092, Dorat 1089 Road, approximately 6 km from Stuart Highway, NT (-13.2851º, $\left.131.1174^{\circ} \mathrm{E}\right)$; NTM R38191 1090 (field \# CCM2882), NTM R38192 (field \# CCM2884), Tolmer Falls turnoff, Litchfield NP, NT 1091 (-13.1965은 $\left.130.7139^{\circ} \mathrm{E}\right)$; NTM R38193 (field \# CCM2935), Florence Falls turnoff, Litchfield 1092 NP, NT (-13.1264오, $\left.130.8046^{\circ} \mathrm{E}\right)$; NTM R38194 (field \# CCM6052), NTM R38195 (field \# 1093 CCM6053), Mount Pleasant, Tipperary Station, NT (-13.5915º S, $\left.131.1678^{\circ} \mathrm{E}\right)$; NTM R38196 1094 (field \# CCM6070), Litchfield Mining Camp, 5km from Daly River Road, NT (-13.5096 ${ }^{\circ}$, $\left.1095130.7727^{\circ} \mathrm{E}\right)$.

1096 Referred material. See Tables S1-S2.

1097 Diagnoses. A large Gehyra species (up to $79.5 \mathrm{~mm} \mathrm{SVL),} \mathrm{differing} \mathrm{from} \mathrm{all} \mathrm{other} \mathrm{Gehyra}$ 1098 species outside the G. koira complex as per the diagnosis above. Differs from other members of 1099 the G. koira complex in the combination of: moderate size within complex (max SVL $79.5 \mathrm{~mm}$, 1100 mean $74.2 \mathrm{~mm}$ ); pre-cloacal pores in males not numerous (9-13); first chin shield pair not 1101 bordered posteriorly by a single enlarged medial gular scale, or if present, median scale is not the 1102 largest in first row of gulars; second chin shields approximately two thirds length of first chin 1103 shields (mean ratio 0.68 , range $0.62-0.74)$; usually only 2 internasals ( $80 \%$ individuals); and 
1104 adults with plain grey to brownish dorsum across the head and body with no distinct pattern of 1105 barring, banding or spots.

1106 Further diagnosed from other species within the G. koira complex genetically by nine 1107 unique amino acids in the ND2 locus (Table 1).

1108 Gehyra lapistola sp. nov. is morphologically similar to the other geographically disjunct 1109 rock-dwelling members of the G. koira complex (G. koira, G. ipsa and G. calcitectus sp. nov.) 1110 that occur further to the west; it differs, however, in its plainer and often almost unpatterned 1111 dorsum (vs usually brown with light transverse bars and/or blotches). It further differs from $G$.

1112 koira in generally having fewer pre-clocal pores (9-13 vs 13-23) and a lower number of 1113 internasals (usually 2 [80\%], rarely 3-4 [20\%] vs rarely 2 [12.5\%], usually 3-4 [87.5\%]). From 1114 G. ipsa, it differs in fewer pre-cloacal pores (9-13 vs 14-18) and first chin shield pair not 1115 bordered posteriorly by a single enlarged medial gular scale, or if present, median scale is not the 1116 largest in first row of gulars (vs present and always largest scale of first gular row). From $G$.

1117 calcitectus sp. nov., it differs in having a dorsal pattern including pale transverse stripes (vs light 1118 pale tan ocelli or blotches). Although geographically disjunct from other members of the $G$.

1119 koira complex, some specimens, especially juveniles, weakly patterned females or preserved 1120 specimens, may only be accurately diagnosed on the basis of locality and/or genetic data. one species of the G. australis complex, G. australis. From G. australis, it differs in its larger 1123 size (mean and maximum adult SVL, respectively: $74.2 \mathrm{~mm}$ and $79.5 \mathrm{~mm}$ vs $62.7 \mathrm{~mm}$ and 68.1 $1124 \mathrm{~mm}$ ) and more pale and plainer colouration in both preservative and life with little or no pattern 1125 (vs usually with at least some dorsal pattern of darker brown spots or flecks). Comparison of 1126 preserved animals also suggests that the pore series is more sharply angled in G. lapistola sp. 
1127 nov. than in G. australis; however, this character is difficult to accurately measure as it varies

1128 with angle of limb preservation.

1129 Description. As for G. koira complex description treated herein above, with the differences and 1130 variation outlined in the diagnoses above and in Table 2.

1131 Colour and pattern. Photos of live or recently euthanized adults shows fleshy pink, light cream 1132 or light brownish dorsal colouration (Fig. 9E-F). Head and tail have the same colouration as the 1133 body. In preservative, dorsal surfaces of head, body, limbs and tail grey to light brownish grey

1134 with no discernable pattern. Ventral surfaces of torso, head, limbs and tail off-white, usually

1135 unpatterned, but more rarely with scattered pale brownish-grey maculations, especially on throat,

1136 limbs and latero-ventral surfaces of torso.

1137 Summary description of holotype (NTM R37093). All measurement in mm: SVL 79.5; TrunkL

1138 34.2; TrunkW 12.5; ForelimbL 8.4; HindlimbL 10.0; HeadL 17.8; HeadD 8.9; HeadW 14.8;

1139 SnoutL 6.9; SnoutD 6.0; ToeL 7.5. A moderately large Gehyra (SVL 78.6 mm), head slightly

1140 narrow (HW/HL 0.77) and deep (HD/HL 0.96). Dorsal head scales small and granular,

1141 interorbitals 36; rostral protruding, with medial crease in upper third. Nostrils separated by two

1142 large internasal scales and one smaller intervening internasals scale with two granules above it;

1143 supralabials to mid-point of eye 10 on right side and 9 on left side. Infralabials 8 on both sides;

1144 mental scale with lunate posterior edge; chin shields elongate, rounded and in two enlarged and

1145 rounded pairs, second pair approximately two thirds length of first; parainfralabials rounded, first

1146 approximately half diameter of second chinshield. Limbs relatively short, with 10 undivided

1147 lamellae on right fourth toe. No claw on fifth toes. Original tail intact, curved at tip. Pre-cloacal

1148 pores 13 , arranged in a broad chevron formation. 
1149 Distribution, habitat and ecology. Restricted to the rocky ranges of north-eastern NT, especially

1150 in escarpments and outcrops in Litchfield NP, and extending south at least as far as Fish River

1151 Gorge on the other side of the Daly River (Fig 2). Gehyra lapistola sp. nov. is usually collected

1152 on rocky substrate including both open rock faces and boulders, or more rarely on trees within

1153 this habitat.

1154 Gehyra lapistola sp. nov. has been observed in sympatry with three other Gehyra species:

1155 G. australis, G. nana, G. paranana and G. australis. Where these distributions overlap they

1156 show evidence of ecological segregation, G. lapistola sp. nov. uses large rocks and open rock

1157 faces, G. paranana occurs on smaller rocks and boulders and closer to retreats, G. nana around

1158 the bottom of rock boulders and G. australis appears to be largely restricted to trees (C. Moritz,

1159 P.M. Oliver, pers. obs.).

1160 Etymology. The species epithet is formed from the Latin words lapis (rock, stone) and stolo

1161 (runner), used in its adjectival form as stola, as in 'rock-running', in reference to the species

1162 occurrence in rocky escarpment and outcrop habitats.

1163

1164 Gehyra calcitectus sp. nov.

1165 urn:1sid:zoobank.org:act:52919622-D6CD-4023-80B5-3ABEF515DB29

1166 Relictual Karst Gecko

1167 koira3 of Oliver et al. (2019)

1168

1169 Figs. 6-7, 9G-H, 20

1170 
1171 Holotype. WAM R177691 (field \# CCM3235), adult male, collected from Limestone Billy Hills,

1172 Gogo Station, WA (-18.3272 ${ }^{\circ}$ S, $125.7650^{\circ}$ E), collected by P.M. Oliver, P. Skipwith and G.

1173 Armstrong, 3 November 2014.

1174 Paratypes $(N=12)$. Western Australia. WAM R177692 (field \# CCM3236), Limestone Billy

1175 Hills, Gogo Station, WA (-18.3272 S, $\left.125.7650^{\circ} \mathrm{E}\right)$; WAM R177693 (field \# CCM3259), south

1176 entrance of Menyous Gap, Pillara Range, Gogo Station, WA (-18.4044을 $\left.125.8370^{\circ} \mathrm{E}\right)$; WAM

1177 R177695 (field \# CCM3333), WAM R177696 (field \# CCM3334), Virgin Hills, near Bobs Bore,

1178 Gogo Station, WA (-18.5149º S, $\left.125.9256^{\circ} \mathrm{E}\right)$; WAM R177697 (field \# CCM7276), WAM

1179 R177698 (field \# CCM7277), WAM R177699 (field \# CCM7278), WAM R177700 (field \#

1180 CCM7279, Lissadell Station, WA (-16.6635으, $\left.128.5265^{\circ} \mathrm{E}\right)$; WAM R177701 (field \#

1181 CCM7330), Pillara Range, Gogo Station, WA (-18.3697 S, $\left.125.7363^{\circ} \mathrm{E}\right)$; WAM R177702 (field

1182 \# CCM7466), WAM R177703 (field \# CCM7470), WAM R177704 (field \# CCM7473), Duncan

1183 Road, Argyle Station, WA (-16.5964응 $\left.128.9536^{\circ} \mathrm{E}\right)$.

1184 Referred material. See Table S1-S2.

1185 Diagnosis. A large Gehyra species (to $77.1 \mathrm{~mm}$ SVL) differing from all other Gehyra species

1186 outside the G. koira complex as per the diagnosis above. Differs from other members of the $G$.

1187 koira complex in the combination of: moderate size within complex (adult SVL up to $77.1 \mathrm{~mm}$,

1188 mean $69.4 \mathrm{~mm}$ ); head relatively wide (HW/SVL 0.19-0.21); nostrils usually separated by more

1189 than 2 internasal scales $(87.5 \%)$, rarely $2(14.3 \%)$; second chin shields approximately two-thirds

1190 the length of first chin shields (mean ratio 0.66, range 0.53-0.79); first chin shield pair not

1191 bordered posteriorly by a single enlarged medial gular scale, or if present, median scale is not the

1192 largest in first row of gulars; pores in males relatively few (9-14); and adults with tan to 
1193 brownish dorsum and tails, and with a dorsal pattern including distinct light tan ocelli or blotches

1194 (as opposed to transverse light bands).

1195 Further diagnosed from other species within the G. koira complex genetically by 6

1196 unique amino acids in the ND2 locus (Table 1).

1197 Gehyra calcitectus sp. nov. differs from two members of G. koira complex with which its

1198 distribution abuts or overlaps as follows: from G. koira in having a dorsal pattern including light

1199 pale tan ocelli or blotches (vs transverse bars), lower number of pre-cloacal pores (9-14 vs 12-

1200 23), and for eastern populations in having dark-brown dorsal spots across the head and often

1201 torso (vs absent); and from G. ipsa in its smaller size (mean and maximum adult SVL

1202 respectively $69.4 \mathrm{~mm}$ and $77.1 \mathrm{~mm}$ vs $84.9 \mathrm{~mm}$ and $94.9 \mathrm{~mm}$ ), absence of an enlarged scale

1203 behind the first pair of chin shields (vs presence) and pale dorsal pattern elements consisting of

1204 ocelli or pale blotches (vs pale transverse bands). From the geographically disjunct G. lapistola

1205 sp. nov., it differs in having a dorsal pattern comprising pale ocelli or blotches (vs at most pale

1206 transverse bands).

1207 The distribution of G. calcitectus sp. nov. is largely geographically disjunct from most

1208 members of the G. koira complex, including G. ipsa, G. lapistola sp. nov. and G. chimera sp.

1209 nov., and accurate locality data may permit identification of morphologically similar specimens.

1210 Description. As for G. koira complex description treated herein above, with the differences and

1211 variation outlined in the diagnoses above and in Table 2.

1212 Colour and pattern. In life, dorsal base colouration light to dark brown, always with rows of

1213 large pale yellowish-brown or off-white spots or ocelli across the back and usually head.

1214 Specimens from Lissadell Station and Argyle Rocks (Fig. 9G) in the east also tend to have dark

1215 brown spotting, blotching or striping on the head, and often torso, while specimens from Gogo 
1216 Station (Fig. 9H) lack dark dorsal pattern. Limbs same base colouration as torso, and also usually

1217 with at least some pale brown blotching. Tail colouration usually consisting of bands or

1218 transverse series of blotches of varying in colour and width from thin pale brown bands on a

1219 medium brown background, to alternating broad dark brown and light brown bands. In

1220 preservative, dorsal surfaces light grey-brown, with weakly defined very pale grey ocelli usually,

1221 but not always, visible on body, limbs, and tail. Specimens from the two northern localities

1222 usually have a dark brown canthal stripe with further dark brown spots on the head, occasionally

1223 extending on to the torso and tail. Ventral surfaces of torso, head, limbs and tail pale cream,

1224 largely unpatterned, but often with scattered brownish-grey maculations, especially on throat,

1225 limbs and latero-ventral surfaces of torso and tail.

1226 Summary description of holotype (WAM R177691). All measurement in mm: SVL 67.6; TrunkL

122729.7 mm; TrunkW 11.2; ForelimbL 8.4; HindlimbL 8.7; HeadL 16.3; HeadD 8.3; HeadW 14.0;

1228 SnoutL 6.1; SnoutD 5.9; ToeL 6.9. Rostral flat, with medial crease in dorsal third. Nostrils

1229 separated by 2 large internasal scales; supralabials to mid-point of eye 9 on both sides.

1230 Infralabials 8 on right, 7 on left; mental scale pentagonal; chin shields relatively short, rounded

1231 and in two enlarged and rounded pairs, second pair approximately two thirds length of first;

1232 parainfralabials rounded, first approximately half the width and height of second chinshield.

1233 Limbs relatively short, with 9 undivided lamellae on right fourth toe. Tail largely original, with

$123420 \mathrm{~mm}$ regrown section at tip. Pre-cloacal pores 11, in a broad chevron formation

1235 Distribution, habitat and ecology. Known only from three isolated and disjunct limestone ranges

1236 along the southern and western edge of the Kimberley region, in Pillara Range on Gogo Station,

1237 and on Lissadell and Argyle Stations (Fig. 2). 
1239 limestones and small faces $(<3 \mathrm{~m})$. At Gogo and Lissadell Stations they were observed on larger

$1240(>5 \mathrm{~m})$ limestone faces and boulders. At Lissadell Station nearby sandstone ranges were occupied

1241 by G. koira. Similarily, only G. koira was found in limestone system in the east (Ningbing) and

1242 south (Mt Piere Station) Kimberley and in the Victoria Rivers District (Judburra NP).

1243 Etymology. The species epithet is formed from the Latin words calcis (limestone) and tectus

1244 (hidden, hideaway), as in 'limestone-hidden' or 'limestone hideaway', in reference to the species

1245 occurrence in and apparent preference for relictual limestone habitats of the Kimberley limestone

1246 ranges. Used as a noun in apposition.

1247 Remarks. Gehyra calcitectus sp. nov. is the fourth recently described or redescribed lizard

1248 species with a restricted range in the limestone ranges along the southern and eastern fringes of

1249 the Kimberley (Oliver et al., 2014, 2016a; Doughty, Ellis \& Oliver, 2016). Additional limestone

1250 endemics lineages from the southern and eastern Kimberley, and the Victoria Rivers District

1251 district are likely to represent additional undescribed species (Personal observations, C. Moritz,

1252 2018), further emphasising the biological significance and importance of limestone ranges in

1253 north-west Australia as hotspots of endemism and evolutionary refugia (Oliver et al., 2017;

1254 Rosauer et al., 2018).

1255

1256

1257 DISCUSSION

1258 Documenting and describing morphologically similar, yet genetically and evolutionarily

1259 distinctive cryptic species poses well-recognised, but ongoing challenges for systematists, 
1260 evolutionary biologists and conservation managers (Bickford et al., 2007; Oliver, Keogh \&

1261 Moritz, 2015; Singhal et al., 2018). The existence of multiple species within the G. australis

1262 group was not apparent based on prima-facie morphological data. Indeed, in light of high levels

1263 of morphological similarity among many species, and given sparse geographic sampling in

1264 previous exon multilocus studies (Noble et al. 2018; Oliver et al., 2019), it was only after

1265 generating a SNP data set based on geographically extensive sampling that the case for the

1266 recognition of multiple evolutionarily distinct and isolated lineages (i.e. species) became

1267 compelling. The SNP data provided a crucial test for the lack of gene flow between closely

1268 related taxa in areas of geographic contact or even overlap. Many analyses of mtDNA diversity

1269 in other Australian lizard species have revealed similarly deep genetic divergences (e.g., Oliver,

1270 Doughty \& Palmer, 2012; Laver et al., 2017; Laver, Doughty \& Oliver, 2018), but corroborating

1271 independent evidence for evolutionary distinctiveness and the absence of contemporary of gene

1272 flow has been lacking. Where geographic sampling is sufficiently extensive, SNP data offer the

1273 potential to provide for direct tests of lack of recent genetic introgression between such

1274 problematic populations (Singhal et al., 2018). Conversely, increasing use of SNP methods may

1275 also serve to highlight instances of taxonomic oversplitting stemming from over-interpretation of

1276 morphological variation or results from genetic studies with inadequate sampling of geography

1277 and genes (e.g. Georges et al., 2018; Hillis, 2019).

1278 Resolving species boundaries within morphologically conservative groups can yield new

1279 insights into speciation processes and eco-evolutionary drivers of spatial patterns of diversity

1280 (Fišer, Robinson \& Malard, 2018). As cases in point, using genetic data to resolve species limits

1281 in Gehyra has revealed instances of parallel evolution (e.g. independently arboreal G. chimera

1282 sp. nov. and G. australis group; Oliver et al., 2019), body size evolution associated with 
1283 establishment of sympatric assemblages (Doughty et al., 2018a; Moritz et al., 2018) and the high

1284 prevalence of short-range taxa in complex rocky environments (Ashman et al., 2018), and

1285 association of chromosome change with speciation (King, 1979, 1983b; Moritz, 1986). On the

1286 latter, King (1983b) karyotyped several individuals within G. australis s.l., all with the same

$12872 \mathrm{~N}=40 \mathrm{a}$ karyotype (but variable sex chromosomes) that by location can be assigned to $G$.

1288 australis s.s., G. genima and G. arnhemica. He also observed a different, $2 \mathrm{n}=44$ karyotype from

1289 several rock-dwelling individuals from central Kimberley which were ascribed to G. occidentalis

1290 by King (1984). There is no further information on chromosome variation across the taxa

1291 considered here, and given the association of such with speciation in Gehyra, especially in rock-

1292 dwelling forms, this should be rectified.

1293 Many of the taxa described or revised here have wide geographic ranges and have been

1294 recorded from buildings and other anthropogenic structures, specifically: G. australis, G. gemina

1295 sp. nov. and G. chimera sp. nov. Our genetic data suggest that colonising of anthropogenic

1296 habitats has also led to human-mediated dispersal within northern Australia in some of these

1297 species. An isolated record of G. gemina sp. nov. from a roadhouse on the Stuart Highway in the

1298 NT at Daly Waters (SAMA R34176) is near genetically identical (mtDNA) to a clade within this

1299 species otherwise mainly known from the Kimberley region from WA ( $\sim 500 \mathrm{~km}$ distant). More

1300 interestingly, the SNP dataset highlighted a single putative hybrid between G. australis and G.

1301 gemina sp. nov. that was collected on the Renner Springs roadhouse, an important stopover point

1302 for traffic along the main route (the Stuart Highway) running south of Darwin. This single

1303 anomalous individual from a highly disturbed anthropogenic setting raises the possibility that

1304 hybridisation has occurred as a result of human-assisted translocation and mixing of (potentially

1305 naïve) individuals of cryptic species. 
1307 has provided support for three taxa with relatively restricted ranges; i.e. qualifying as short-range

1308 endemics sensu Harvey et al. (2011). Our revised taxonomy across the two complexes also

1309 highlights emerging biodiversity hotspots across northern Australia, including the Selwyn Range

1310 (Oliver \& Doughty, 2016; Noble et al., 2018), Litchfield escarpment and surrounding areas

1311 (Rosauer et al., 2016), the Purnululu region in the eastern Kimberley and the fringing limestone

1312 of the Kimberley Craton (Oliver et al., 2017; Rosauer et al., 2018). Most taxa in these hotspots

1313 are ecologically associated with rocks, although G. lauta sp. nov. is mostly arboreal, suggesting

1314 persistence on trees within the Selwyn Range refugia (Noble et al., 2018). Perhaps the taxon with

1315 the most enigmatic distribution, however, is the widely disjunct and morphologically variable $G$.

1316 calcitectus sp. nov. Known localities for this taxon indicate it is closely associated with

1317 limestone (suggesting ecological specialisation), does not occur in sympatry with widespread $G$.

1318 koira (suggesting displacement or competition) and occurs in widely disjunct localities

1319 (suggesting range contraction). One possible hypothesis is that populations of this species have

1320 been isolated by the expansion of sandy deserts over formerly more widespread limestone ranges

1321 along western and southern edge of the Kimberley Craton.

1322 More generally, here, as in other systems (Bickford et al., 2007), cryptic species are

1323 emerging as a substantial component of diversity. For the AMT specifically, most low vagility

1324 vertebrate species that have been adequately surveyed genetically, even if just with a few loci,

1325 have revealed deep and geographically fine-grained phylogeographic structure (e.g. Oliver,

1326 Doughty \& Palmer, 2012; Moritz et al., 2016, 2018; Potter et al., 2016; Laver et al., 2017; Laver,

1327 Doughty \& Oliver, 2018). With a few exceptions (Doughty, Ellis \& Oliver, 2016; Afonso Silva

1328 et al., 2017; Moritz et al., 2018), the taxonomic status of much of this diversity remains to be 
1329 evaluated. But even with the conservative criteria used here, it is likely that the current taxonomy

1330 substantially underestimates the true species diversity of the AMT. However, even though there

1331 is often a delay between the publication of genetic data and the eventual taxonomic revisions, it

1332 is possible to incorporate the new phylogeographic knowledge into conservation assessments

1333 (Coates, Byrne \& Moritz, 2018). For the AMT, this approach has revealed novel hotspots of

1334 diversity, with high conservation importance (Rosauer et al., 2016, 2018; Oliver et al., 2017).

1335

1336 ABBREVIATIONS

1337

1338 ANU Australian National University

1339 ANWC Australian National Wildlife Collection, Canberra, ACT

1340 NHMUK Natural History Museum of the United Kingdom, London, United Kingdom

1341 (formerly British Museum of Natural History)

1342 NMV Museums Victoria, Melbourne, Victoria

1343 NP National Park

1344 NT Northern Territory

1345 NTM Museum and Art Gallery of the Northern Territory, Darwin, NT

1346 Qld Queensland

1347 QM Queensland Museum, Brisbane, Qld

1348 WA Western Australia

1349 WAM Western Australian Museum, Welshpool, WA 
1350

1351

1352

1353 We thank the following people for providing access to specimens and samples in their care:

1354 Andrew Amey (QM), Gavin Dally (NTM), Conrad Hoskin (James Cook University), Eric

1355 Rittmeyer (Rutgers University), and Katie Date and Jane Melville (NMV). Chris Jolly, Steve

1356 Richards, Peter Waddington and Steve Zozaya provided photographs. Numerous members of the

1357 Moritz Lab (ANU) in addition to Graham Armstrong, Philip Skipwith and Mike Hammer

1358 assisted with fieldwork and logistics. We also thank landholders, Parks staff, and Indigenous

1359 Rangers and Traditional Owners for access to their lands and for participating in fieldwork.
1361

1362

1363

1364

1365

1366

1367

1368

1369

1370

1371

\section{REFERENCES}

Australian Society of Herpetologists. 2016. Position Statement No. 2: Taxonomy. Canberra: Australian Society of Herpetologists, Inc. 7 pp. Available at: http://www.australiansocietyofherpetologists.org/position-statements/_accessed 29 April $\underline{2019)}$

Afonso Silva AC., Santos N., Ogilvie HA., Moritz C. 2017. Validation and description of two new north-western Australian Rainbow skinks with multispecies coalescent methods and morphology. PeerJ 5:e3724. DOI: 10.7717/peerj.3724.

Ashman LG., Bragg JG., Doughty P., Hutchinson M., Bank S., Matzke N., Oliver PP., Moritz CC. 2018. Diversification across biomes in a continental lizard radiation. Evolution 
1372 72:1553-1569.

1373 Bickford D., Lohman DJ., Sodhi NS., Ng PKL., Meier R., Winker K., Ingram KK., Das I. 2007. 1374 Cryptic species as a window on diversity and conservation. Trends in Ecology \& Evolution $1375 \quad$ 22:148-155. DOI: 10.1016/j.tree.2006.11.004.

1376 Bradburd GS., Coop GM., Ralph PL. 2018. Inferring continuous and discrete population genetic 1377 structure across space. Genetics 210:33-52. DOI: 10.1534/genetics.

1378 Carstens BC., Pelletier TA., Reid NM., Satler JD. 2013. How to fail at species delimitation. 1379 Molecular Ecology 22:4369-4383. DOI: 10.1111/mec.12413.

1380 Catullo RA., Lanfear R., Doughty P., Keogh JS. 2014. The biogeographical boundaries of 1381 northern Australia: evidence from ecological niche models and a multi-locus phylogeny of 1382 Uperoleia toadlets (Anura: Myobatrachidae). Journal of Biogeography 41:659-672. DOI: $1383 \quad 10.1111 /$ jbi.12230.

1384 Coates DJ., Byrne M., Moritz C. 2018. Genetic diversity and conservation units: dealing with the 1385 species-population continuum in the age of genomics. Frontiers in Ecology and Evolution 1386 6:1-13. DOI: $10.3389 /$ fevo.2018.00165.

1387 Cogger HG. 2018. Reptiles and Amphibians of Australia. Clayton: CSIRO Publishing.

1388 Cogger HG., Cameron EE., Cogger HM. 1983. Zoological Catalogue of Australia: Amphibia 1389 and Reptilia. Canberra: Australian Government Publishing Service.

1390 Cracraft J. 1991. Patterns of diversification within continental biotas: Hierarchical congruence 1391 among the areas of endemism of Australian vertebrates. Australian Systematic Botany 1392 4:211-227. DOI: 10.1071/SB9910211.

1393 Doughty P., Bauer AM., Pepper M., Keogh JS. 2018a. Spots before the eyes: revision of the 
1394

1395

1396

1397

1398

1399

1400

1401

1402

1403

1404

1405

1406

1407

1408

1409

1410

1411

1412

1413

1414

1415

saxicoline geckos of the Gehyra punctata (Squamata: Gekkonidae) species complex in the Pilbara region of Western Australia. Records of the Western Australian Museum 33:1-50. DOI: 10.18195/issn.0312-3162.33(1).2018.001-050.

Doughty AP., Bourke G., Tedeschi LG., Pratt RC., Oliver PM., Palmer RA., Moritz C. 2018b. Species delimitation in the Gehyra nana (Squamata: Gekkonidae) complex: Cryptic and divergent morphological evolution in the Australian Monsoonal Tropics, with the description of four new species. Zootaxa 4403:201-244. DOI: 10.11646/zootaxa.4403.2.1.

Doughty P., Ellis RJ., Oliver PM. 2016. Many things come in small packages: Revision of the clawless geckos (Crenadactylus: Diplodactylidae) of Australia. Zootaxa 4168:239-278. DOI: 10.11646/zootaxa.4168.2.2.

Ellis RJ., Doughty P., Bauer A., Pepper M., Keogh JS. 2018. A replacement name for Gehyra punctulata Doughty, Bauer, Pepper \& Keogh, 2018 (Reptilia: Squamata: Gekkonidae) and the nomenclatural status of Phyria punctulata Gray, 1842. Records of the Western Australian Mueseum 33:133-134. DOI: 10.18195/issn.0312-3162.33(1).2018.133-134.

Fišer C., Robinson CT., Malard F. 2018. Cryptic species as a window into the paradigm shift of the species concept. Molecular Ecology 27:613-635. DOI: 10.1111/mec.14486.

Georges A., Gruber B., Pauly GB., White D., Adams M., Young MJ., Kilian A., Zhang X., Shaffer HB., Unmack PJ. 2018. Genomewide SNP markers breathe new life into phylogeography and species delimitation for the problematic short-necked turtles (Chelidae: Emydura) of eastern Australia. Molecular Ecology 27:5195-5213. DOI: 10.1111/mec. 14925 .

González-Orozco CE., Ebach MC., Laffan S., Thornhill AH., Knerr NJ., Schmidt-Lebuhn AN., 
1416 Cargill CC., Clements M., Nagalingum NS., Mishler BD., Miller JT. 2014. Quantifying

1417 phytogeographical regions of Australia using geospatial turnover in species composition.

$1418 \quad$ PLoS ONE 9:e92558. DOI: 10.1371/journal.pone.0092558.

1419 Greer AE. 1989. The Biology and Evolution of Australian Lizards. Sydney: Surrey Beatty and $1420 \quad$ Sons.

1421 Harvey MS., Rix MG., Framenau VW., Hamilton ZR., Johnson MS., Teale RJ., Humphreys G., 1422 Humphreys WF. 2011. Protecting the innocent: Studying short-range endemic taxa 1423 enhances conservation outcomes. Invertebrate Systematics 25:1-10. DOI: 10.1071/IS11011.

1424 Heinicke MP., Greenbaum E., Jackman TR., Bauer AM. 2011. Phylogeny of a trans-Wallacean 1425 radiation (Squamata, Gekkonidae, Gehyra) supports a single early colonization of Australia. 1426 Zoologica Scripta 40:584-602. DOI: 10.1111/j.1463-6409.2011.00495.x.

1427 Hillis, DM. 2019. Species delimitation in herpetology. Journal of Herpetology 53:3 - 12. DOI: $1428 \quad 10.1670 / 18-123$.

1429 Horner P. 2005. Gehyra koira sp. nov. (Reptilia: Gekkonidae), A new species of lizard with two 1430 allopatric subspecies from the Ord-Victoria region of North-western Australia and a key to 1431 the Gehyra australis species complex. The Beagle: Records of The Museums And Art 1432 Galleries of The Northern Territory 21:165-174.

1433 Hutchinson MN., Sistrom MJ., Donnellan SC., Hutchinson RG. 2014. Taxonomic revision of the 1434 Australian arid zone lizards Gehyra variegata and G. montium (Squamata, Gekkonidae) 1435 with description of three new species. Zootaxa 3814:221-241. DOI:

$1436 \quad 10.11646 /$ zootaxa.3814.2.4.

1437 Jaccoud D., Peng K., Feinstein D., Kilian A. 2001. Diversity arrays: a solid state technology for 

sequence information independent genotyping. Nucleic Acids Research 29:e25, 1-7.

1439 Kaiser H., Crother BI., Kelly CM., Luiselli L., O’Shea M., Ota H., Passos P., Scleip WD., 1440 Wüster W. 2013. Best Practices: In the 21st Century, taxonomic decisions in herpetology 1441 are acceptable only when supported by a body of evidence and published via peer-review. $1442 \quad$ Herpetological Review 44:8-23.

1443 Kealley L., Doughty P., Pepper M., Keogh JS., Hillyer M., Huey J. 2018. Conspicuously 1444 concealed: revision of the arid clade of the Gehyra variegata (Gekkonidae) group in 1445 Western Australia using an integrative molecular and morphological approach, with the 1446 description of five cryptic species. PeerJ 6:e5334. DOI: 10.7717/peerj.5334.

1447 King M. 1979. Karyotypic evolution in Gehyra (Gekkonidae: Reptilia) I. the Gehyra variegata1448 punctata complex. Australian Journal of Zoology 27:331-347. DOI: 10.1071/ZO9790373.

1449 King M. 1982. Karyotypic evolution in Gehyra (Gekkonidae: Reptilia): II.* A new species from 1450 1451 the Alligator rivers region in Northern Australia. Australian Journal of Zoology 30:1-14. DOI: $10.1071 / Z O 9820093$.

1452 King M. 1983a. The Gehyra australis species complex (Sauria: Gekkonidae). Amphibia Reptilia 1453 4:147-169.

1454 King, M. 1983b. Karyotypic evolution in Gehyra (Gekkonidae: Reptilia). III The Gehyra 1455 australis complex. Australian Journal of Zoology 31:723-741.

1456 Kuhn M., Wing J., Weston S., Williams A., Keefer C., Engelhardt A. 2012. Caret: Classification 1457 and Regression Training. https://Cran.R-Project.Org/Package=Caret. DOI: $1458 \quad 10.1053 /$ j.sodo.2009.03.002.

1459 Laver RJ., Doughty P., Oliver P. 2018. Origins and patterns of endemic diversity in two 

specialized lizard lineages from the Australian Monsoonal Tropics (Oedura spp.). Journal of Biogeography 45:142-153. DOI: 10.1111/jbi.13127.

1462 Laver RJ., Nielsen S V., Rosauer DF., Oliver PM. 2017. Trans-biome diversity in Australian 1463 grass-specialist lizards (Diplodactylidae: Strophurus). Molecular Phylogenetics and 1464 Evolution 115:62-70. DOI: 10.1016/j.ympev.2017.07.015.

1465 Leaché AD., Fujita MK., Minin VN., Bouckaert RR. 2014. Species delimitation using genome1466 wide SNP Data. Systematic Biology 63:532-542. DOI: 10.1093/sysbio/syu018.

1467 Leaché AD., Oaks JR. 2017. The utility of single nucleotide polymorphism (SNP) data in 1468 phylogenetics. Annual Review of Ecology, Evolution, and Systematics 48:69-84. DOI: 10.1146/annurev-ecolsys-110316-022645.

Leaché AD., Zhu T., Rannala B., Yang Z. 2018. The spectre of too many species. Systematic 1471 Biology 68:168-181. DOI: 10.1093/sysbio/syy051.

1472 Melville J., Haines ML., Boysen K., Hodkinson L., Kilian A., Smith Date KL., Potvin DA., 1473 Parris KM. 2017. Identifying hybridization and admixture using SNPs: application of the 1474 1475 1476 1477 Senckenbergiana Biologica 46:287-319. Mitchell FJ. 1965. Australian geckos assigned to the genus Gehyra Gray (Reptilia, Gekkonidae).

Moritz C. 1986. The population biology of Gehyra (Gekkonidae): Chromosome change and 1479 speciation. Systematic Biology 35:46-67. DOI: 10.1093/sysbio/35.1.46. 
1482

1483

1484

1485

1486

1487

1488

1489

1490

1491

1492

1493

1494

1495

1496

1497

1498

1499

1500

1501

1502

1503

reveals nested endemism in a gecko across the monsoonal tropics of Australia. Molecular Ecology 25:1354-1366. DOI: 10.1111/mec.13511.

Moritz C., Pratt RC., Bank S., Bourke G., Bragg JG., Doughty P., Keogh JS., Laver RJ., Potter S., Teasdale, Luisa C Tedeschi LG., Oliver PM. 2018. Cryptic lineage diversity, body size divergence and sympatry in a species complex of Australian lizards (Gehyra). Evolution 72:54-66.

Noble C., Laver RJ., Rosauer DF., Ferrier S., Moritz CC. 2018. Phylogeographic evidence for evolutionary refugia in the Gulf sandstone ranges of northern Australia. Australian Journal of Zoology 65:408-416.

Oliver PM., Ashman LG., Bank S., Pratt RC., Tedeschi LG., Moritz CCCC., Laver RJ., Pratt RC., Tedeschi LG., Moritz CC. 2019. On and off the rocks: persistence and ecological diversification in a tropical Australian lizard radiation. BMC Evolutionary Biology 19:81. DOI: $10.1186 / \mathrm{s} 12862-019-1408-1$.

Oliver PM., Bourke G., Pratt RC., Doughty P., Moritz C. 2016a. Systematics of small Gehyra (Squamata: Gekkonidae) of the southern Kimberley, Western Australia: Redescription of G. kimberleyi Börner \& Schüttler, 1983 and description of a new restricted range species. Zootaxa 4107:49-64. DOI: 10.11646/zootaxa.4107.1.2.

Oliver PM., Clegg JR., Fisher RN., Richards SJ., Taylor PN., Jocque MMT. 2016b. A new biogeographically disjunct giant gecko (Gehyra: Gekkonidae: Reptilia) from the East Melanesian Islands. Zootaxa 4208:61-76. DOI: 10.11646/zootaxa.4208.1.3.

Oliver PM., Doughty P. 2016. Systematic revision of the marbled velvet geckos (Oedura marmorata species complex, Diplodactylidae) from the Australian arid and semi-arid zones. 
1505 Oliver PM., Doughty P., Palmer R. 2012. Hidden biodiversity in rare northern Australian 1506 vertebrates: The case of the clawless geckos (Crenadactylus, Diplodactylidae) of the 1507 Kimberley. Wildlife Research 39:429-435. DOI: 10.1071/WR12024.

1508 Oliver P., Keogh JS., Moritz C. 2015. New approaches to cataloguing and understanding 1509 evolutionary diversity: A perspective from Australian herpetology. Australian Journal of 1510 Zoology 62:417-430. DOI: 10.1071/ZO14091.

1511 Oliver PM., Laver RJ., De Mello Martins F., Pratt RC., Hunjan S., Moritz CC. 2017. A novel 1512 hotspot of vertebrate endemism and an evolutionary refugium in tropical Australia. 1513 Diversity and Distributions 23:53-66. DOI: 10.1111/ddi.12506.

1514 Oliver PM., Laver RJ., Melville J., Doughty P. 2014. A new species of Velvet Gecko (Oedura: 1515 Diplodactylidae) from the limestone ranges of the southern Kimberley, Western Australia. 1516 Zootaxa 3873:49-61. DOI: 10.11646/zootaxa.3873.1.4.

1517 Padial JM., Miralles A., De la Riva I., Vences M. 2010. The integrative future of taxonomy. $1518 \quad$ Frontiers in Zoology 7:16. DOI: 10.1186/1742-9994-7-16.

1519 Potter S., Bragg JG., Peter BM., Bi K., Moritz C. 2016. Phylogenomics at the tips: Inferring 1520 lineages and their demographic history in a tropical lizard, Carlia amax. Molecular Ecology 1521 25:1367-1380. DOI: 10.1111/mec.13546.

1522 De Queiroz K. 2007. Species concepts and species delimitation. Systematic biology 56:879-886. 1523 DOI: $10.1080 / 10635150701701083$.

1524 Rosauer DF., Blom MPK., Bourke G., Catalano S., Donnellan S., Gillespie G., Mulder E., Oliver 1525 PM., Potter S., Pratt RC., Rabosky DL., Skipwith PL., Moritz C. 2016. Phylogeography, 
1526 hotspots and conservation priorities: an example from the Top End of Australia. Biological 1527 Conservation 204:83-93. DOI: 10.1016/j.biocon.2016.05.002.

1528 Rosauer DF., Byrne M., Blom MPK., Coates DJ., Donnellan S., Doughty P., Keogh JS., Kinloch 1529 J., Laver RJ., Myers C., Oliver PM., Potter S., Rabosky DL., Afonso Silva AC., Smith J., 1530 Moritz C. 2018. Real-world conservation planning for evolutionary diversity in the 1531 Kimberley, Australia, sidesteps uncertain taxonomy. Conservation Letters 11:e12438. DOI: $1532 \quad 10.1111 /$ conl.12438.

1533 Singhal S., Hoskin CJ., Couper P., Potter S., Moritz C. 2018. A framework for resolving cryptic 1534 species: a case study from the Lizards of the Australian Wet Tropics. Systematic Biology $1535 \quad$ 67:1061-1075. DOI: 10.1093/sysbio/syy026.

1536 Sistrom M., Donnellan SC., Hutchinson MN. 2013. Delimiting species in recent radiations with 1537 low levels of morphological divergence: A case study in Australian Gehyra geckos. 1538 Molecular Phylogenetics and Evolution 68:135-143. DOI: 10.1016/j.ympev.2013.03.007.

1539 Sistrom M., Hutchinson M., Bertozzi T., Donnellan S. 2014. Evaluating evolutionary history in 1540 the face of high gene tree discordance in Australian Gehyra ( Reptilia : Gekkonidae ). 1541 Heredity:113:52. DOI: 10.1038/hdy.2014.6.

1542 Skipwith PL., Oliver PM. 2014. A new Gehyra (Gekkonidae: Reptilia) from New Guinea with 1543 unique caudal scalation. Zootaxa 3827:57-66. DOI: 10.11646/zootaxa.3827.1.5.

1544 Smith KL., Harmon LJ., Shoo LP., Melville J. 2011. Evidence of constrained phenotypic 1545 evolution in a cryptic species complex of agamid lizards. Evolution 65:976-992. DOI: $1546 \quad$ 10.1111/j.1558-5646.2010.01211.x.

1547 Sukumaran J., Knowles LL. 2017. Multispecies coalescent delimits structure, not species. 
1548

1549

1550

1551

1552 Unmack PJ., Sandoval-Castillo J., Hammer MP., Adams M., Raadik TA., Beheregaray LB.

1553

1554

1555

1556

1557

1558

1559

1560

1561

1562

1563

1564

1565

Proceedings of the National Academy of Sciences 114:1607-1612. DOI: 10.1073/pnas.1607921114.

Uetz P., Freed P., Hošek J. The Reptile Database. Available at http://www.reptile-database.org (accessed January 18, 2017). 2017. Genome-wide SNPs resolve a key conflict between sequence and allozyme data to confirm another threatened candidate species of river blackfishes (Teleostei: Percichthyidae: Gadopsis). Molecular Phylogenetics and Evolution 109:415-420. DOI: 10.1016/j.ympev.2017.02.013.

Venables WN., Ripley BD. 2002. MASS: modern applied statistics with S. Issues of Accuracy and Scale:868. DOI: 10.1198/tech.2003.s33.

Wells, SJ., James, D. 2018. Contrasting gene flow at different spatial scales revealed by genotyping-by-sequencing in Isocladus armatus, a massively colour polymorphic New Zealand marine isopod. PeerJ 5462:1-27. DOI: 10.7717/peerj.5462.

Wilson S., Swan G. 2017. A Complete Guide to Reptiles of Australia. New Holland.

Yang Z., Rannala B. 2010. Bayesian species delimitation using multilocus sequence data. Proceedings of the National Academy of Sciences 107:9264-9269. DOI: 10.1073/pnas.0913022107. 


\section{TABLE CAPTIONS}

1567 Table 1. Position and name of diagnostic amino acids in the ND2 sequences for species of

1568 the Gehyra australis complex and G. koira complex. No asterisk = Amino acid without an

1569 asterisk are diagnostic for all specimens, $*=1-2$ individuals within the species do not share the

1570 character, $* *=$ when a majority, but not all, of the individuals share the character.

1571

1572 Table 2: Diagnostic morphological characters for species of the Gehyra australis complex

1573 and G. koira complex. Key traits that help to distinguish species from other morphologically

1574 similar taxa are in bold. 


\section{FIGURE CAPTIONS}

1576 Figure 1 Phylogeny for the Gehyra australis group. Bayesian coalescent tree (50 exons) from

1577 Oliver et al. (2019). Highlighted are: A) G. australis complex - blue; B) saxicoline taxa in G.

1578 koira complex and C) G. chimera sp. nov. - green.

1579

1580 Figure 2 Distribution of species in the Gehyra australis and G. koira complexes based on 1581 genotyped individuals. Putatively hybrid individual from Renner Springs (NTM R38156; field 1582 \# CCM1948) is highlighted with an arrow.

1583

1584 Figure 3 Sampling and clustering results of DArT analyses. Pie charts on the map indicate the 1585 ConStruct results, with the background polygon colour corresponding to the species groups on 1586 the Principal Coordinates Analysis (PCoA) for (A) G.australis complex with putative hybrid at 1587 Renner Springs indicated with arrow (NTM R38156; field \# CCM1948) and (B) G. koira 1588 complex.

1589

1590

Figure 4 Visualisation of outcomes of linear discriminant analysis on morphological traits 1591 of Gehyra australis group specimens. (A) taxa in the G. australis and G. koira complexes

1592 (koira 4); (B) taxa in the Gehyra australis complex; and (C) taxa in the Gehyra koira complex 1593 including the arboreal G. chimera sp. nov. (koira 4). Vectors indicate the relative contributions of 1594 strongly loading traits for the first 2 LDA axes.

1595

1596 Figure 5 Ranges for univariate morphological and meristic traits for species in the Gehyra 1597 australis and G. koira complexes. (A) Snout Vent Length (SVL); (B) Head Width/SVL; (C) 
1598 Head Depth/SVL; (D) Head Depth/Head Length; (E) Head Width/Head Length; (F) Snout 1599 Depth/SVL; (G) Snout Length/SVL; (H) number of pores; (I) number of lamellae; (J) Hindlimb 1600 length/SVL; (K) Forelimb length/SVL; (L) Toe length/SVL.

1601

1602 Figure 6 Pre-cloacal pore arrangements in adult males of species in the Gehyra australis 1603 and G. koira complexes. G. australis NTM R38170 (field \# CCM7006); G. arnhemica sp. nov. 1604 NTM R22626; G. gemina sp. nov. WAM R172873; G. lauta sp. nov. NTM R21311; G. chimera 1605 sp. nov. WAM R177684; G. koira WAM R164768; G. ipsa WAM R101238; G. lapistola sp. 1606 nov. NTM R37093; G.calcitectus sp. nov. WAM R177691.

1607

1608

1609

Figure 7 Chin shield arrangements in for species in the Gehyra australis and G. koira complexes. G. australis NTM R38170 (field \# CCM7006); G. arnhemica sp. nov. NTM

1610 R22626; G. gemina sp. nov. WAM R172873; G. lauta sp. nov. NTM R21311; G. chimera sp. 1611 nov. WAM R177684; G. koira WAM R164768; G. ipsa WAM R101238; G. lapistola sp. nov. 1612 NTM R37093; G. calcitectus sp. nov. WAM R177691.

1613

1614 Figure 8 Species in the Gehyra australis complex in life. (A) G. australis, Mary River

1615 Roadhouse, NT (photo credit - Tom Parkin); (B) G. arnhemica sp. nov., Wongalara Station, NT 1616 (Stephen Zozaya); (C) G. arnhemica sp. nov., Wongalara Station, NT (Stephen Zozaya); (D) G. 1617 gemina sp. nov., Halls Creek, WA (Stephen Zozaya); (E) G. lauta sp. nov., Sybella Creek, Qld 1618 (QM J90707 holotype; Mark Hutchinson); (F) G. lauta sp. nov., Calvert River, NT (Stephen 1619 Zozaya). 
1621 Figure 9 Species in the Gehyra koira complex in life. (A) G. koira Coucal Falls, WA (WAM 1622 R173932; photo credit - Ryan Ellis); (B) G. koira Gogo Station, WA (NMV D77028; Paul 1623 Horner); (C) G. ipsa Purnululu P, WA (Ray Lloyd); (D) G. ipsa Purnululu NP, WA (Brad 1624 Maryan); (E) G. lapistola sp. nov. Lost City, Litchfield NP, NT (Chris Jolly); (F) G. lapistola sp. 1625 nov. Snake Creek Bunkers, Adelaide River Township, NT (Chris Jolly); (G) G. calcitetus sp. 1626 nov. Argyle Station, WA (WAM R177704 paratype; Leonardo Tedeschi); (H) G. calcitectus sp. 1627 nov. Gogo Station, WA (WAM R177691 holotype; Paul Oliver).

1628

1629 Figure 10 Gehyra chimera sp. nov. and near sympatric G. gemina sp. nov. in life. (A) $G$. 1630 chimera sp. nov. holotype (WAM R177687), Bell Creek Crossing, Gibb River Road, WA 1631 (WAM R177687), (B) G. chimera sp. nov. paratype (WAM R177686), same locality as 1632 holotype, (C) G. gemina sp. nov. (WAM R177732), Gibb River Road, Border of Wilinggin 1633 Conservation Park. (All photos - Paul Oliver.)

1634

1635 Figure 11 Lectotype specimen of Gehyra australis (NHMUK xxii.55b).

1636

1637 Figure 12 Variation among preserved Gehyra australis. From left to right, NTM R38168 1638 (field \# CCM4981), NTM R36903, NTM R36854, NTM R38197 (field \# CCM6342), NTM 1639 R38170 (field \# CCM7006). Scale bar $=10 \mathrm{~mm}$.

1640

1641 Figure 13 Variation among preserved Gehyra arnhemica sp. nov. specimens. From left to 1642 right, (A) holotype (NTM R22626) and (B) four paratypes (NTM R38180, NTM R38181, 1643 NTM R38179, NTM R38175). Scale bar = $10 \mathrm{~mm}$. 
1644

1645 Figure 14 Variation among preserved type series of Gehyra gemina sp. nov. (A) From left to 1646 right, (A) holotype (WAM R179349) and (B) four paratypes (NTM R38158, NTM R38159, 1647 NTM R38164, NTM R38163). Scale bar = $10 \mathrm{~mm}$.

1648

1649 Figure 15 Variation among preserved type series of Gehyra lauta sp. nov. From left to right, 1650 (A) holotype (QM J90707) and (B) four paratypes (QM J96624, NTM R21310, NTM R21309, 1651 QM J96621). Scale bar $=10 \mathrm{~mm}$.

1652

1653 Figure 16 Variation among preserved type series of Gehyra chimera sp. nov. From left to 1654 right, (A) holotype (WAM R177687) and (B) four paratypes (WAM R177685, WAM R177682, 1655 WAM R177683, WAM R177684). Scale bar $=10 \mathrm{~mm}$.

1656

1657 Figure 17 Variation among preserved Gehyra koira. From left to right, WAM R166471, 1658 WAM R173986, WAM R164768, WAM R173982, WAM R177673. Scale bar = $10 \mathrm{~mm}$. 1659

1660

Figure 18 Variation among preserved Gehyra ipsa. From left to right, WAM R177671, WAM 1661 R177670, WAM R164786, WAM R164772. Scale bar $=10 \mathrm{~mm}$.

1662

1663 Figure 19 Variation among preserved type series of Gehyra lapistola sp. nov. From left to 1664 right, (A) holotype (NTM R37093) and (B) four paratypes (NTM R37051, NTM R37055, NTM 1665 R37092, NTM R38195). Scale bar $=10 \mathrm{~mm}$. 
1667 Figure 20 Variation among preserved type series of Gehyra calcitectus sp. nov. From left to

1668 right, (A) holotype (WAM R177691) and (B) four paratypes (WAM R177701, WAM R177704, 1669 WAM R177699, WAM R177697). Scale bar $=10 \mathrm{~mm}$.

1670 


\section{SUPPLEMENTARY FILES}

\section{Table S1. Specimen information for the species treated herein.}

1673 Specimens are registered in the Australian Museum (AMS), Museums Victoria (NMV),

1674 Northern Territory Museum (NTM), Queensland Museum (QM), and Western Australian

1675 Museum (WAM). States acronyms: Northern Territory (NT), Queensland (QLD), Western

1676 Australia (WA). CCM numbers correspond to tissues and specimens held at the Australian

1677 National University, Canberra.

1678

1679

Table S2. Measurements for all specimens from which morphological data was collected.

1680 Specimens are registered in the Australian Museum (AMS), Museums Victoria (NMV),

1681 Northern Territory Museum (NTM), Queensland Museum (QM), and Western Australian

1682 Museum (WAM). States acronyms: Northern Territory (NT), Queensland (QLD), Western

1683 Australia (WA). Meaning other acronyms is explained in methods section above.

1684

1685 Data File S1. Zip file of original DArT SNP coding.

1686

1687

1688 


\section{Table $\mathbf{1}$ (on next page)}

Position and name of diagnostic amino acids in the ND2 sequences for species of the Gehyra australis complex and G. koira complex.

No asterisk $=$ Amino acid without an asterisk are diagnostic for all specimens, $*=1-2$

individuals within the species do not share the character, $* *=$ when majority of the individuals in a the species but not all share the character. 


\begin{tabular}{|c|c|c|c|c|c|c|c|c|c|}
\hline \multirow[b]{2}{*}{ Codon } & \multicolumn{4}{|c|}{ G. australis complex } & \multicolumn{5}{|c|}{ G. koira complex } \\
\hline & 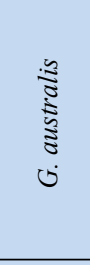 & 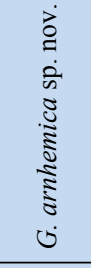 & 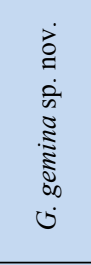 & 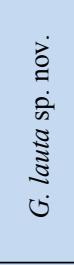 & $\frac{0}{0}$ & $\begin{array}{l}\check{0} \\
\stackrel{0}{0} \\
ن\end{array}$ & 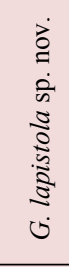 & 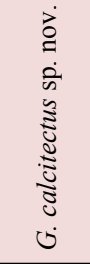 & 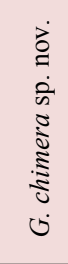 \\
\hline 10 & & & & Thr* & & & & & \\
\hline 19 & & & Thr* & & & Met* & & & Thr \\
\hline 25 & Leu & & Leu & & & Leu & & & \\
\hline 28 & Val* & & & & & & & & \\
\hline 55 & & & & & & & & Met** & \\
\hline 82 & & Met & Met & & & & & & \\
\hline 127 & Met** & & & & & Val & & & \\
\hline 130 & $\mathrm{Thr}$ & & Thr & Thr & & & & & \\
\hline 139 & & & & & & & Thr & & \\
\hline 196 & & & & & & & & Thr* & Thr* \\
\hline 205 & Met & Met & Met & Met & & & & & \\
\hline 226 & & & & & Leu & Leu & Leu & Leu & Leu \\
\hline 241 & & & & & & & Tyr & & \\
\hline 253 & & Ala & Ala* & & $\mathrm{Ala}^{* *}$ & & & & \\
\hline 265 & & & & & & & Pro & & \\
\hline 268 & & Ser & & & & & & & \\
\hline 274 & & Ala* & & & & & & Ala & \\
\hline 277 & & & & & & & Ala & & \\
\hline 286 & & $\mathrm{Ile}^{* *}$ & & & & & & & \\
\hline 289 & & Val** & & & & & & & \\
\hline 292 & & & & Thr & & & & & \\
\hline 307 & & & & Leu & & & & & \\
\hline 322 & & & & & Met & & & & \\
\hline 370 & & & & & & & & Phe & \\
\hline 376 & & & Ala** & & & & & & Ala \\
\hline 382 & & & & Met & & & & & \\
\hline 406 & & Met* & & & & & & & \\
\hline 415 & & Leu & & & & & & & \\
\hline 418 & & & & & Thr & Thr & & & Thr \\
\hline 433 & & & & & Thr** & & & & \\
\hline 436 & & & & & Tyr** & & & & \\
\hline 451 & His & His & His & Leu & & & & & \\
\hline 454 & Ser** & & & & & & & & \\
\hline 460 & $\mathrm{Ile}^{* *}$ & Thr* & Ile* & Ile & & & & & \\
\hline 466 & & & Phe & & Ile** & & & & \\
\hline 469 & $\mathrm{Val}^{*}$ & Ala* & & & Ala* & & & & Ile \\
\hline 484 & & & & & & & & & \\
\hline 490 & & Val & Phe* & & Phe** & & & & \\
\hline 499 & Leu & Leu & Leu & Leu & & & & & \\
\hline 502 & & & & & & Thr & & & Thr* \\
\hline 559 & & & & & & Thr & & & Thr \\
\hline 583 & Ser* & Ser & Ser & Ser & & & & & \\
\hline 586 & & & & & & & Met & & \\
\hline
\end{tabular}




\begin{tabular}{|c|c|c|c|c|c|c|c|c|c|}
\hline 589 & & Asn & Asn* & Asn & & Asn & Asp* & & Asn \\
\hline 592 & Gin & Gin & Gin & Gin & & & & & \\
\hline 595 & & & & & Trp* & & & & \\
\hline 616 & & & & & & Ile & & & \\
\hline++ & \multicolumn{4}{|c|}{ G. australis complex } & \multicolumn{5}{|c|}{ G. koira complex } \\
\hline 619 & Ile & Ile & & Ile & & & & & Val* \\
\hline 625 & Ile & Ile* & Ile & Ile & & & & & \\
\hline 628 & & & & & Met* & & Met & Met & \\
\hline 631 & Thr & Thr & & Thr & & & & & \\
\hline 649 & & & & Leu & Ala* & & & Ala & \\
\hline 658 & & & & Ser & & & & & \\
\hline 661 & & & & Ala & & & & Met* & \\
\hline 664 & Thr & Thr & & Thr & & & & Thr & \\
\hline 667 & Ser & Ser & Ala & & & & & & \\
\hline 679 & & & & & Met & & & Met & \\
\hline 682 & & & & & Lys & & & Lys & \\
\hline 694 & & & & & Met* & & Ile & Met & \\
\hline 697 & & & & & & & & Ala* & \\
\hline 706 & Thr & & & & & & & Thr & \\
\hline 715 & & & & Pro & & & Pro & & \\
\hline 721 & & & & & & & & Met* & Met** \\
\hline 781 & Leu & & Leu & & & & & & \\
\hline 811 & & & & & $\mathrm{Ala}^{* *}$ & & & & \\
\hline 814 & & & & & & & & & $\mathrm{Ala}^{* *}$ \\
\hline 820 & & Thr** & & & & & & & \\
\hline 823 & & & & & & Met & & & \\
\hline 826 & & & & & Met* & & & & \\
\hline 832 & & & & & & & & Met* & \\
\hline 835 & Met* & $\mathrm{Thr}$ & Thr & Thr & & & & & \\
\hline 838 & & & & & & & Ile & & \\
\hline 841 & & & & & Thr* & & & Gly & \\
\hline 847 & & & & & & & Thr & & \\
\hline 880 & $\mathrm{Val}^{*}$ & & $\mathrm{Val}^{*}$ & Val & & & & & \\
\hline 886 & & & & & & Val & & & Val \\
\hline 910 & & & & Ile & Ala** & Ala & Ala & Ala* & \\
\hline 937 & & His & & & & & & & \\
\hline 961 & Pro & Pro* & & Pro & His & His* & His & His* & His \\
\hline 964 & & & & Asn & & & & & \\
\hline 967 & & & & Arg & & Pro* & & Arg* & $\mathrm{Val}^{*}$ \\
\hline 970 & His & His & His & His & & Gly* & & & \\
\hline 976 & & & & Ala & & & Ala* & & \\
\hline 982 & Met & & & & $\mathrm{Ala}^{* *}$ & Pro* & Ala & Ala & \\
\hline 994 & & & & & Thr & Thr* & Thr & Thr* & Thr \\
\hline
\end{tabular}


1

\begin{tabular}{|l|l|l|l|l|l|l|l|l|l|}
1021 & Met & & Met & & Ala* $^{*}$ & & & & \\
\hline 1030 & & Ala* $^{*}$ & Ala* & & & Ala* & & & \\
\hline 1033 & & & & Ile & $\mathrm{Ile}^{*}$ & & & & \\
\hline
\end{tabular}

Peer] reviewing PDF | (2019:04:36958:1:2:NEW 27 Sep 2019) 


\section{Table 2 (on next page)}

Diagnostic morphological characters for species of the Gehyra australis complex and G. koira complex.

Key traits that help to distinguish species from other morphologically similar taxa are in bold. 


\begin{tabular}{|c|c|c|c|c|c|c|c|c|c|}
\hline & $\begin{array}{l}\text { Gehyra } \\
\text { australis }\end{array}$ & $\begin{array}{c}\text { Gehyra } \\
\text { gemina sp. } \\
\text { nov. }\end{array}$ & $\begin{array}{c}\text { Gehyra } \\
\text { arnhemica sp. } \\
\text { nov. } \\
\end{array}$ & $\begin{array}{c}\text { Gehyra } \\
\text { lauta sp. nov. }\end{array}$ & $\begin{array}{c}\text { Gehyra } \\
\text { chimera sp. nov. }\end{array}$ & $\begin{array}{l}\text { Gehyra } \\
\text { koira }\end{array}$ & $\begin{array}{c}\text { Gehyra } \\
\text { ipsa }\end{array}$ & $\begin{array}{c}\text { Gehyra } \\
\text { lapistola sp. } \\
\text { nov. }\end{array}$ & $\begin{array}{c}\text { Gehyra } \\
\text { calcitectus sp. } \\
\text { nov. }\end{array}$ \\
\hline SVL & $\begin{array}{c}61.5 \\
(50.9-68.1)\end{array}$ & $\begin{array}{c}62.9 \\
(54.2-68.9)\end{array}$ & $\begin{array}{c}62.9 \\
(56.4-68.2)\end{array}$ & $\begin{array}{c}72.2 \\
(64.4-83.1)^{*}\end{array}$ & $\begin{array}{c}62.5 \\
(50.1-73.7)\end{array}$ & $\begin{array}{c}72.5 \\
(64.4-80.4)\end{array}$ & $\begin{array}{c}87.9 \\
(77.6-94.9)\end{array}$ & $\begin{array}{c}74.2 \\
(66.9-79.5)\end{array}$ & $\begin{array}{c}69.4 \\
(57.4-77.9)\end{array}$ \\
\hline Pre-cloacal pores & $\begin{array}{c}13 \\
(11-14)\end{array}$ & $\begin{array}{c}12 \\
(10-16)\end{array}$ & $\begin{array}{c}24 \\
(21-26)\end{array}$ & $\begin{array}{c}26 \\
(22-32)\end{array}$ & $\begin{array}{c}10 \\
(9-11)\end{array}$ & $\begin{array}{c}17 \\
(12-23)\end{array}$ & $\begin{array}{c}16 \\
(15-18)\end{array}$ & $\begin{array}{c}10 \\
(9-13)\end{array}$ & $\begin{array}{c}12 \\
(9-14)\end{array}$ \\
\hline HeadW/SVL & $\begin{array}{c}0.180 \\
(0.172-0.190)\end{array}$ & $\begin{array}{c}0.188 \\
(0.163-0.204)^{*}\end{array}$ & $\begin{array}{c}0.180 \\
(0.170-0.196)\end{array}$ & $\begin{array}{c}0.183 \\
(0.175-0.198)\end{array}$ & $\begin{array}{c}0.185 \\
(0.175-0.194)\end{array}$ & $\begin{array}{c}0.190 \\
(0.176-0.216)\end{array}$ & $\begin{array}{c}0.183 \\
(0.172-0.194)\end{array}$ & $\begin{array}{c}0.181 \\
(0.173-0.189)\end{array}$ & $\begin{array}{c}0.199 \\
(0.183-0.219)\end{array}$ \\
\hline HeadD/SVL & $\begin{array}{c}0.113 \\
(0.104-0.120)\end{array}$ & $\begin{array}{c}0.109 \\
(0.099-0.122)\end{array}$ & $\begin{array}{c}0.110 \\
(0.102-0.119)\end{array}$ & $\begin{array}{c}0.111 \\
(0.099-0.119)\end{array}$ & $\begin{array}{c}0.113 \\
(0.103-0.112)\end{array}$ & $\begin{array}{c}0.100 \\
(0.081-0.123)\end{array}$ & $\begin{array}{c}0.109 \\
(0.103-0.112)\end{array}$ & $\begin{array}{c}0.111 \\
(0.100-0.121)\end{array}$ & $\begin{array}{c}0.107 \\
(0.090-0.122)\end{array}$ \\
\hline Snoutd/SVL & $\begin{array}{c}0.79 \\
(0.074-0.085)\end{array}$ & $\begin{array}{c}0.079 \\
(0.074-0.085)\end{array}$ & $\begin{array}{c}0.079 \\
(0.072-0.086)\end{array}$ & $\begin{array}{c}0.077 \\
(0.074-0.083)\end{array}$ & $\begin{array}{c}0.084 \\
(0.081-0.087)\end{array}$ & $\begin{array}{c}0.074 \\
(0.061-0.085)\end{array}$ & $\begin{array}{c}0.08 \\
(0.076-0.084)\end{array}$ & $\begin{array}{c}0.078 \\
(0.073-0.084)\end{array}$ & $\begin{array}{c}0.079 \\
(0.063-0.085)\end{array}$ \\
\hline HindlimbL/SVL & $\begin{array}{c}0.128 \\
(0.115-0.144)\end{array}$ & $\begin{array}{c}0.125 \\
(0.100-0.150)\end{array}$ & $\begin{array}{c}0.125 \\
(0.113-0.134)\end{array}$ & $\begin{array}{c}0.120 \\
(0.106-0.127)^{*}\end{array}$ & $\begin{array}{c}0.129 \\
(0.120-0.166)\end{array}$ & $\begin{array}{c}0.141 \\
(0.125-0.169)\end{array}$ & $\begin{array}{c}0.148 \\
(0.127-0.165)\end{array}$ & $\begin{array}{c}0.130 \\
(0.124-0.134)\end{array}$ & $\begin{array}{c}0.142 \\
(0.123-0.162)\end{array}$ \\
\hline $\begin{array}{l}\text { Relative chinshield } \\
\text { length }\end{array}$ & $\begin{array}{c}0.63 \\
(0.58-0.70)\end{array}$ & $\begin{array}{c}0.69 \\
(0.56-0.92)\end{array}$ & $\begin{array}{c}0.67 \\
(0.57-0.77)\end{array}$ & $\begin{array}{c}0.77 \\
(0.70-0.88)\end{array}$ & $\begin{array}{c}0.75 \\
(0.68-0.80)\end{array}$ & $\begin{array}{c}0.72 \\
(0.64-0.79)\end{array}$ & $\begin{array}{c}0.78 \\
(0.75-0.81)\end{array}$ & $\begin{array}{c}0.68 \\
(0.62-0.74)\end{array}$ & $\begin{array}{c}0.66 \\
(0.53-0.79)\end{array}$ \\
\hline $\begin{array}{l}\text { Relative chinshield } \\
\text { width }\end{array}$ & $\begin{array}{c}0.78 \\
(0.64-0.92)\end{array}$ & $\begin{array}{c}0.79 \\
(0.61-0.84)\end{array}$ & $\begin{array}{c}0.79 \\
(0.59-0.95)\end{array}$ & $\begin{array}{c}0.87 \\
(0.73-1.01)\end{array}$ & $\begin{array}{c}0.85 \\
(0.61-0.95)\end{array}$ & $\begin{array}{c}0.85 \\
(0.69-1.08)\end{array}$ & $\begin{array}{c}0.79 \\
(0.74-0.83)\end{array}$ & $\begin{array}{c}0.87 \\
(0.77-0.96)\end{array}$ & $\begin{array}{c}0.77 \\
(0.65-0.89)\end{array}$ \\
\hline $\begin{array}{l}\text { Enlarged scale behind } \\
\text { first chinshield pair }\end{array}$ & no & no & no & no & no & no & usually & no & no \\
\hline pale ocelli on dorsum & no & no & no & no & no & no & no & no & yes \\
\hline $\begin{array}{l}\text { Pale buff or brown } \\
\text { transverse barring }\end{array}$ & no & no & no & no & rarely & usually & always & no & no \\
\hline $\begin{array}{l}\text { Dark brown/grey patter } \\
\text { on dorsum }\end{array}$ & sometimes & sometimes & sometimes & no & often & rarely & sometimes & no & $\begin{array}{l}\text { sometimes } \\
\text { (eastern pops only) }\end{array}$ \\
\hline Habitat & $\begin{array}{l}\text { trees, rocks } \\
\text { buildings }\end{array}$ & trees, buildings & $\begin{array}{l}\text { trees, rocks } \\
\text { buildings }\end{array}$ & trees & trees, buildings & rocks & rocks & rocks & rocks (limestone) \\
\hline
\end{tabular}


Figure 1

Phylogeny for the Gehyra australis group.

Bayesian coalescent tree (50 exons) from Oliver et al. 2009. Highlighted are: A) G. australis complex - blue; B) saxicoline taxa in G. koira complex and C) G. chimera sp. nov. - green. 


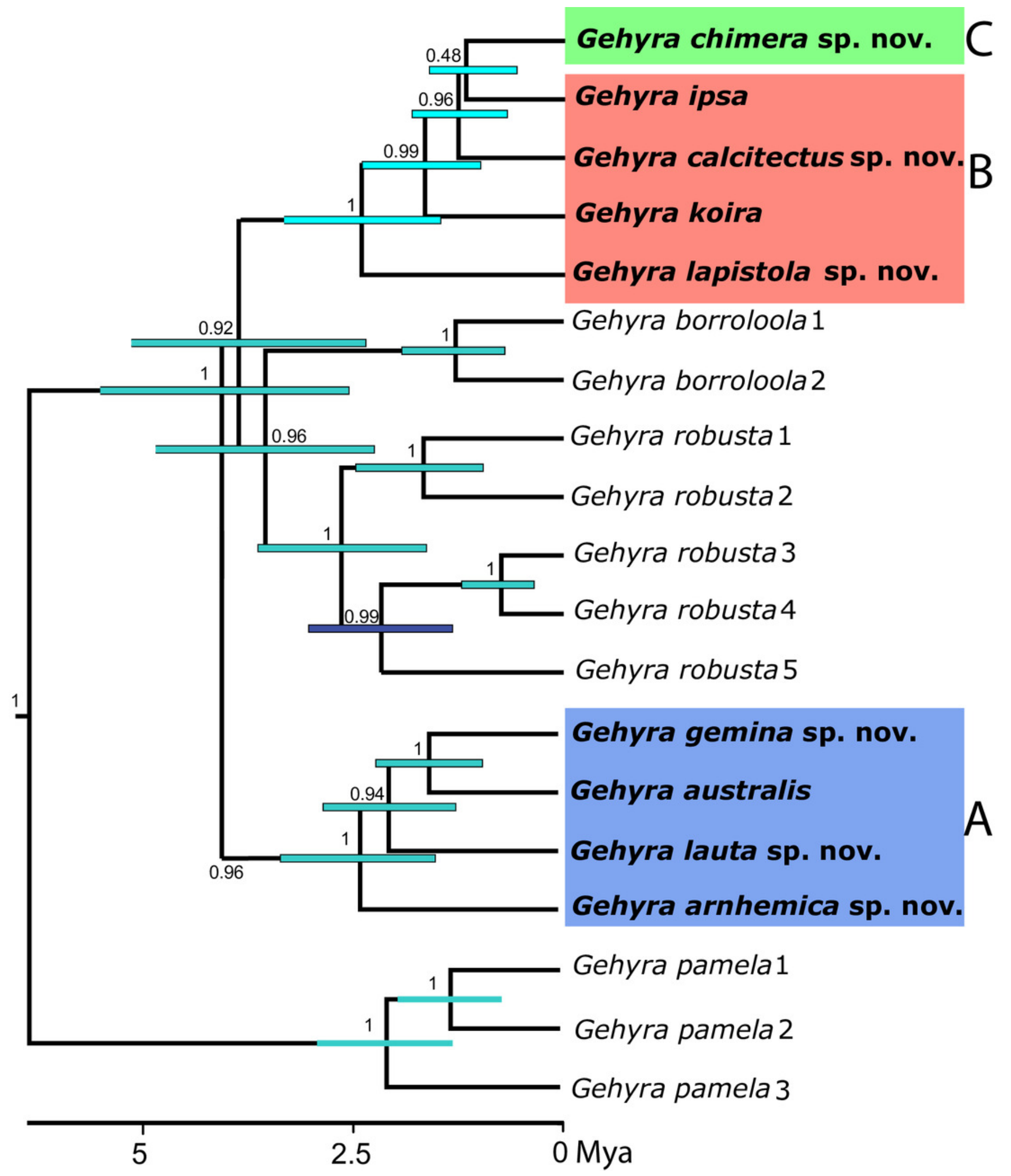


Figure 2

Distribution of species in the Gehyra australis and G. koira complexes based on genotyped individuals.

Putatively hybrid individual from Renner Springs (NTM R38156; field \# CCM1948) is highlighted with an arrow.
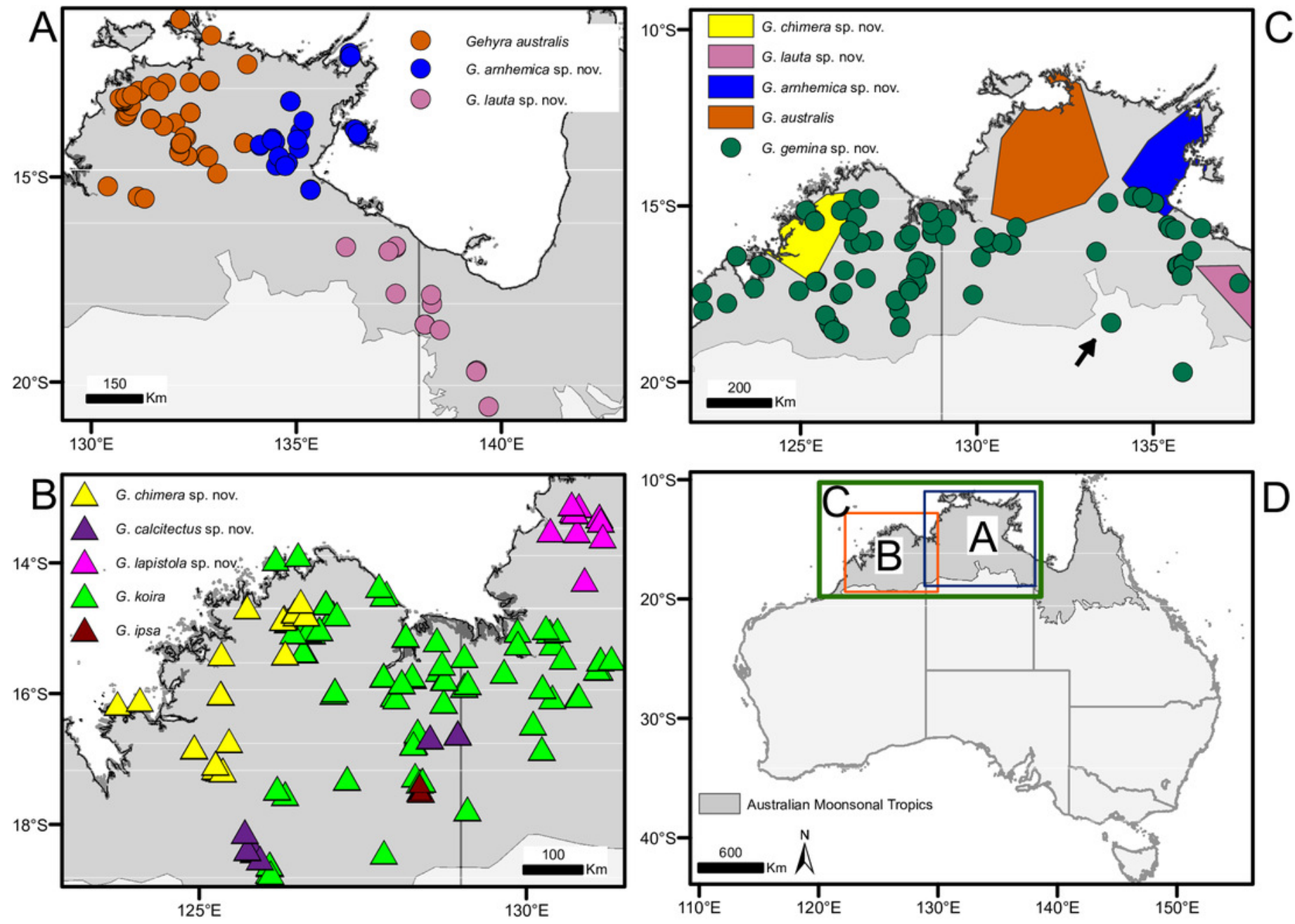


\section{Figure 3}

Sampling and clustering results of DArT analyses.

Pie charts on the map indicate the ConStruct results, with the background polygon colour corresponding to the species groups on the Principal Coordinates Analysis (PCOA) for (A) G.australis complex with putative hybrid at Renner Springs indicated with arrow (NTM R38156; field \# CCM1948) and (B) G. koira complex.
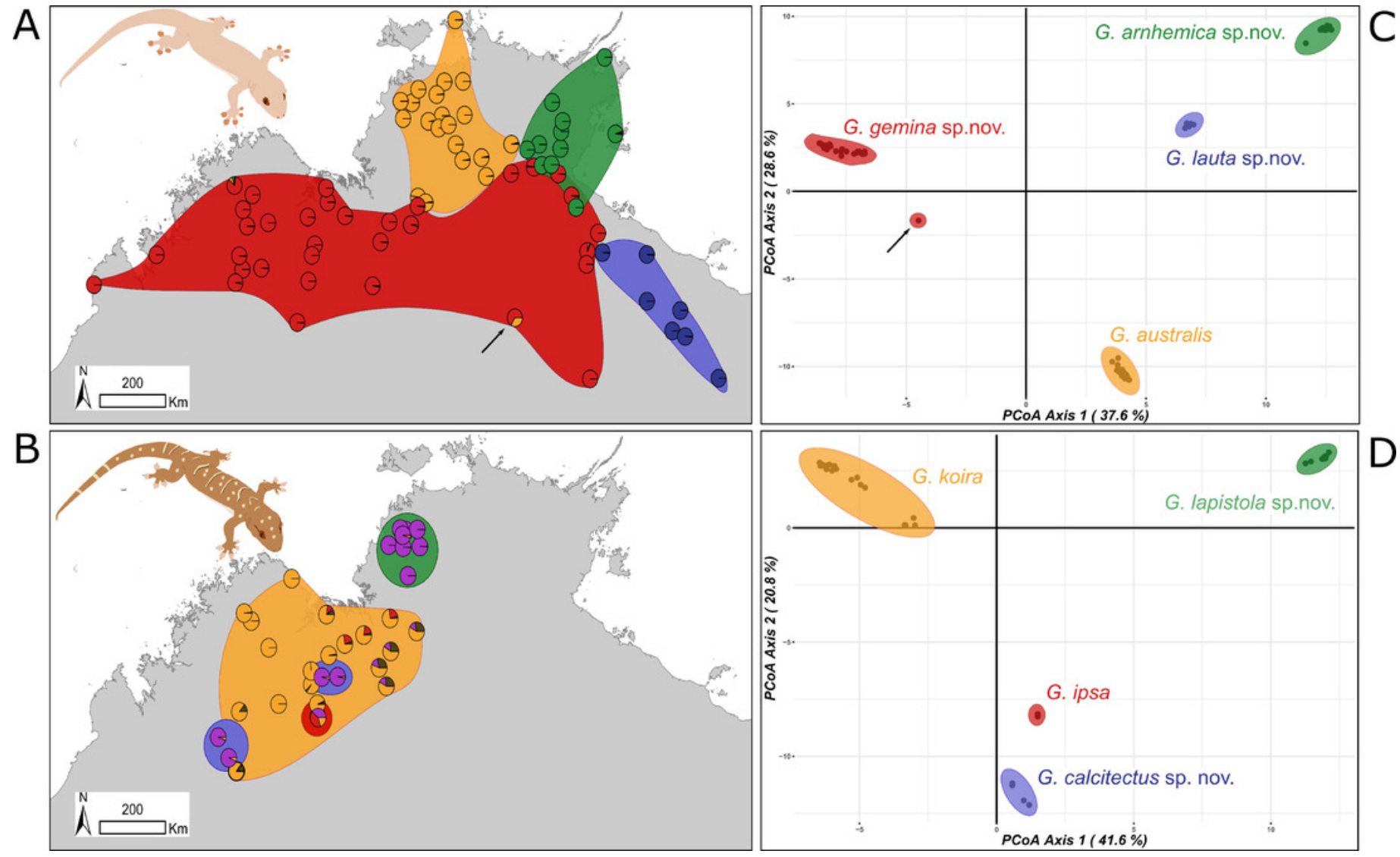
Figure 4

Visualisation of outcomes of linear discriminant analysis on morphological traits of Gehyra australis group specimens.

(A) taxa in the G. australis and G. koira complexes (koira 4); (B) taxa in the Gehyra australis complex; and (C) taxa in the Gehyra koira complex including the arboreal Gehyra chimera sp. nov. (koira 4). Vectors indicate the relative contributions of strongly loading traits for the first 2 LDA axes. 


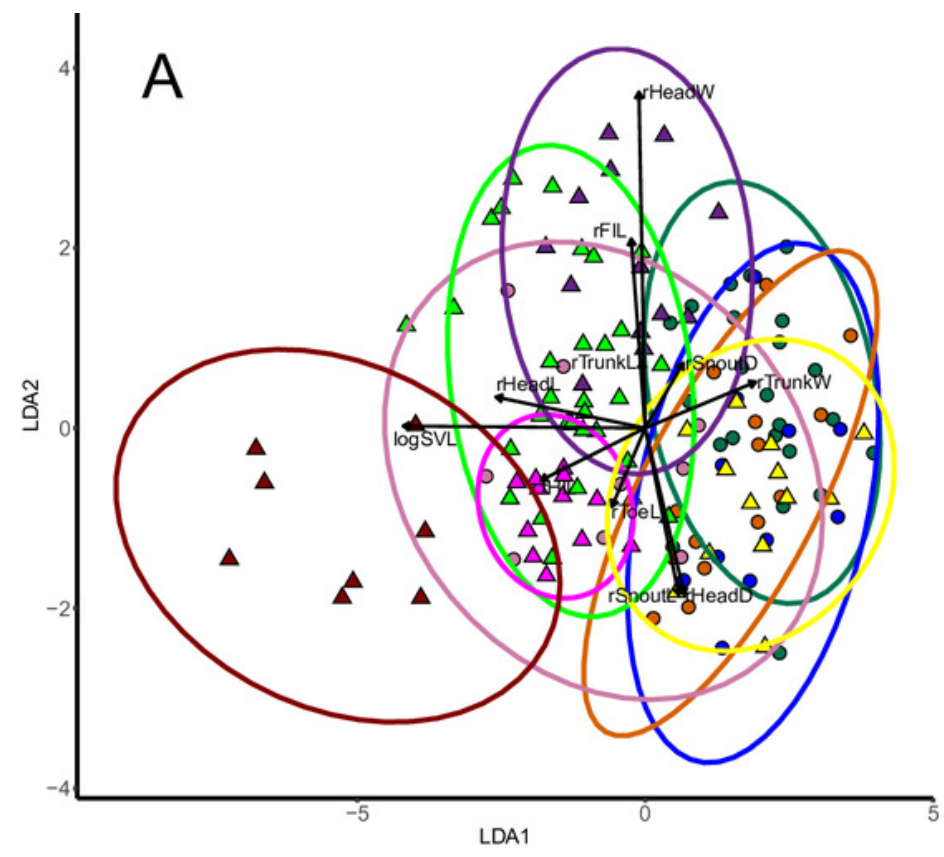

G. australis

- G. gemina sp. nov.

- G. arnhemica sp. nov.

G. lauta sp. nov.

$\Delta$ G. ipsa

$\triangle$ G. koira

$\triangle$ G. lapistola sp. nov.

$\triangle$ G. calcitectus sp. nov.

$\triangle$ G. chimera sp. nov.
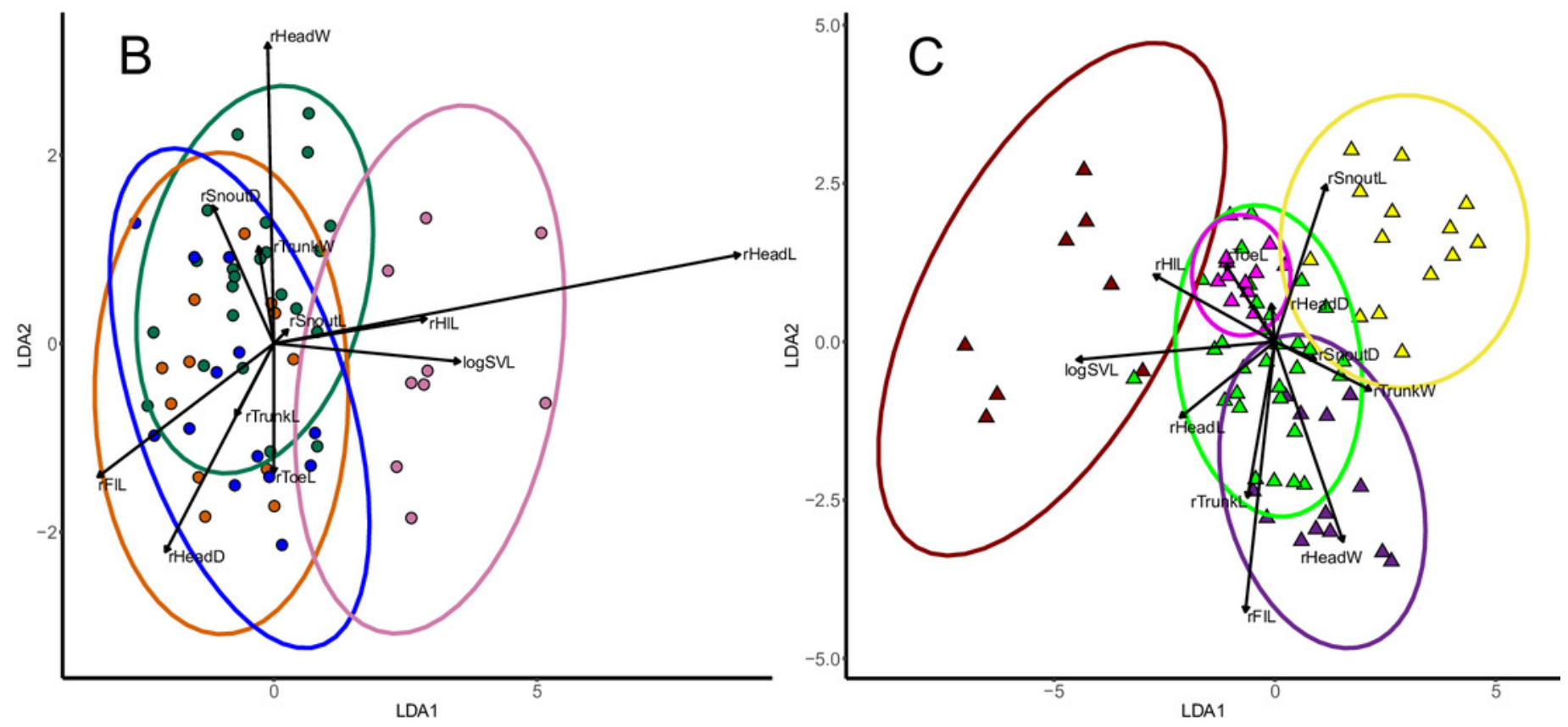
Figure 5

Ranges for univariate morphological and meristic traits for species in the Gehyra australis and G. koira complexes.

(A) Snout-vent Lenght (SVL); (B) Head Width/SVL; (C) Head Depth/SVL; (D) Head Depth/Head Length; (E) Head Width/Head Length; (F) Snout Depth/SVL; (G) Snout Length/SVL; (H) number of pores; (I) number of lamallae; (J) Hindlimb length/SVL; (K) Forelimb length; (L) Toe length/SVL.
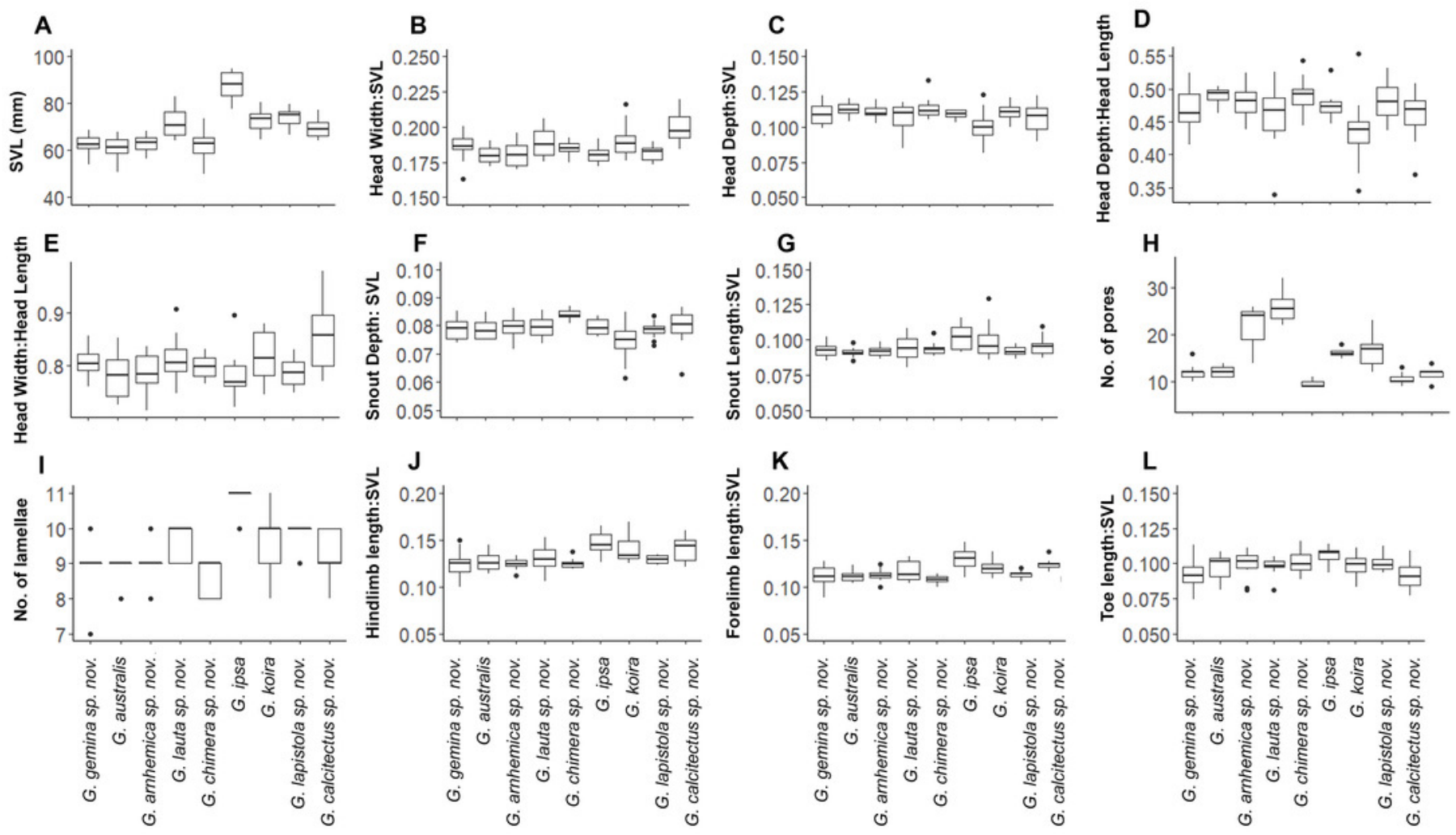


\section{Figure 6}

Pre-cloacal pore arrangements in adult males of species in the Gehyra australis and $G$. koira complexes.

G. australis NTM R38170 (field \# CCM7006); G. arnhemica sp. nov. NTM R22626; G. gemina sp. nov. WAM R172873; G. lauta sp. nov. NTM R21311; G. chimera sp. nov. WAM R177684; G. koira WAM R164768; G. ipsa WAM R101238; G. lapistola sp. nov. NTM R37093; G.calcitectus sp. nov. WAM R177691.

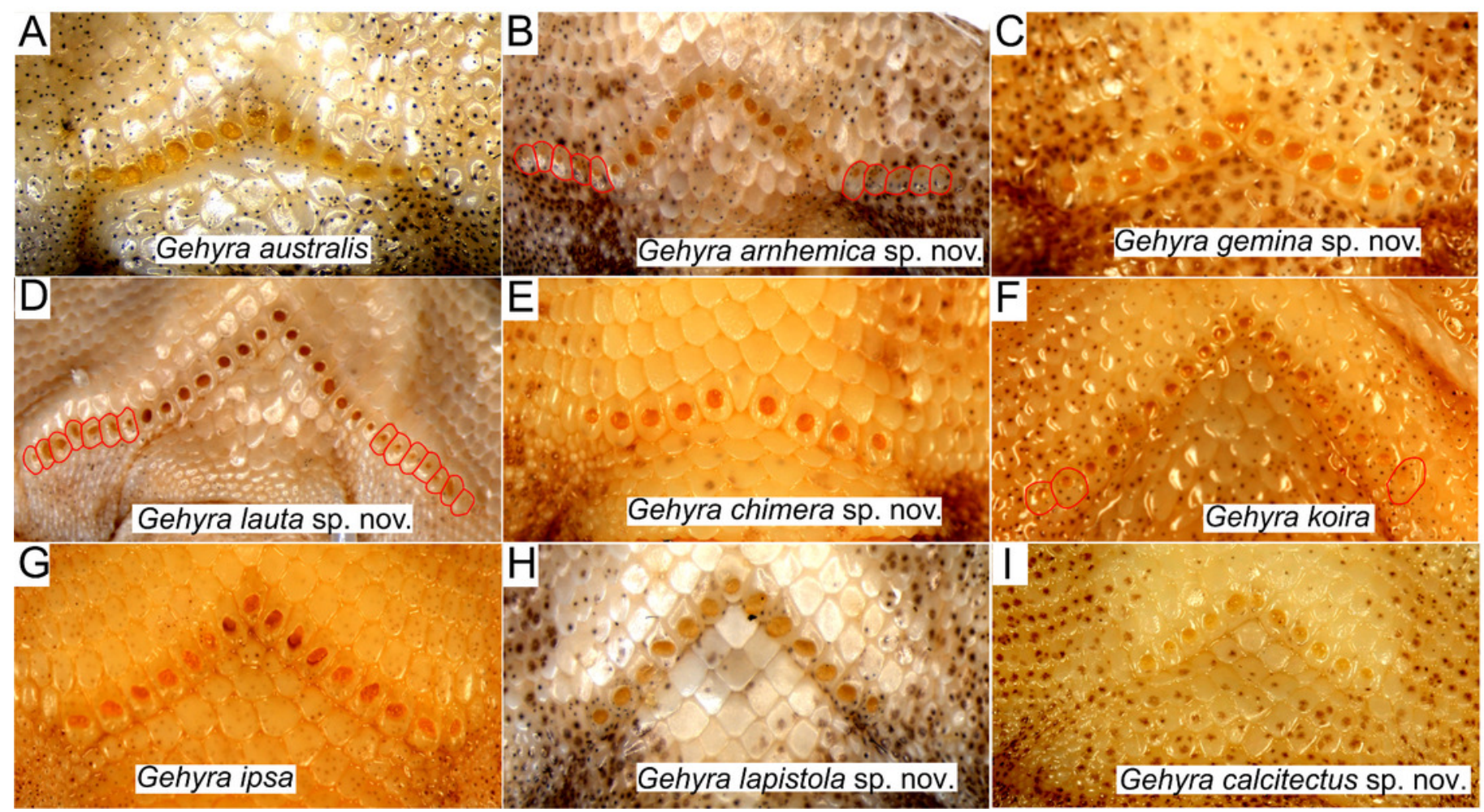




\section{Figure 7}

Chin shield arrangements in for species in the Gehyra australis and G. koira complexes.

G. australis NTM R38170 (field \# CCM7006); G. arnhemica sp. nov. NTM R22626; G. gemina sp. nov. WAM R172873; G. lauta sp. nov. NTM R21311; G. chimera sp. nov. WAM R177684; G. koira WAM R164768; G. ipsa WAM R101238; G. lapistola sp. nov. NTM R37093; G. calcitectus sp. nov. WAM R177691.

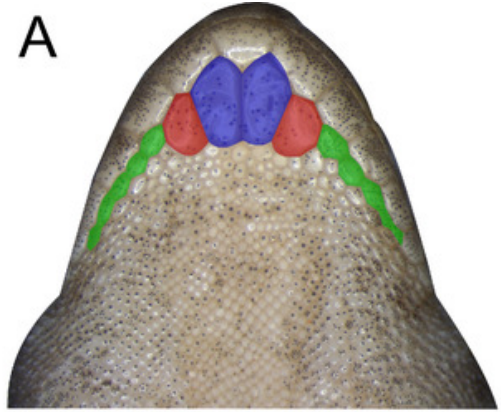

Gehyra australis

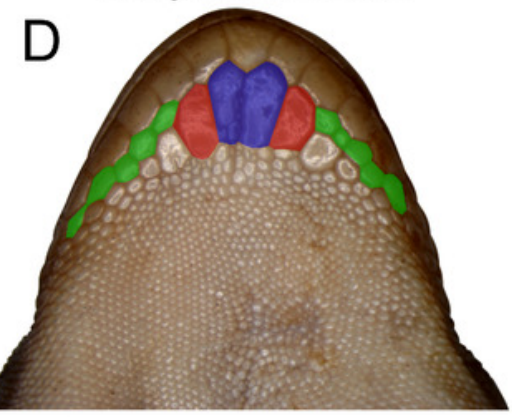

Gehyra lauta sp. nov.

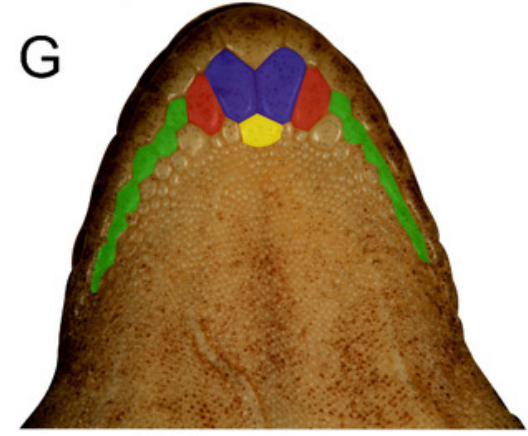

Gehyra ipsa

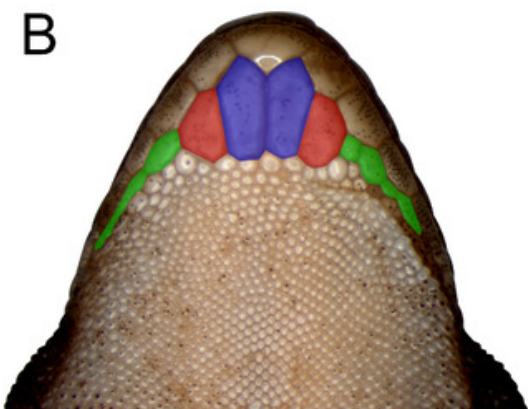

Gehyra arnhemica sp. nov.

E

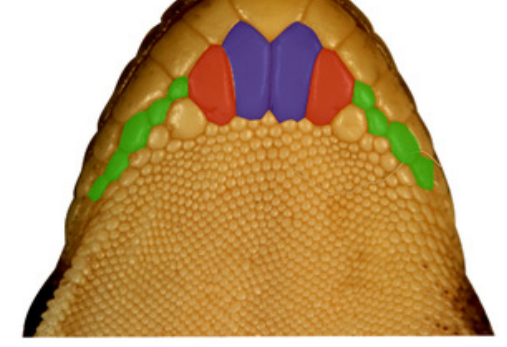

Gehyra chimera sp. nov.

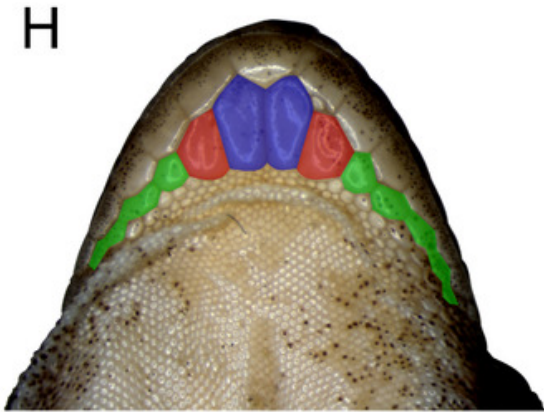

Gehyra lapistola sp. nov.

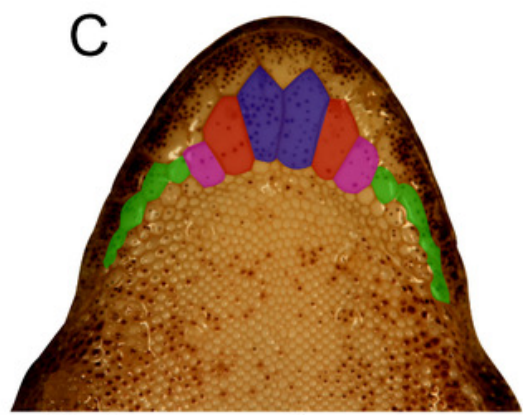

Gehyra gemina sp. nov.

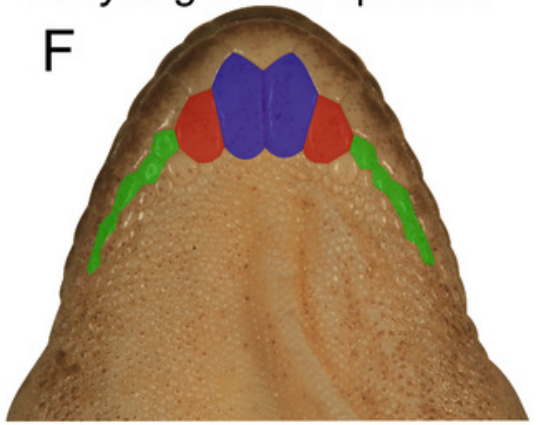

Gehyra koira

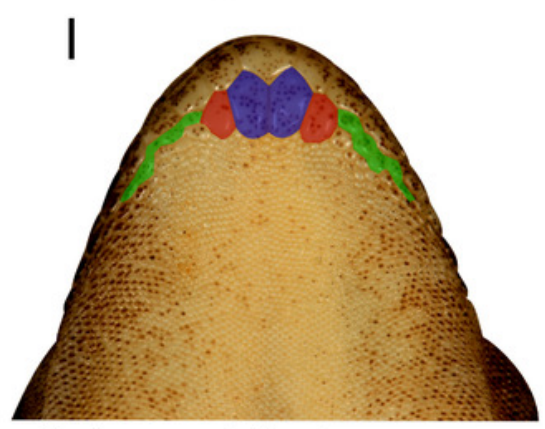

Gehyra calcitectus sp. nov. 


\section{Figure 8}

Species in the Gehyra australis complex in life.

(A) G. australis Mary River Roadhouse, NT (photo credit - Tom Parkin); (B) G. arnhemica sp. nov. Wongalara Station, NT (Stephen Zozaya); (C) G. arnhemica sp. nov. Wongalara Station, NT (Stephen Zozaya); (D) G. gemina sp. nov. Halls Creek, WA (Stephen Zozaya); (E) G. lauta sp. nov. Sybella Creek, QLD (QM J90707 holotype; Mark Hutchinson); (F) G. lauta sp. nov. Calvert River, NT (Stephen Zozaya). 


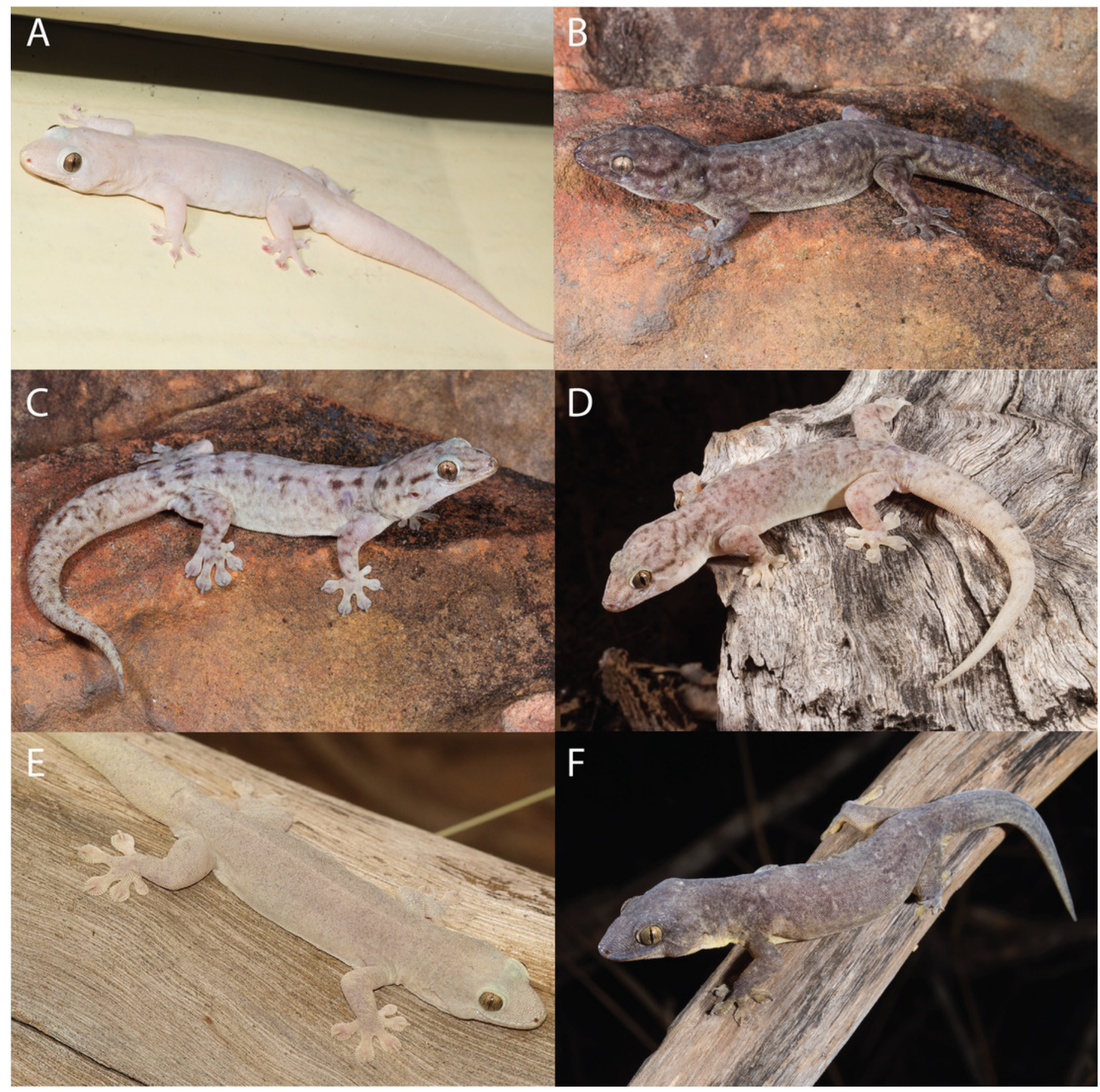




\section{Figure 9}

Species in the Gehyra koira complex in life.

(A) G. koira Coucal Falls, WA (WAM R173932; photo credit - Ryan Ellis); (B) G. koira Gogo Station, WA (NMV D77028; Paul Oliver); (C) G. ipsa Purnululu P, WA (Ray Lloyd); (D) G. ipsa Purnululu NP, WA (Brad Maryan); (E) G. lapistola sp. nov. Lost City, Litchfield NP, NT (Chris Jolly); (F) G. lapistola sp. nov. Snake Creek Bunkers, Adelaide River Township, NT (Chris Jolly);

(G) G. calcitetus sp. nov. Argyle Station, WA (WAM R177704 paratype; Leonardo Tedeschi);

(H) G. calcitectus sp. nov. Gogo Station, WA (WAM R177691 holotype; Paul Oliver). 


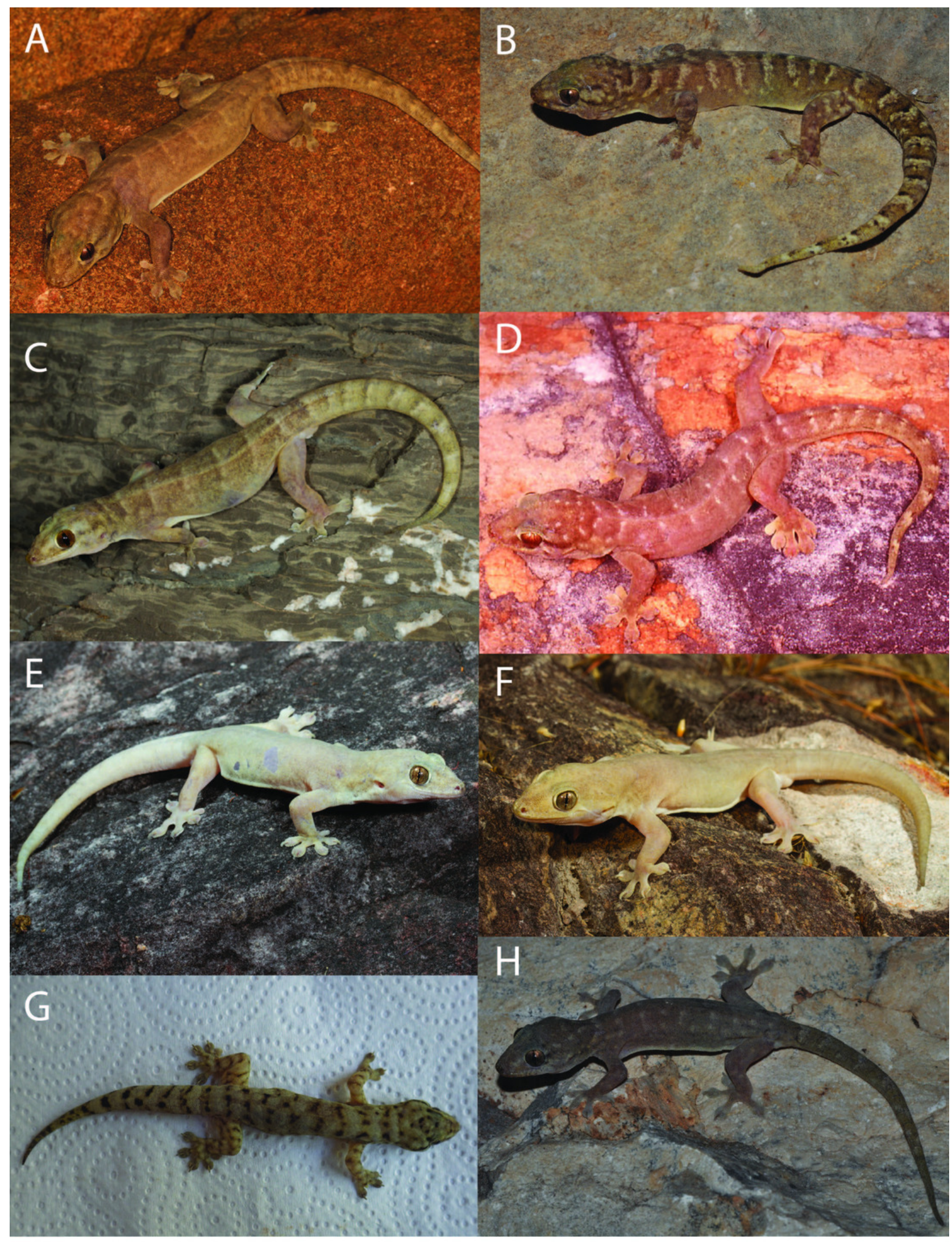




\section{Figure 10}

Gehyra chimera sp. nov. and near sympatric G. gemina sp. nov. in life.

(A) G. chimera sp. nov. holotype (WAM R177687), Bell Creek Crossing, Gibb River Road, WA (WAM R177687), (B) G. chimera sp. nov. paratype (WAM R177686), same locality as holotype, (C) G. gemina sp. nov. (WAM R177732), Gibb River Road, Border of Wilinggin Conservation Park. (All photos - Paul Oliver.) 


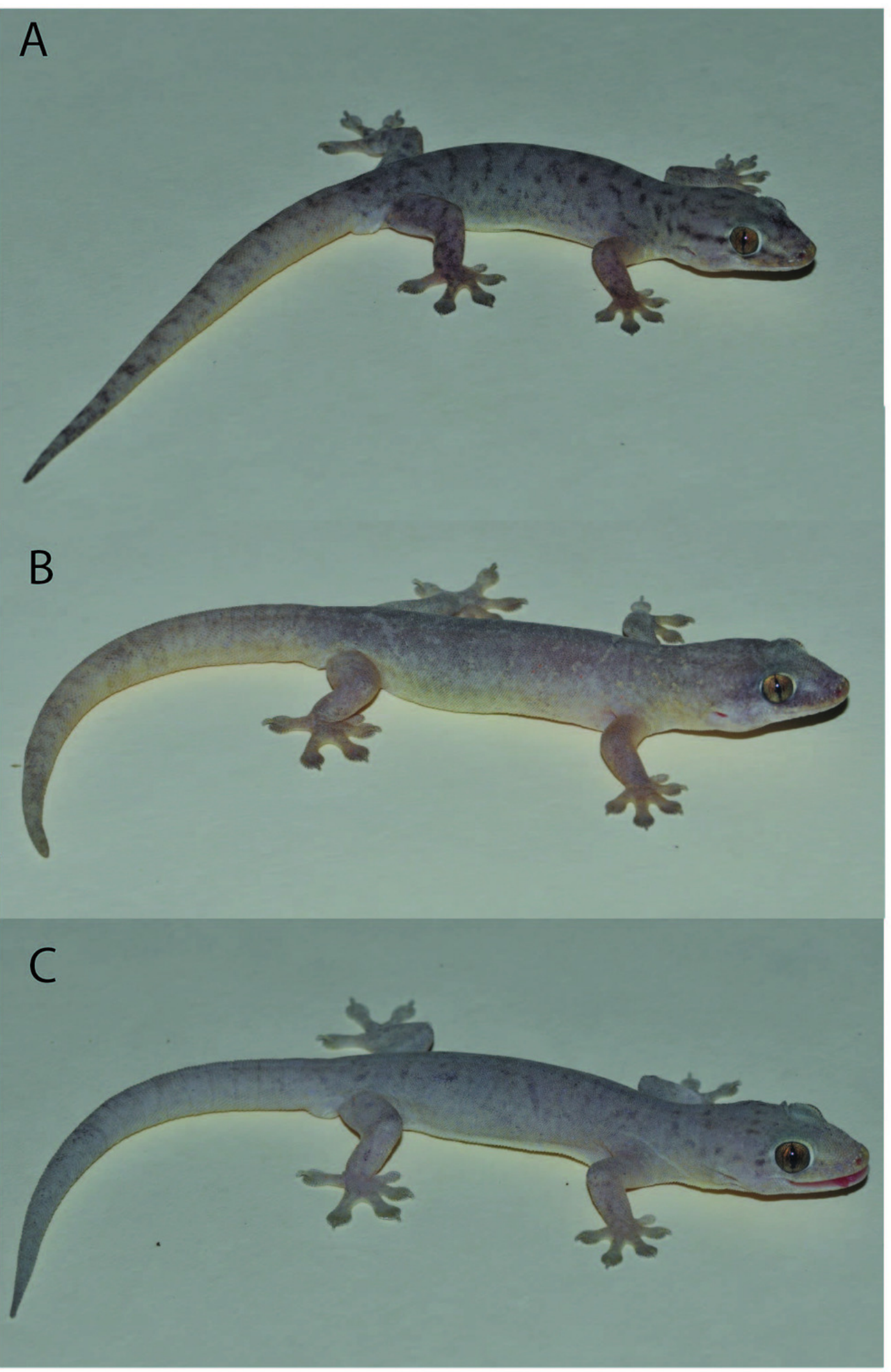


Figure 11

Lectotype specimen of Gehyra australis (NHMUK xxii.55b).
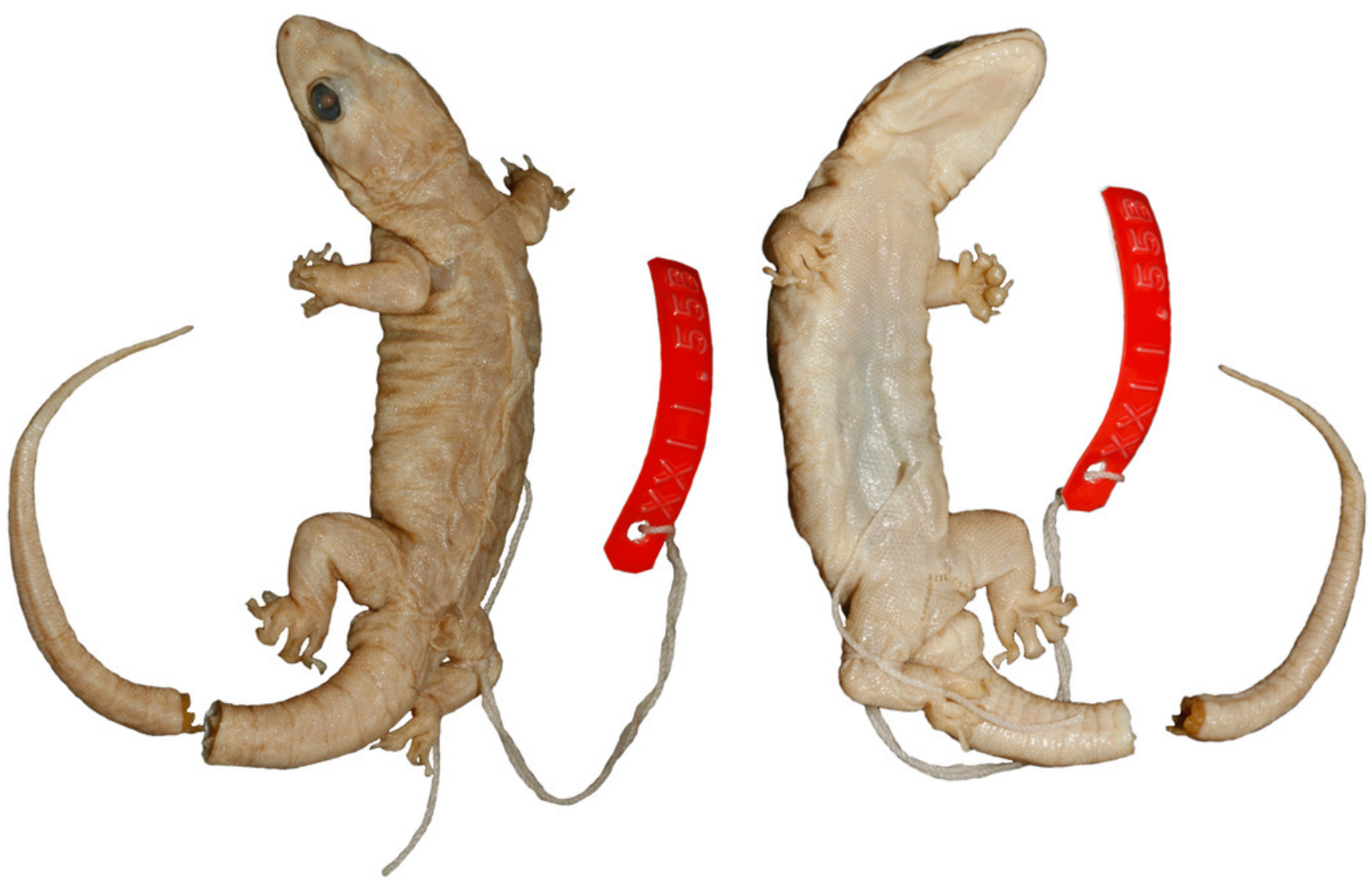
Figure 12

Variation amongst preserved Gehyra australis.

From left to right, NTM R38168 (field \# CCM4981), NTM R36903, NTM R36854, NTM R38197 (field \# CCM6342), NTM R38170 (field \# CCM7006). Scale bar $=10 \mathrm{~mm}$.

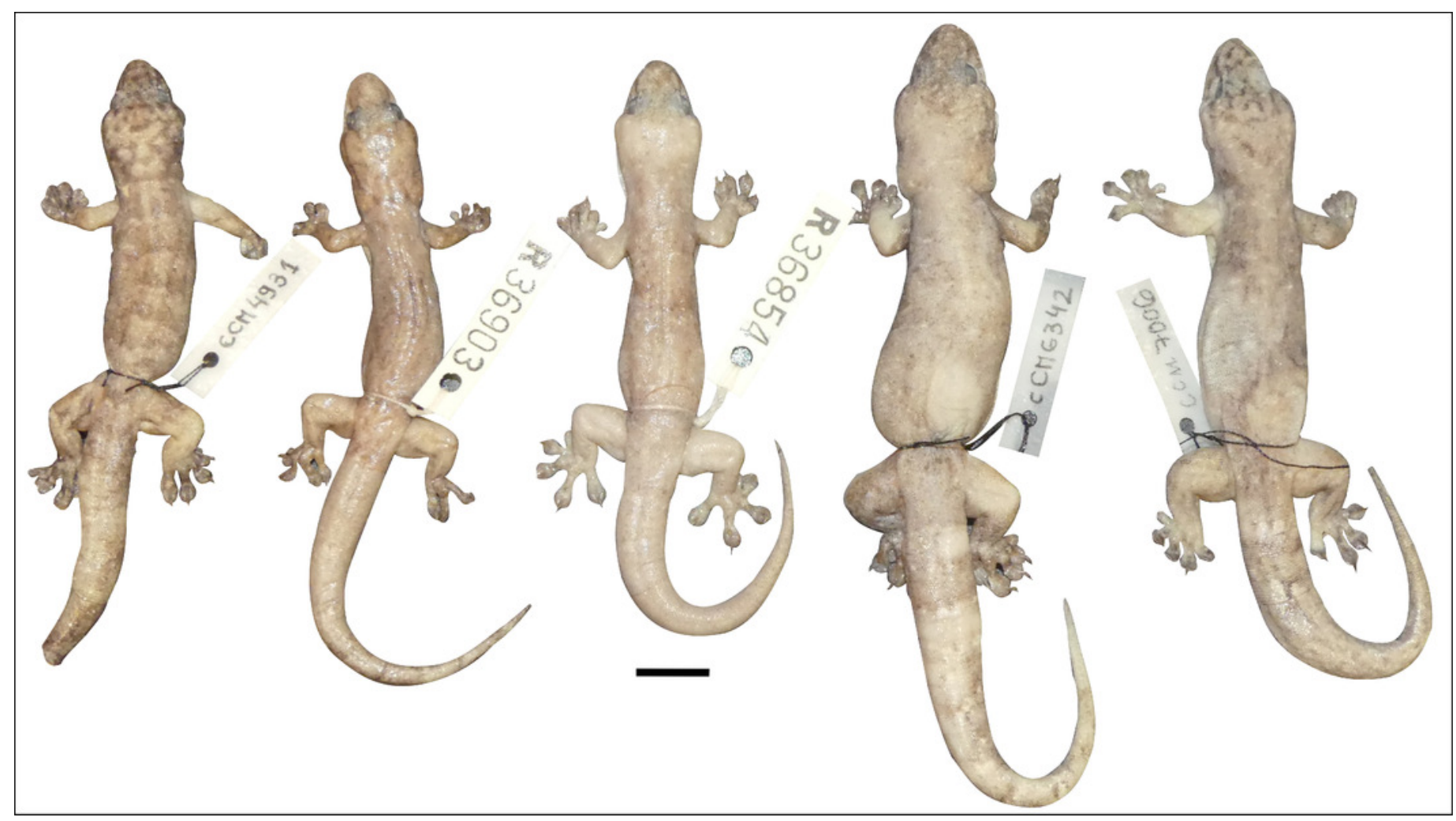


Figure 13

Variation amongst preserved Gehyra arnhemica sp. nov. specimens.

From left to right, (A) holotype (NTM R22626) and (B) four paratypes (NTM R38180, NTM R38181, NTM R38179, NTM R38175). Scale bar $=10 \mathrm{~mm}$.

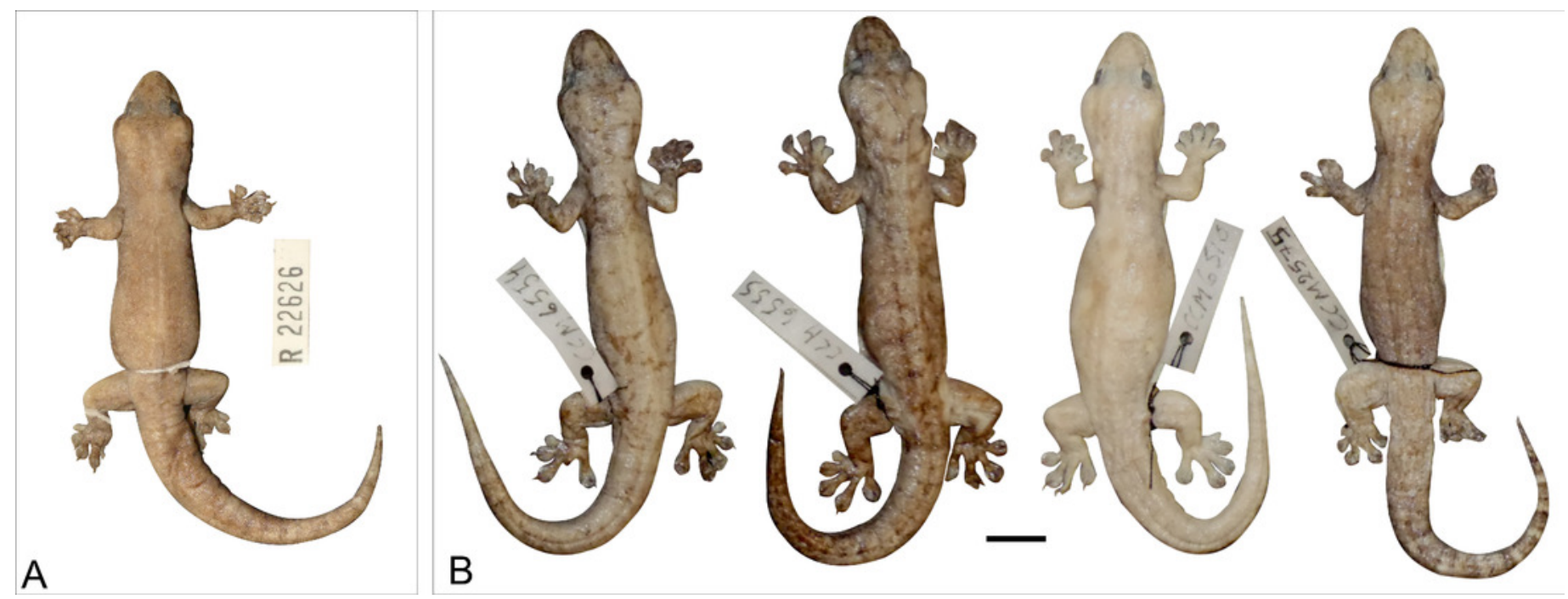


Figure 14

Variation amongst preserved type series of Gehyra gemina sp. nov.

(A) From left to right, (A) holotype (WAM R179349) and (B) four paratypes (NTM R38158, NTM R38159, NTM R38164, NTM R38163). Scale bar $=10 \mathrm{~mm}$.
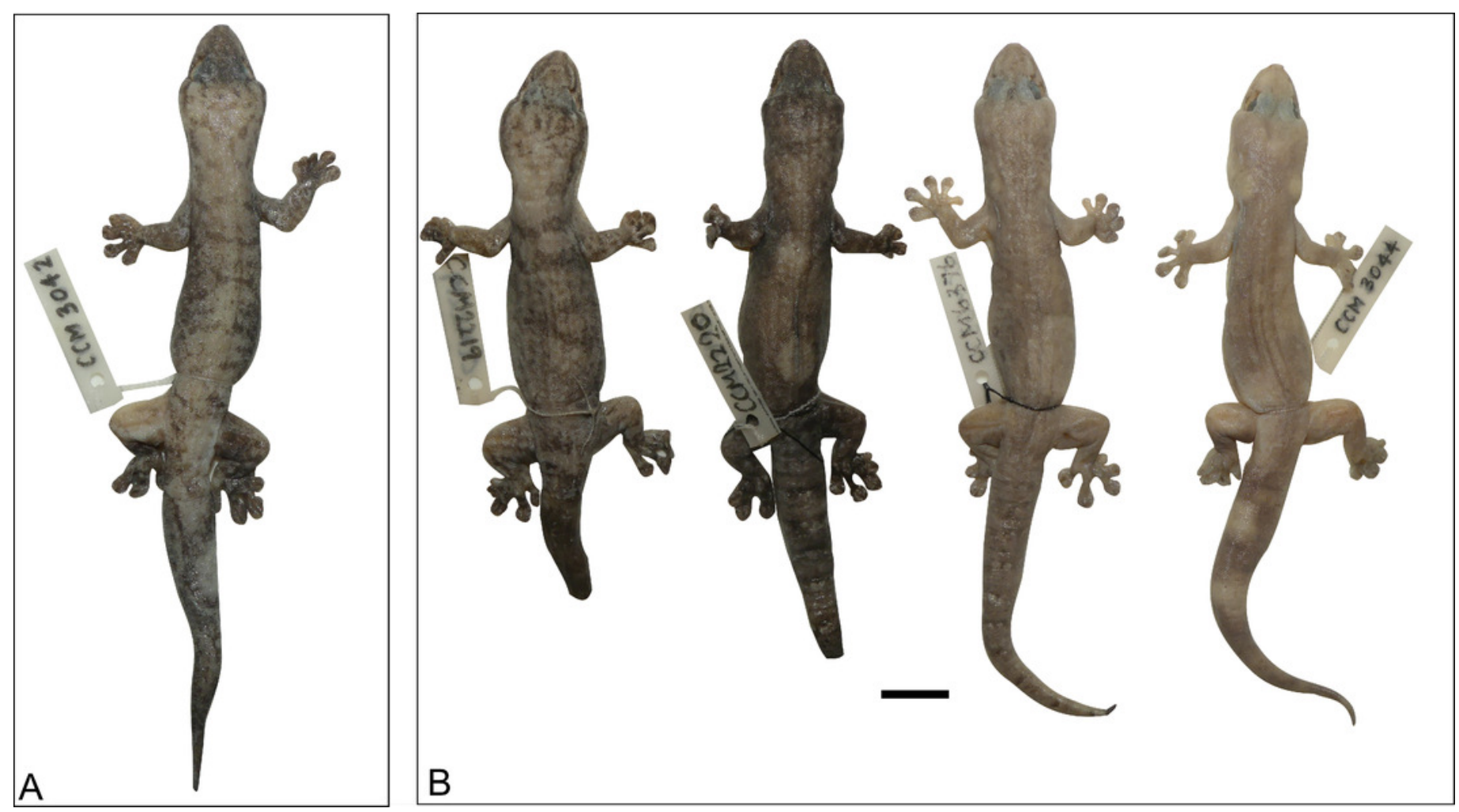
Figure 15

Variation amongst preserved type series of Gehyra lauta sp. nov.

From left to right, (A) holotype (QM J90707) and (B) four paratypes (QM J96624, NTM R21310, NTM R21309, QM J96621). Scale bar $=10 \mathrm{~mm}$.
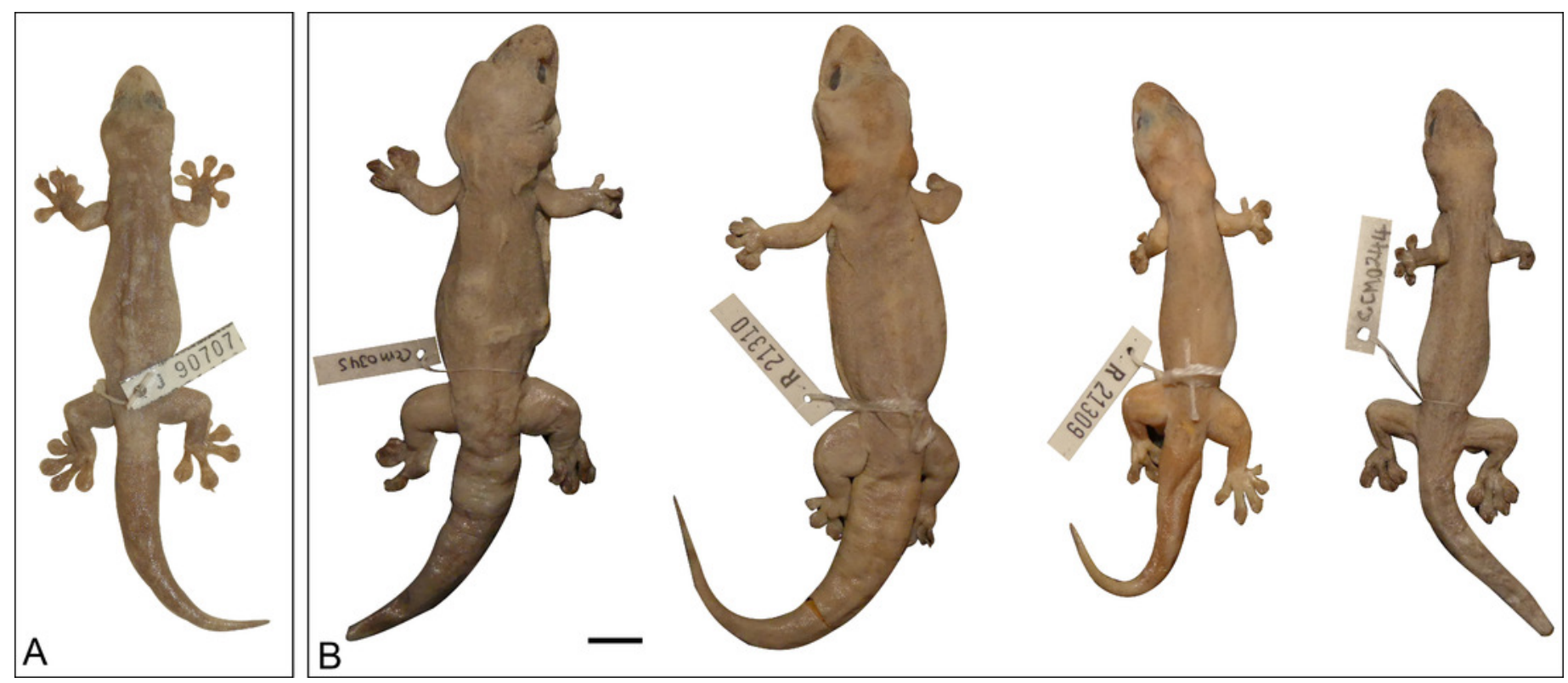
Figure 16

Variation amongst preserved type series of Gehyra chimera sp. nov.

From left to right, (A) holotype (WAM R177687) and (B) four paratypes (WAM R177685, WAM R177682, WAM R177683, WAM R177684). Scale bar $=10 \mathrm{~mm}$.
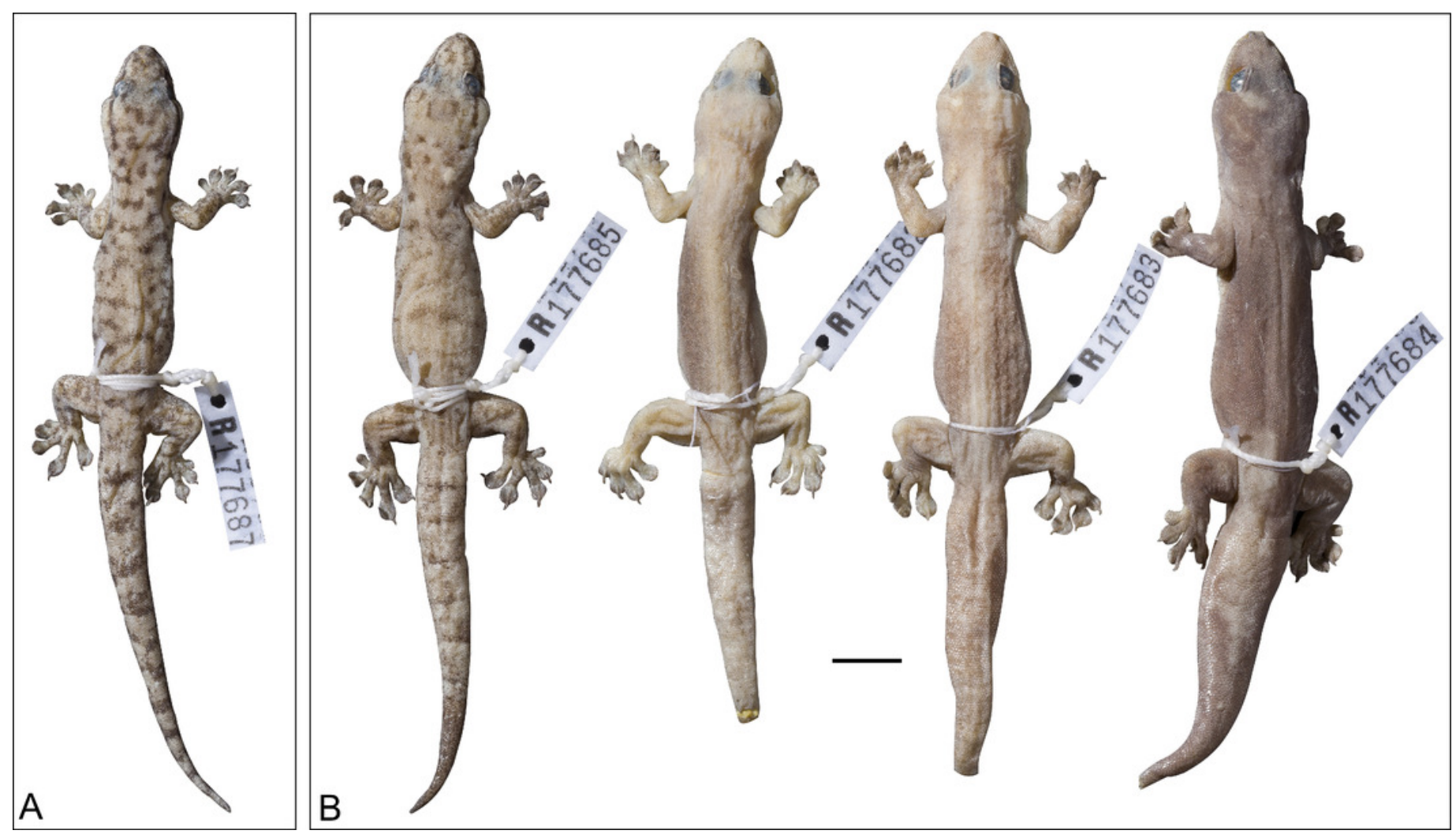
Figure 17

Variation amongst preserved Gehyra koira.

From left to right, WAM R166471, WAM R173986, WAM R164768, WAM R173982, WAM

R177673. Scale bar $=10 \mathrm{~mm}$.

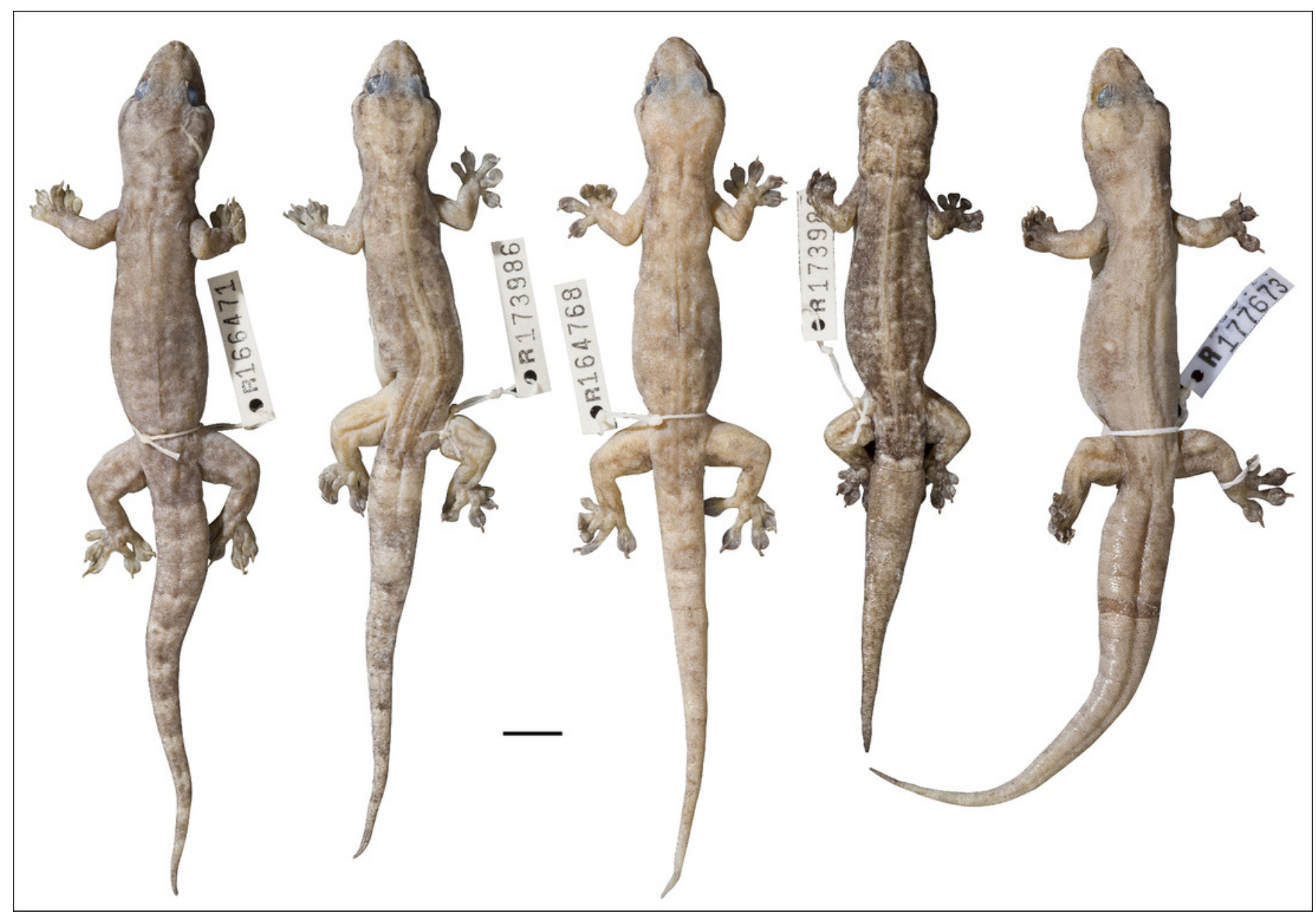


Figure 18

Variation amongst preserved Gehyra ipsa.

From left to right, WAM R177671, WAM R177670, WAM R164786, R164772. Scale bar $=10$ $\mathrm{mm}$.

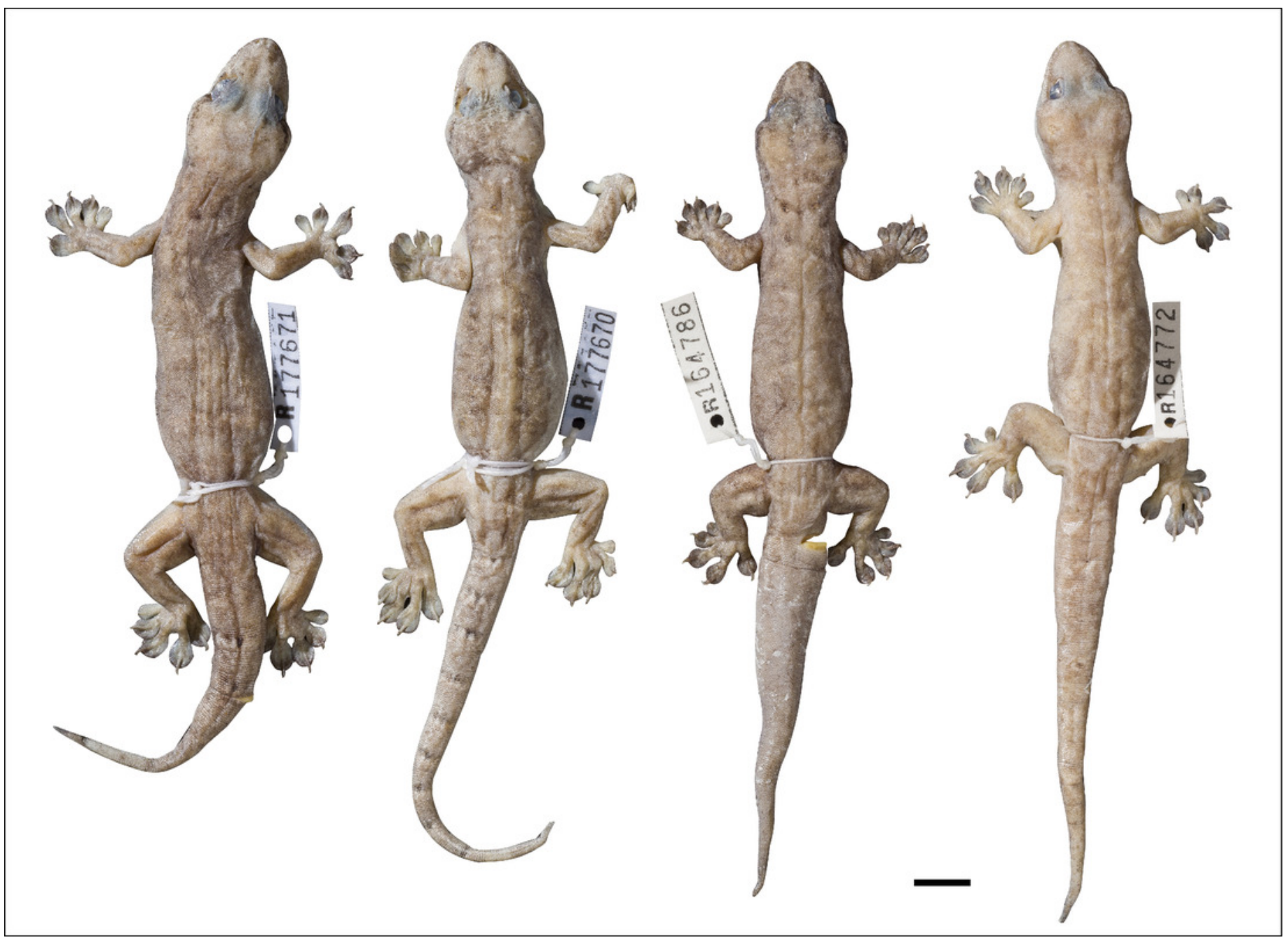


Figure 19

Variation amongst preserved type series of Gehyra lapistola sp. nov.

From left to right, (A) holotype (NTM R37093) and (B) four paratypes (NTM R37051, NTM R37055, NTM R37092, NTM R38195). Scale bar $=10 \mathrm{~mm}$.
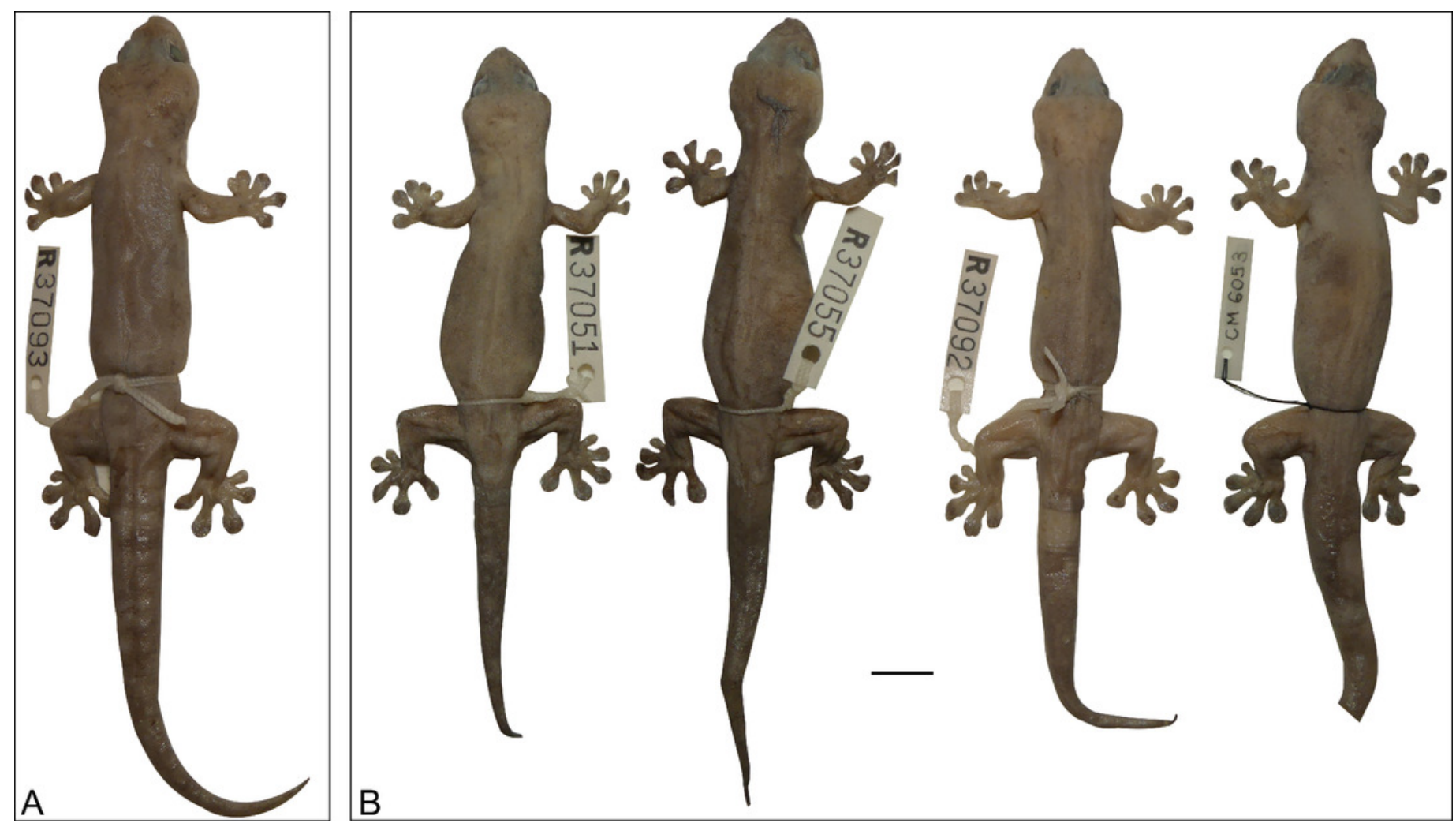
Figure 20

Variation amongst preserved type series of Gehyra calcitectus sp. nov.

From left to right, (A) holotype (WAM R177691) and (B) four paratypes (WAM R177701, WAM R177704, WAM R177699, WAM R177697). Scale bar $=10 \mathrm{~mm}$.
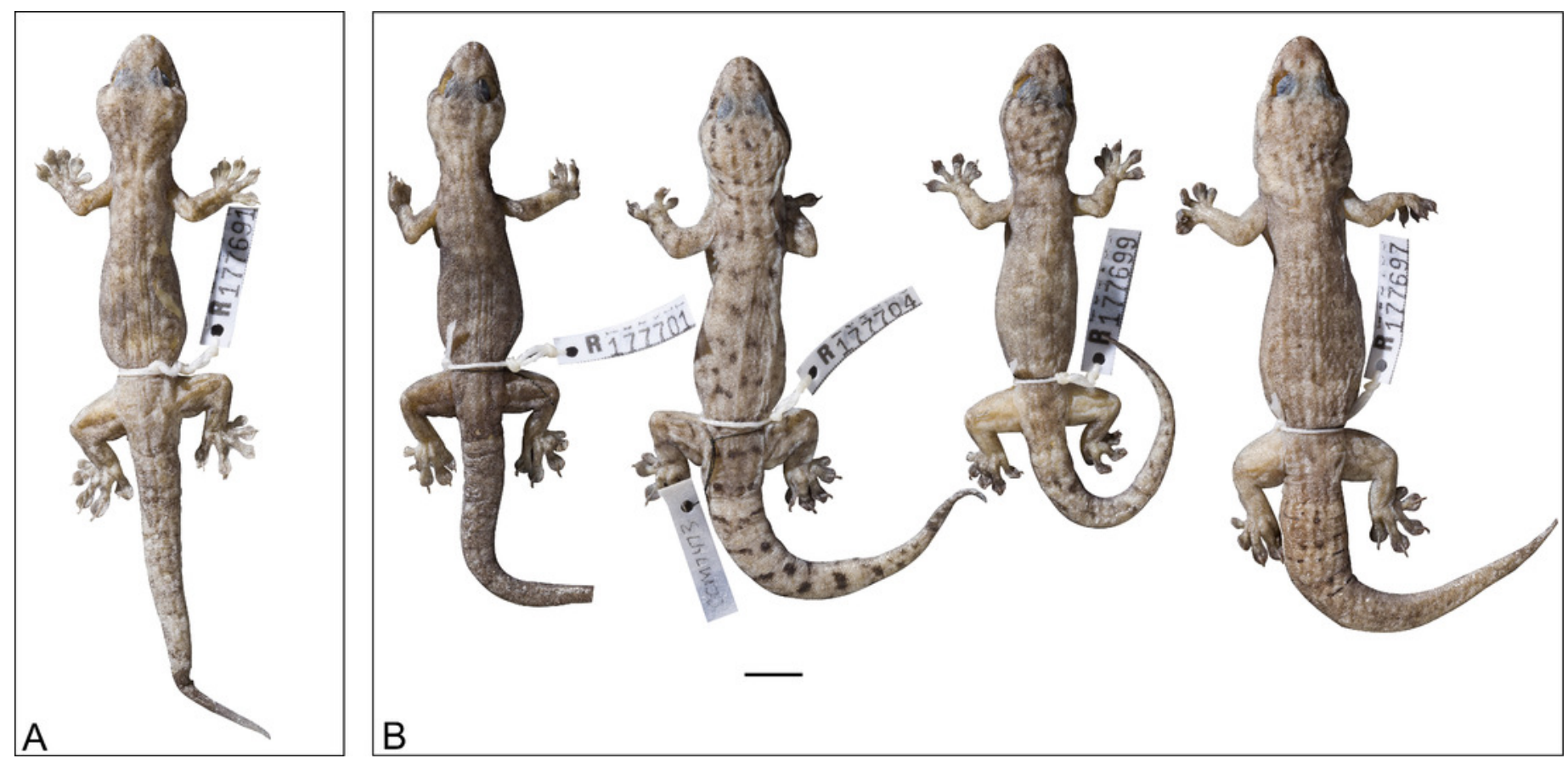